\title{
Criação, proteção e uso legal de informação em ambientes da World Wide Web
}

\author{
Elizabeth Roxana Mass Araya \\ Silvana Aparecida Borsetti Gregório Vidotti
}

ARAYA, ERM., and VIDOTTI, SABG. Criação, proteção e uso legal de informação em ambientes $d a$ World Wide Web [online]. São Paulo: Editora UNESP; São Paulo: Cultura Acadêmica, 2010. 144 p. ISBN 978-85-7983-115-7. Available from SciELO Books 〈http://books.scielo.org>.

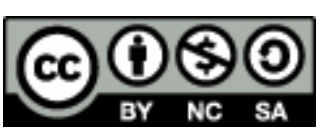

All the contents of this work, except where otherwise noted, is licensed under a Creative Commons Attribution-Non Commercial-ShareAlike 3.0 Unported.

Todo o conteúdo deste trabalho, exceto quando houver ressalva, é publicado sob a licença Creative Commons Atribuição Uso Não Comercial - Partilha nos Mesmos Termos 3.0 Não adaptada.

Todo el contenido de esta obra, excepto donde se indique lo contrario, está bajo licencia de la licencia Creative Commons Reconocimento-NoComercial-CompartirIgual 3.0 Unported. 


\section{Criação, PROTEÇÃo E USO LEGAL DE INFORMAÇÃO EM AMBIENTES DA WORLD WIDE WEB}


CONSELHO EDITORIAL ACADÊMICO

Responsável pela publicação desta obra

\author{
Edberto Ferneda \\ Helen de Castro Silva Casarin \\ João Batista Ernesto de Moraes \\ José Augusto Chaves Guimarães \\ Mariângela Spotti Lopes Fujita \\ Marta Ligia Pomim Valentim
}


ELIZABETH ROXANA MASS ARAYA E SILVANA APARECIDA BORSETTI GREGORIOVIDOTTI

\section{Criação, PRoteção E USO LEGAL DE INFORMAÇÃO EM AMBIENTES DA WORLD WIDE WEB}


(C) 2010 Editora UNESP

\section{Cultura Acadêmica}

Praça da Sé, 108

01001-900 - São Paulo - SP

Tel.: (0xx11) 3242-7171

Fax: (0xx11) 3242-7172

www.editoraunesp.com.br

feu@editora.unesp.br

CIP - Brasil. Catalogação na fonte

Sindicato Nacional dos Editores de Livros, RJ

A692c

Araya, Elizabeth

Criação, proteção e uso legal de informação em ambientes da World Wide Web / Elizabeth Roxana Mass Araya, Silvana Aparecida Borsetti Gregorio Vidotti. São Paulo: Cultura Acadêmica, 2010.

Inclui bibliografia

ISBN 978-85-7983-115-7

1. Ciência da informação. 2. Tecnologia da informação. 3. Comunicações digitais. 4. Direitos autorais e processamento eletrônico de dados. 5. Tecnologia e direito. I. Vidotti, Silvana Aparecida Borsetti Gregorio. II. Título.

11-0104.

CDD: 025.04

CDU: 007

Este livro é publicado pelo Programa de Publicações Digitais da Pró-Reitoria de Pós-Graduação da Universidade Estadual Paulista "Júlio de Mesquita Filho" (UNESP)

Editora afiliada:

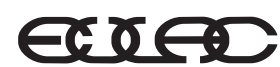

Asociación de Editoriales Universitarias de América Latina y el Caribe

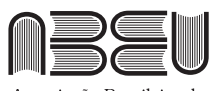

Associação Brasileira de Editoras Universitárias 
Para aqueles que sempre têm acompanhado nossas realizações: nossa família.

Aos participantes do Grupo de Pesquisas Novas Tecnologias em Informação da Unesp, em especial à professora Plácida L. V. Amorim da Costa Santos, ao Ricardo César Gonçalves Sant'Ana e à Maria José Vicentini Jorente pelas significativas contribuições para a realização desta obra. 



\section{SUMÁRIO}

Introdução 9

1 Ambientes informacionais digitais 15

2 Autoria e legislação de conteúdo intelectual 57

3 Alternativas emergentes para criação, disseminação e uso legal de informação no contexto da Web 85

Referências bibliográficas 135 



\section{INTRODUÇÃO}

O século XX constituiu-se predominantemente de indivíduos consumidores de conteúdo informacional produzido e disseminado por uma pequena parcela da sociedade, na maioria das vezes profissionalizada, e por meio de tecnologias como a imprensa, o rádio, a televisão, o cinema e o vídeo. Tal fato convergiu para a modelação da cultura prevalecente, na qual a criatividade do indivíduo em geral não era a mais aparente.

A transição da informação de suportes analógicos para suportes digitais transforma definitivamente as formas de criação intelectual. As Tecnologias de Informação e Comunicação (TIC), em cujas interfaces computacionais apresentam-se múltiplos instrumentos que interferem nos modos de produção de informação e de conhecimento, tornam homens e máquinas um novo sistema hibridizado pelas suas formas de interação. NesSe contexto deve-se pensar na informação digital para o usuário em geral e no papel do profissional da informação, especialmente quando esse profissional lida com a concepção, a ampliação e a projeção de novos sistemas de autoria da intercomunicação, da produção coautorada e de formas alternativas de validação dos conhecimentos (Matuck, ${ }^{1}$ 2005, p.4).

1 Artur Matuck, artista multimídia, videomaker, performer e escritor formado em artes pela ECA/USP e com pós-graduação em artes visuais pela Univer- 
A informação digital, comparada com a informação analógica, é aquela codificada em um formato que o computador pode interpretar (codificação binária). A computabilidade (necessidade de um computador acompanhando um software ou um algoritmo preciso) é uma de suas propriedades. Qualquer morfologia de informação textual, imagética ou sonora é representada por esse único tipo de linguagem (bits: série de zeros e uns) que, além de lhe atribuir a característica de virtualidade, possibilita a multimídia, ou seja, a combinação de pelo menos um tipo de mídia estática (texto, fotografia, gráfico) com um tipo de mídia dinâmica (vídeo, áudio, animação). Nessa linguagem expressam-se e armazenam-se dados e instruções, fato gerador da interatividade própria dos sistemas de informação digitais, teoricamente sem limites. Essa interatividadeprocesso em que um sistema de informação ou de comunicação permite ações dos usuários e lhes oferece respostas de acordo com suas especificidades - favorece o acesso e a recuperação de informação, pois possibilita que o usuário da informação digital realize diversas operações de busca e de descobrimento no ambiente informacional. Na hipertextualidade, forma de interatividade efetiva possibilitada pelos ambientes hipermídia, o usuário constrói seu próprio caminho de navegação pelos documentos e/ou parte deles utilizando-se dos enlaces que ele próprio realiza (Codina, 2001, p.19-21).

A produção, a disseminação e o uso de informação por meio da Internet e em seus ambientes informacionais Web favorecem o desenvolvimento de uma cultura baseada em práticas de colaboração e remix. Consequentemente, cria-se um descompasso que necessita ser solucionado no que diz respeito à criação de um novo "modelo de sociedade, de cultura, de informação e de ciência no qual direitos

-sidade da Califórnia, em San Diego, depois de ter conseguido bolsa da Fundação Fullbright para fazer uma pesquisa sobre o copyright na Universidade de Iowa. Desenvolveu também, em 1991, o projeto Reflux, na Carnegie-Mellon University, em Pittsburgh, e outro sobre escritura alterada por computador, na Universidade da Flórida, em Gainesville. Disponível em: <http://www. cibercultura.org.br/tikiwiki/tiki-index.php? page=Artur+Matuck $>$. Acesso em: 3 mar. 2009. 
atuais e emergentes sejam contemplados para que os homens não sejam apenas periféricos desSe sistema cada vez mais ubíquo" (Matuck, 2005, p.7).

As modificações relacionadas ao tempo e ao espaço da passagem da informação trouxeram um novo elaborar do conhecimento: "Os espaços de informação agregaram em um mesmo ambiente de comunicação os estoques de itens de informação, as memórias, os meios de transferência e a realidade de convívio dos receptores de informação", destaca Barreto (2002, p.73), pesquisador sênior do CNPq (Conselho Nacional de Desenvolvimento Científico e Tecnológico) e da coordenadoria de Ensino, Pesquisa e Tecnologia da Informação do IBICT (Instituto Brasileiro de Informação em Ciência e Tecnologia) no Rio de Janeiro.

Um número cada vez maior de produtores de conteúdo informacional, embora, de acordo com os padrões culturais prevalecentes, nem sempre seja considerado qualitativamente favorável, evidencia uma nova configuração cultural exponencialmente representativa no fluxo da informação em que o indivíduo, que não há muito tempo era um mero consumidor de conteúdo intelectual, é agora também um participante ativo na criação desses conteúdos.

Os indivíduos que lidam com essas novas formas de produzir, disseminar e usar conteúdos informacionais devem estar conscientes das diferenças que se impõem quando a informação é digital. Eles devem conhecer as implicações quanto ao fluxo da informação e seus aspectos simbólicos, bem como saber sob quais condições a lei de direitos autorais estabelece que essas práticas devam acontecer.

É nesse aspecto que se inserem as principais transversalidades entre as esferas da Ciência da Informação e dos Direitos Autorais, que denotam a necessidade de indivíduos - em geral, conhecedores das exigências que a contemporaneidade impõe para a criação e o efetivo acesso, uso, preservação e disseminação de conteúdos informacionais nas formas propiciadas pelas $\mathrm{TIC}$ - e de profissionais da informação, em especial, identificando problemas que impeçam ou dificultem práticas ilícitas e, principalmente, buscando e analisan- 
do alternativas propiciadoras de caminhos que garantam o direito básico à informação do cidadão e seu empoderamento no âmbito mundial dentro de padrões que atendam às exigências legais que regem a sociedade atual.

É esse o motivo do presente trabalho, que surge a partir da dissertação de mestrado de Elizabeth Roxana Mass Araya, realizada sob orientação da professora Silvana Aparecida Borsetti Gregorio Vidotti e coorientação de Ricardo César Gonçalves Sant'Ana. A continuação dos estudos resultou na atualização e ampliação do texto científico, ora apresentado em formato de livro sob autoria de Elizabeth Roxana Mass Araya e Silvana Aparecida Borsetti Gregorio Vidotti.

O primeiro capítulo (Ambientes informacionais digitais), em uma revisitação histórica, trata da Internet como Tecnologia de Informação e Comunicação propiciadora do ambiente informacional Web e suas derivações Web 2.0 e Web Semântica. Aborda também o desenvolvimento de um ambiente informacional na Web predominantemente colaborativo em virtude dos serviços e aplicações nele propiciados. Baseado na descrição de práticas de colaboração e remix, consideradas representativas da Web Colaborativa e identificadas em websites denominados blogs e wikis e nos websites de hospedagem e partilha de imagens fotográficas Flickr e de vídeos YouTube, observa-se a consolidação de uma ciber-cultura-remix que passa a constituir uma preocupação quanto aos aspectos legais relativos ao uso e produção de conteúdo intelectual.

O segundo capítulo (Autoria e legislação de conteúdo intelectual) trata de aspectos relacionados à autoria e à produção intelectual ao longo da história, os primórdios da primeira legislação relativa à proteção da obra intelectual e sobre o que a lei de copyright, a lei $n^{\circ} 9610$ de 19.2 .98 e algumas normas internacionais estabelecem quanto à criação, à recriação, ao uso, ao reúso, à preservação e à disseminação de produção intelectual.

O terceiro capítulo (Alternativas emergentes para criação, disseminação e uso legal de informação no contexto da Web) apresenta algumas manifestações da sociedade contemporânea no ambiente 
informacional Web Colaborativa que refletem conflitos emergentes do antagonismo entre o que o uso das tecnologias potencializa no âmbito da produção intelectual e o que a lei estabelece quanto aos direitos autorais. Trata sobre as licenças alternativas Copyleft e Creative Commons como propostas emergentes que, dentro dos padrões que a legislação permite, podem contribuir para o reequilíbrio dos processos de produção e recepção de conteúdo informacional rearquitetados na interatividade propiciada pelas TIC. 



\section{1 \\ AMBIENTES INFORMACIONAIS DIGITAIS}

Este capítulo traz, em um breve relato, a história da Internet, da Web e suas derivações Web 2.0 e da ainda não concretizada Web Semântica, por serem estes os agentes que têm contribuído para o desenvolvimento de um ambiente informacional colaborativo que, em virtude dos serviços e das aplicações, vem possibilitando e induzindo à interação, prática em que indivíduos diferenciados em suas competências e habilidades, para usar as palavras de Spyer (2007, p.27), convivem, relacionam-se, criam e compartilham informações. Trata-se, portanto, também de uma Web Colaborativa, abordando-a a partir da observação de blogs e wikis e dos websites de hospedagem e partilha de imagens fotográficas Flickr e de vídeos YouTube.

\section{Internet}

A rede mundial de computadores Internet, definida por Sherman \& Price (2001, p.7-17) como sendo a canalização necessária para que a informação dos mais diversos tipos possa fluir de um computador para outro por todo o planeta, surgiu da preocupação de seus criadores de solucionar um único problema: como conectar 
computadores separados em uma rede universal e permitir que esses computadores se comunicassem entre si, independentemente de seu tipo ou de sua localização.

A origem da Internet remonta-se a 1958, quando o Departamento de Defesa dos Estados Unidos cria a Advanced Research Projects Agency (Arpa) para favorecer a pesquisa no ambiente universitário e alcançar a superioridade tecnológica militar ante a União Soviética, que por causa de seu programa espacial tinha se tornado uma ameaça à segurança nacional norte-americana. Em 1962, a Arpa fundou o Information Processing Techniques Office (IPTO), departamento encarregado de estimular a pesquisa em comando e controle (computação) e cujo primeiro diretor foi o professor e pesquisador norte-americano Joseph Carl Robnett Licklider, do Massachusetts Institute of Technology (MIT).

Para o desenvolvimento de seus projetos no IPTO, Licklider procurou reunir os principais pesquisadores dispersos entre a Rand Corporation (um grande centro de estudos prospectivos do mundo, situado em Santa Mônica, na Califórnia) e o MIT, em Massachusetts. A inspiração de Licklider viria do Projeto Lincoln, iniciado em 1951, quando a Força Aérea estadunidense comissionou o MIT para projetar uma rede de alerta contra ataques de bombardeiros nucleares soviéticos. O Projeto Lincoln propunha criar um sistema em que todos os radares de vigilância fossem coordenados por computadores.

A ideia - radical para a época - era criar um sistema em que todos os radares de vigilância, os alvos de monitoramento e outras operações fossem coordenados por computadores, que por sua vez teriam a base em uma máquina do MIT altamente experimental conhecida como Whirlwind: o primeiro computador a ser operado em "tempo real" capaz de responder a eventos tão rapidamente quanto eles acontecessem. O Projeto Lincoln, consequentemente, resultaria em um sistema abrangendo 23 centros, de modo que cada um deles hospedaria até 50 operadores humanos de radar, além de dois computadores redundantes, em tempo real, capazes de moni- 
torar até 400 aviões de uma só vez. Esse sistema Semi-Automatic Ground Enviroment (SAGE) também incluiria a primeira rede do mundo de longa distância que permitiria que os computadores transferissem dados entre os 23 centros através de linhas telefônicas. (Waldrop, 2008, p.79, tradução nossa) ${ }^{1}$

Em 1951, Licklider era professor de Psicologia Experimental do MIT e trabalhava nos aspectos relacionados com os fatores humanos do painel de controle do SAGE. Em 1957, o pesquisador já não falava em um sistema focado na segurança nacional, mas destacava o poder da mente. Ao contrário dos 23 centros de defesa aérea, Licklider imaginava uma rede nacional de "centros de pensamentos" em que os computadores contassem com vastas bibliotecas que abrangessem todo tipo de assuntos: "no lugar dos painéis de controle do radar, imaginava uma multidão de terminais interativos, cada um capaz de exibir textos, equações, figuras, diagramas ou qualquer outra forma de informação" (ibidem, tradução nossa). ${ }^{2}$ Um ano depois, Licklider falava de uma simbiose entre homens e máquinas e, em 1960, explicava suas ideias detalhadamente no artigo Man-Computer Symbiosys. No mesmo ano, definia uma agenda de pesquisa para fazer de sua visão uma realidade.

Em 1963, já na Arpa e financiado pelo Pentágono, Licklider teve a oportunidade de implementar essa agenda. Reuniu pesqui-

1 The idea-radical at the time - was to create a system in which all the radar surveillance, target tracking, and other operations would be coordinated by computers, which in turn would be based on a highly experimental MIT machine known as Whirlwind: the first "real-time" computer capable of responding to events as fast as they occurred. Project Lincoln would eventually result in a continentspanning system of 23 centers that each housed up to 50 human radar operators, plus two redundant real-time computers capable of tracking up to 400 airplanes at once. This Semi-Automatic Ground Environment (SAGE) system would also include the world's first long-distance network, which allowed the computers to transfer data among the 23 centers over telephone lines.

2 (...) in place of the radar consoles, he imagined a multitude of interactive terminals, each capable of displaying text, equations, pictures, diagrams, or any other form of information. 
sadores que estivessem seguindo sua linha de estudos e com eles formou uma comunidade autossustentável que desenvolveu tecnologias como a interface usuário controlada por mouse, a computação gráfica e a inteligência artificial, e lançou as bases da computação atual. Contudo, Licklider via que o programa do IPTO não seria realizado em sua plenitude: "[...] a nascente comunidade Arpa nunca poderia chegar a ser algo além de uma Torre de Babel high-tech, em que encraves dispersos produziam máquinas incompatíveis, linguagens incompatíveis e softwares incompatíveis" (idem, p.7980, tradução nossa). ${ }^{3}$ Em 1964, Licklider deixava a Arpa.

Em 1966, quando o IPTO estava sob a direção de Robert Taylor, a proliferação de sistemas incompatíveis acontecia tal como Licklider temera. O próprio Taylor viu-se obrigado a instalar três diferentes terminais em seu escritório no Pentágono para poder conectar-se com os três principais sistemas da Arpa. Após obter os recursos financeiros necessários para iniciar um projeto de rede, em 1967, Taylor procurou Larry Roberts, do Lincoln Laboratory (sucessor do Projeto Lincoln), para administrá-lo. A arquitetura da nova rede, ainda presente na Internet atual, foi definida por três decisões tecnológicas adotadas por Roberts.

A primeira dessas decisões, relata Waldrop (idem, p.80-81), refere-se à necessidade da agência de locar uma série de linhas de telefone de longa distância e de alta capacidade que permitisse a conexão ininterrupta dos computadores com os diversos sites da Arpa, porque, como ela não disporia de recursos para ter seus próprios cabos de transmissão em todo o país, seria obrigada a realizar a transmissão de dados por meio do sistema telefônico da American Telephone and Telegraph (AT\&T). Como segunda medida, Roberts decidiu que as mensagens digitais não seriam enviadas pela rede como uma corrente contínua de bits, mas, sim, segmentadas como "pacotes", para protegê-las da estática e de distorções na linha. Essa

3 (...) the nascent ARPA community might never become anything more than a high-tech Tower of Babel, in which widely scattered enclaves produced incompatible machines, incompatible languages, and incompatible software. 
medida, embora não eliminasse o ruído, permitiria que os erros pudessem ser isolados e assim o sistema teria a chance de arrumá-los ou de solicitar ao remetente original que enviasse uma nova cópia. A tecnologia de comutação de pacote tinha sido desenvolvida anos antes por Paul Baran, na Rand Corporation, e estudada na tese de doutorado de Leonard Kleinrock, colega de Roberts no MIT.

A terceira medida que Larry Roberts adotaria seria a completa descentralização da rede. Não haveria um computador mestre responsável pela classificação e direcionamento dos pacotes aos seus destinos.

[...] os sites da Arpa seriam ligados em um complexo modelo, mais exatamente como o mapa de uma rodovia interestadual, e cada site compartilharia igualmente as responsabilidades pela rota. Isto é, o computador lá leria o endereço digital em cada pacote conforme ele viesse, aceitaria esse pacote se o endereço fosse local ou, do contrário, o remeteria novamente para a próxima etapa da sua jornada. Esse acesso à comutação de pacote significaria mais complexidade e mais programação durante a fase de configuração. Mas o sistema final seria muito mais robusto. Nenhuma falha poderia derrubá-lo. (idem, p.83, tradução nossa) ${ }^{4}$.

O esquema de Roberts seria ainda melhorado pela sugestão de Wesley Clark, da Washington University, para adicionar a Interface Message Processor (IMP), um computador menor que eliminaria a necessidade de conduzir os pacotes por meio dos computadores principais. Ele guiaria as tarefas de encaminhamento.

4 (...) the ARPA sites would be linked in a complex pattern rather like the Interstate highway map, and that each site would share the routing responsibilities equally. That is, the computer there would read the digital address on each packet as it came in, accept that packet if the address was local, or else send it off again on the next stage of its journey. This "packet-switching" approach would mean more complexity and more programming during the set-up phase. But the final system would be far more robust: No one failure could bring it down. 
Ao invés de solicitar a cada site para conduzir os pacotes corretamente através de seus computadores principais, que era como tentar executar uma rodovia interestadual corretamente através da rua principal de cada pequena cidade no seu caminho, a rede seria o equivalente digital de uma estrada de acesso limitado. Só fora de cada cidade haveria um "trevo rodoviário", sob a forma de um pequeno computador - denominado de Interface Message Processor (IMP) - que guiaria todas as tarefas de encaminhamento. O resultado seria uma interface limpa: a Arpa assumiria a responsabilidade pela concepção e implementação da rede adequada - isto é, as rodovias e os trevos digitais -, enquanto os pesquisadores em cada local se focariam na tarefa relativamente simples de ligar seu computador central no IMP. (ibidem, tradução nossa) ${ }^{5}$

Em dezembro de 1968, narra Waldrop (idem, p.84), Roberts adjudicou à empresa Bolt Beranek and Newman (BBN), de Massachusetts, a construção dos IMPs. Nove meses depois, a BBN entregaria o primeiro deles, constituindo-se no primeiro nó da primeira rede interativa de computadores: a Arpanet, instalada na Universidade da Califórnia, em Los Angeles, (Ucla). No mesmo ano, Roberts assumiria a direção do IPTO. Dois anos mais tarde, a Arpanet contava com 15 nós, a maioria em centros universitários.

Em 1972, Roberth Kahn, que fizera parte da equipe original do IMP na BBN, foi contratado para supervisionar as iniciativas para a nova rede. $\mathrm{Na}$ época, o IPTO incluía experimentos em comunicação de comutação por pacote via rádio e satélite, e Kahn passou

5 Instead of asking each site to run the packets right through their main computers, which was like trying to run an Interstate highway right through the main street of every little town in its path, the network would be the digital equivalent of a limited-access highway. Just outside each town would be an "interchange" in the form of a small computer - dubbed the Interface Message Processor (IMP) - that would handle all the routing chores. The result would be a clean interface: ARPA would take responsibility for designing and implementing the network proper - meaning the information highways and the digital interchanges - while the researchers at each site would focus on the comparatively simple task of linking their central computer to IMP. 
a procurar uma forma de eliminar as grandes incompatibilidades existentes entre esses sistemas de transmissão de pacotes e o sistema utilizado pela Arpanet: a linha telefônica. A possibilidade encontrada consistia em tornar cada uma das redes totalmente independente. Teria seu próprio IMP, seu próprio software e sua própria transmissão de protocolos, e seria ligada à Arpanet por meio de um computador especializado cujo trabalho consistiria em traduzir os pacotes da Arpanet em pacotes via satélite, por exemplo, e viceversa. Os padrões de interface de ambos os lados poderiam ser definidos separadamente. Nenhuma das partes precisaria conhecer os detalhes internos da outra e poderiam ser ligadas juntas por meio de uma entrada: "como ligar um aparelho em uma tomada elétrica normal, e os pacotes fluiriam conforme necessitassem. [...] poderia, do mesmo modo, facilmente conectar-se a um pacote de rede de rádio ou qualquer outro tipo de rede que viesse a aparecer" (ibidem, tradução nossa). ${ }^{6}$

Para o desenvolvimento da arquitetura básica de seu projeto, Kahn trabalhou em conjunto com Vinton Cerf, um ex-aluno de Leonard Kleinrock, do grupo Ucla, na época em que o primeiro IMP fora instalado nesse local. À Vinton Cerf coube a responsabilidade de definir os padrões da interface básica, e para isso, por analogia, ele inspirou-se no sistema postal ao observar que, quando as coisas paravam,

a tentativa de enviar um pacote de uma rede para outra se assemelhava à tentativa de enviar um cartão-postal escrito em caracteres japoneses kanji por meio de uma agência postal nos Estados Unidos: ninguém lá saberia lê-lo, assim seguiria para a seção de cartas não entregues. (ibidem, tradução nossa) ${ }^{7}$

6 (...) like plugging an appliance into a standard electric socket, and the packets would flow as needed. Moreover, you could just as easily plug in a packet radio network, or any other type of network that might come along.

7 (...) trying to send a packet from one network into another was like trying to send a postcard written in Japanese Kanji characters through a post office in the United 
Contudo, adaptando-se às maiores possibilidades de comunicação, isso poderia ser solucionado se cada cartão-postal fosse enviado em um envelope endereçado na linguagem local e, quando cruzasse a fronteira, fosse colocado em um novo envelope com a linguagem local correspondente: "Os classificadores de correspondência local leriam kanji no Japão, inglês nos Estados Unidos, árabe no Oriente Médio, e assim por diante" (ibidem, tradução nossa). ${ }^{8}$ E para traduzir sua ideia em termos de rede, Cerf pensou:

[...] imagine que cada computador começasse com um protocolo universal específico para endereçar seus pacotes (Este seria o software equivalente a todo mundo ter concordado em endereçar seus cartões-postais no lado direito, usando o alfabeto romano, com o nome, rua, cidade, Estado, país, e assim por diante, em uma ordem, padrão. Mas, antes de lançar os pacotes diretamente na rede local, que poderia não entender o protocolo universal, o computador colocaria cada pacote dentro de um "envelope" de bits extras que a rede local entenderia. Dessa forma, cada pacote poderia navegar através de sua rede doméstica até alcançar a entrada para a próxima rede em linha. Logo, o computador de entrada retiraria cada pacote de seu envelope, leria o endereço escrito no protocolo universal, colocaria o pacote em um novo envelope adequado aos seus novos arredores e o mandaria para frente no seu caminho.

O protocolo universal em si teria que lidar com uma série de aspectos práticos, incluindo um "protocolo de inter-redes", que codificaria coisas tais como endereço final de um pacote, e um esquema de controle de transmissão que permitiria ao computador de destino solicitar substituições de pacotes que tivessem sido perdidos no tráfego. (idem, p.84-85, tradução nossa) ${ }^{9}$

States: Nobody there would know how to read it, and it would go straight to the dead-letter office.

8 The local mail sorters would read Kanji in Japan, English in the United States, Arabic in the Middle East, an so on.

9 (...) imagine that every computer started with a specific, universal protocol for addressing its packets. (This would be the software equivalent of having everybody 
Vint Cerf e seu grupo de pesquisas em Stanford trabalharam durante um ano para concretizar a ideia que resultaria no Transmission Control Protocol/Internet Protocol (TCP/IP): um conjunto de protocolos de comunicação em que o TCP cuidaria da transmissão de dados e da correção de erros, e o IP, do endereçamento. Os computadores de uma rede poderiam comunicar-se entre si e possibilitariam a evolução da rede como um sistema aberto de comunicação por computadores capaz de abranger o mundo inteiro (Castells, 2003, p.14-21).

Em 1974, Cerf e Kahn publicaram no artigo A protocol for packet network interconnection a primeira descrição da arquitetura de como a Internet funcionaria como uma rede de redes utilizando o protocolo TCP/IP. Nove anos depois, a própria Arpanet mudaria para esse protocolo.

Em 1975, ao ser transferida para a Defense Communication Agency (DCA), a Arpanet passou a usar a rede para operações militares. Isso provocou uma coexistência incômoda entre militares e pesquisadores acadêmicos, e em 1983 a rede foi dividida em Milnet (Military Net), uma rede independente para usos militares específicos, e Arpa-Internet, rede dedicada à pesquisa. No ano seguinte, a National Science Foundation (NSF) - agência federal independente cuja missão inclui apoiar todos os campos da ciência, exceto

agree to address their postcards on the right-hand side, using the Roman alphabet, with the name, street, city, state, country, and so on in a standard order.) But before launching the packets straight out into the local network, which might not understand the universal protocol, the computer would wrap each one inside an "envelope" of extra bits that the local network would understand. In that form, each packet could sail through its home network until it reached the gateway to the next network in line - whereupon the gateway computer would take each packet out of its envelope, read the address written in the universal protocol, wrap the packet in a new envelope appropriate to its new surroundings, and send it on its way.

The universal protocol itself would have to deal with a number of practicalities, including an "inter-networking protocol" that would encode such things as a packet's ultimate address, and a transmission control scheme that would allow the destination computer to request replacements for packets that had been lost in transit. 
Ciências Médicas e da Engenharia -, com o intuito de conectar pesquisadores acadêmicos, montou sua própria rede de comunicação entre computadores: a NSFNet. Em 1988, a Arpa-Internet passou a ser usada pela NSF como seu backbone (idem, 2002, p.15).

Em 1990, a Arpanet deixou de operar e a Internet foi libertada de seu ambiente militar. No mesmo ano, o governo dos Estados Unidos confiou a administração da Internet à NSF, que ante um cenário de tecnologias de redes de computadores no domínio público e de telecomunicações desreguladas tentou levar a Internet à privatização. Não foi possível, pois na década de 1980 o Departamento de Defesa tinha decidido comercializar a tecnologia da Internet, e para isso financiara fabricantes de computadores nos Estados Unidos para que eles incluíssem o padrão universal de comunicação TCP/IP em seus protocolos. Quando o controle foi confiado à NSC, a maior parte dos computadores pessoais norte-americanos tinha capacidade de entrar em rede. Isso representou a base da difusão da interconexão de redes (ibidem).

Castells (idem, p.16) destaca que, embora o desenvolvimento da Internet possa ter começado com a Arpanet, ele foi propiciado também, entre outros fatores, pelas contribuições dos estudantes de Chicago Ward Christensen e Randy Sues. Eles criaram e liberaram para o domínio público o modem (periférico utilizado para transferir informações entre vários computadores via um apoio de transmissão telegráfico, como linhas telefônicas, por exemplo) e o Computer Bulletin Board System (software que permitia a participação simultânea de vários usuários enviando e recebendo arquivos e e-mails).

Outros acontecimentos que favoreceram o desenvolvimento da Internet seriam:

- a intervenção do programador Tom Jennings, criador do Fido (programa do bolletim board system) e quem iniciou a Fidonet (a rede de comunicação por computadores mais barata e mais acessível no mundo, baseando-se em PCs e ligações por linhas telefônicas convencionais); 
- a rede experimental iniciada por Ira Fuchs e Greydan Freeman com base no protocolo RJE da IBM que se tornou conhecida como Bitnet (acrônimo para Because It's Time Network);

- a liberação para as universidades do sistema operacional, portátil e multitarefa, Unix, inclusive de seu código fonte. Esse sistema foi desenvolvido pelos Laboratórios Bell, que permitiram a alteração da fonte;

- a distribuição, em 1978, do programa UUCP (Unix-to-Unix copy), também dos Laboratórios Bell. Esse programa permitia que computadores copiassem arquivos uns dos outros;

- o programa projetado em 1979 para a comunicação entre computadores Unix baseado no programa UUCP e a distribuição gratuita, em 1980, de uma versão aperfeiçoada que permitiu a formação de redes de comunicação entre computadores (a Usenet News fora o backbone da Arpanet);

- o surgimento do movimento de fonte aberta que tentava manter aberto o acesso a toda informação relativa a sistemas de software;

- o sistema operacional baseado no Unix desenvolvido por Linus Torvalds, da Universidade de Helsinki, chamado de Linux e que foi distribuído gratuitamente pela Internet com o pedido de que os usuários o aperfeiçoassem e comunicassem os resultados.

Por fim, em 24 de outubro de 1995, a Federal Networking Council, grupo responsável pela avaliação e coordenação das políticas e necessidades de redes de agências federais norte-americanas, definiu oficialmente que o termo "Internet" referia-se ao sistema de informação global que: é logicamente ligado por um endereço único global baseado no Internet Protocol (IP) ou em suas subsequentes extensões; é capaz de suportar comunicações usando o Transmission Control Protocol/Internet Protocol (TCP/IP) ou suas subsequentes extensões e/ou outros protocolos compatíveis ao IP; provê, usa ou torna acessível, tanto pública como privadamente, serviços de alto 
nível portados nas comunicações e na referida infraestrutura (Leiner et al., 2003). ${ }^{10}$

Um conceito-chave na Internet, relatam Leiner et al. (IDEM), é que a rede mundial de computadores não foi desenhada para uma única aplicação. Ela foi arquitetada como sendo uma infraestrutura geral dentro da qual poderiam ser concebidas novas aplicações e novos serviços. A criação da World Wide Web o confirma.

\section{World Wide Web}

A World Wide Web, Web ou www é definida pelo seu idealizador, o físico inglês Tim Berners-Lee (1996), como o universo da informação acessível na rede global. Ela é um espaço abstrato povoado, principalmente, por páginas interconectadas de texto, imagens e animações, com ocasionais sons, mundos tridimensionais e vídeos com os quais os usuários podem interagir.

É comum que as pessoas ainda confundam Web com Internet. Berners-Lee (2001, p.5) fala sobre a diferença em sua página no site da W3C.

A Web é um espaço de informação abstrato (imaginário). $\mathrm{Na}$ Internet você encontra computadores - na Web, você encontra documentos, sons, vídeos,... informação. Na Internet, as conexões são cabos entre computadores; na Web, as conexões são os links de

10 RESOLUTION: The Federal Networking Council (FNC) agrees that the following language reflects our definition of the term "Internet". "Internet" refers to the global information system that -- (i) is logically linked together by a globally unique address space based on the Internet Protocol (IP) or its subsequent extensions/follow-ons; (ii) is able to support communications using the Transmission Control Protocol/Internet Protocol (TCP/IP) suite or its subsequent extensions/ follow-ons, and/or other IP-compatible protocols; and (iii) provides, uses or makes accessible, either publicly or privately, high level services layered on the communications and related infrastructure (...). <http://www.isoc.org/internet/history/brief.shtml>. 
hipertextos. A Web existe devido a programas que se comunicam entre computadores na Internet. A Web não poderia ser criada sem a Internet. A Web tornou a rede útil porque as pessoas estão realmente interessadas em informação (para não citar conhecimento e sabedoria!) e realmente não querem saber sobre computadores e cabos. (tradução nossa) $)^{11}$

A arquitetura da Web foi proposta em março de 1989 por Berners-Lee, com a colaboração de Robert Cailliau. Na época, ambos trabalhavam para a European Organization for Nuclear Research (Cern), na Suíça. A proposta referia-se à gestão das informações mostrando como elas poderiam ser facilmente transferidas por meio da Internet usando o hipertexto - sistema de navegação por meio de links através da informação. A ideia, como relatado no próprio site da Cern, ${ }^{12}$ era conectar o hipertexto com a Internet e os computadores pessoais para dispor de uma rede que ajudasse os físicos do Cern a compartilhar todas as informações armazenadas no laboratório. $\mathrm{O}$ hipertexto permitiria que os usuários navegassem facilmente entre os textos nas páginas Web usando links (Cern, 2008).

Em outubro de 1990, Berners-Lee criou um programa navegador/editor que permitia a criação e a edição de páginas de hipertexto, bem como a navegação por elas. O programa recebeu o nome de World Wide Web. Para a efetivação dessa tecnologia, BernersLee precisou criar: a linguagem de etiquetas de hipertexto HTML (Hyper Text Markup Language) para possibilitar a realização de páginas Web que todos os computadores do mundo pudessem exi-

11 The Web is an abstract (imaginary) space of information. On the Net, you find computers -- on the Web, you find document, sounds, videos,.... information. On the Net, the connections are cables between computers; on the Web, connections are hypertext links. The Web exists because of programs which communicate between computers on the Net. The Web could not be without the Net. The Web made the net useful because people are really interested in information (not to mention knowledge and wisdom!) and don't really want to have know about computers and cables.

$12<$ http://info.cern.ch/>. 
bir de maneira idêntica; o protocolo HTTP (Hyper Text Transfer Protocol), um jogo de regras que os computadores usariam para comunicar-se na Internet e permitiria links para recuperar automaticamente documentos, independentemente de sua localização; e o URL (Uniform Resource Locator), uma forma-padrão de dar aos documentos na Internet um único endereço. Em seguida, juntou tudo na forma de um servidor Web que armazenaria documentos HTML e os disponibilizaria para outros computadores fazendo solicitações HTTP para documentos com URLs. Em dezembro desse ano, Berners-Lee já havia desenvolvido todas as ferramentas necessárias para fazer a Web funcionar: o primeiro navegador, o primeiro servidor Web e as primeiras páginas Web (Sherman \& Price, 2001, p.10-11).

Berners-Lee (s. d., p.1) explica o porquê do nome www:

Procurando um nome para um sistema de hipertexto global, um elemento essencial que queria destacar era sua forma descentralizada que permitia que qualquer coisa pudesse fazer link com qualquer coisa. Essa forma é matematicamente um diagrama, ou teia. Ela foi projetada para ser global, é claro. (Eu tinha observado que nos projetos parecia útil ter uma letra como marca, como no projeto Zebra no CERN, que começou todas suas variáveis com "Z". De fato, quando tinha decidido por www, eu tinha escrito código suficiente usando variáveis que começavam com "HT" para hipertexto em que W não era usado para isso). As alternativas que considerei foram "Mine of information" ("Moi" é um pouco egoísta) e "The Information Mine" ("Tim", ainda mais egocêntrico!), e "Information Mesh" (parecido demais com a palavra "Mess", embora sua capacidade de descrever uma bagunça fosse uma exigência!). Karen Sollins no MIT tem agora um projeto Mesh. (tradução nossa $)^{13}$

13 Looking for a name for a global hypertext system, an essential element I wanted to stress was its decentralized form allowing anything to link to anything. This form is mathematically a graph, or web. It was designed to be global of course. (I had 
Em 1991, destaca o website do Cern, outras instituições disponibilizaram servidores na Europa. Em dezembro do mesmo ano, o primeiro computador-servidor fora do continente europeu foi instalado nos Estados Unidos. Um ano depois havia 26 servidores no mundo, e em outubro de 1993 os números tinham aumentado para mais de duzentos servidores Web conhecidos. Em fevereiro de 1993, o National Center for Supercomputing Aplications (NCSA), na Universidade de Illinois, liberou a primeira versão do Mosaic, navegador que abriu a Web para aqueles que usassem PCs e Apple Macintosh.

Tim Berners-Lee, além de disponibilizar para o mundo sua invenção, formou o Consórcio World Wide Web (W3C), que sob o lema "Conduzindo a Web ao seu potencial máximo", e como explanado no próprio site da W3C, ${ }^{14}$ desenvolve tecnologias interoperáveis (especificações, manuais, softwares e ferramentas) para levar a utilização da rede mundial da Internet ao seu potencial pleno. Berners-Lee (1998) relata esse momento:

Entre o verão de 1991 e 1994, a carga no primeiro servidor Web ("info.cern.ch") aumentou a um ritmo constante de 10 a cada ano. Em 1992 a academia e em 1993 a indústria foram tomando conhecimento. Eu estava sob pressão para definir a evolução futura. Depois de muita discussão decidi formar o World Wide Web Consortium em setembro de 1994 com uma base no MIT nos Estados Unidos, na INRIA na França e agora também na Universidade de Keio no Japão. O Consortium é um fórum aberto neutro onde em-

noticed that projects find it useful to have a signature letter, as the Zebra project at CERN which started all its variables with " $Z$ ". In fact by the time I had decided on WWW, I had written enough code using global variables starting with "HT" for hypertext that W wasn't used for that.). Alternatives I considered were "Mine of information" ("Moi", c'est un peu egoiste) and "The Information Mine ("Tim", even more egocentric!), and "Information Mesh" (too like "Mess" though its ability to describe a mess was a requirement!). Karen Sollins at MIT now has a Mesh project.

14 <http://www.w3.org/>. 
presas e organizações para as quais o futuro da Web é importante venham discutir e acordar sobre novos protocolos comuns de computador. Ele tem sido um centro para levantar questões, desenho e decisão por consenso e também um ponto de observação fascinante do qual pode se observar essa evolução. (tradução nossa) $)^{15}$

Castells (2003, p.17-18) lembra que antes de Berners-Lee houve outras ideias e projetos técnicos que buscavam possibilidades de associar fontes de informação por meio da computação interativa. Em 1945, o cientista norte-americano Vannevar Bush propôs seu sistema Memex (Memory Extender), que operaria por associações como as da mente humana e armazenaria grandes volumes de informação que poderiam ser recuperados, organizados e adicionados a um repositório rapidamente.

O sistema Memex proposto por Bush (1945) era um dispositivo no qual a pessoa pudesse guardar todos os seus livros, revistas, jornais, fotos e correspondências, e consultá-los de forma rápida e flexível, como se fosse uma extensão de sua memória. O armazenamento das informações seria feito em microfichas, microfilmes ou fitas e o acesso a essas informações seria mecânico e através de índices. Dois itens quaisquer seriam codificados para associação através de uma trilha, que poderia ser gerada e/ou manipulada pelo sistema. $\mathrm{O}$ acesso às informações seria feito através de uma tela de televisão munida de alto-falantes. Além dos acessos clássicos

15 Between the summers of 1991 and 1994, the load on the first Web server ("info. cern.ch") rose steadily by a factor of 10 every year. In 1992 academia, and in 1993 industry, was taking notice. I was under pressure to define the future evolution. After much discussion I decided to form the World Wide Web Consortium in September 1994, with a base at MIT is the USA, INRIA in France, and now also at Keio University in Japan. The Consortium is a neutral open forum where companies and organizations to whom the future of the Web is important come to discuss and to agree on new common computer protocols. It has been a center for issue raising, design, and decision by consensus, and also a fascinating vantage point from which to view that evolution. 
por indexação, um comando simples permitiria ao usuário criar ligações independentes de qualquer classificação hierárquica entre uma dada informação e uma outra. Uma vez estabelecida a conexão, cada vez que determinado item fosse visualizado, todos os outros que tivessem sido ligados a ele poderiam ser instantaneamente recuperados, através de um simples toque em um botão. (Vidotti, 2001, p.29-30)

Em 1963, cita Castells, (2003, p.17) o sociólogo e filósofo estadunidense Ted Nelson "anteviu um hipertexto de informação interligada e trabalhou muitos anos na criação de um sistema utópico, Xanadu: um hipertexto aberto, autoevolutivo, destinado a vincular toda a informação passada, presente e futura do planeta". Entretanto, cabe destacar que o próprio Nelson (1987, p.143) referiu-se ao Xanadu como sendo somente uma forma de interconexão para arquivos de computador correspondendo à verdadeira interconexão de ideias que pode ser refinada e elaborada em uma rede compartilhada.

Em dezembro de 1968, o norte-americano Douglas C. Engelbart apresentou na Fall Joint Computer Conference o software OnLine-System (NLS), desenvolvido desde 1962 no Augmentation Research Center no Stanford Research Institute in Menlo Park, Califórnia, em que houve o primeiro uso prático de links de hipertexto e do mouse.

Em 1987, relata Vidotti (2001, p.32), baseado na metáfora do cartão, que possibilita elaborar um documento por meio de uma pilha de cartões, o engenheiro de computação norte-americano Bill Atkinson desenvolveu o sistema HyperCard de interligação de informação, o mais utilizado pelos usuários de computadores Macintosh da época.

Berners-Lee, no entanto, conclui Castells (2002, p.18), foi quem efetivamente pôde concretizar o ideal de associar fontes de informação por meio da computação interativa, isso devido à própria existência da Internet e valendo-se do poder computacional descentralizado por meio de estações de trabalho. 


\section{Web 2.0}

Foi em 2004, durante uma reunião da equipe da O'Reilly Media Inc. - editora americana que atua na produção de livros e conteúdos para Internet - e seu fundador, o empresário irlandês Tim O'Reilly, que surgiu o conceito de Web 2.0. O encontro discutia uma futura conferência que trataria do potencial da Web e observou-se que, embora ela tivesse sido afetada pelos eventos de 2000 que marcaram "o começo de um período de recessão leve, mas relativamente prolongado, nos primeiros anos do novo milênio quando muitas empresas faliram" (Spyer, 2007, p.243), sua importância não havia diminuído. Pelo contrário, ela era ainda maior, e para referir-se a esse momento, em que práticas e princípios evidenciavam uma significativa modificação com relação ao início de uma Web 1.0 (como O'Reilly refere-se à Web original), o termo Web 2.0 foi considerado adequado.

Em fevereiro de 2006, o próprio O'Reilly publicou um artigo para esclarecer o conceito de Web 2.0, que, apesar de ser amplamente utilizado, nem sempre tem o significado atribuído adequadamente. A Web 2.0 é definida por O'Reilly como sendo "um sistema de princípios e práticas que formam um verdadeiro sistema solar de sites que mostram alguns ou todos os princípios, a uma distância variável desse núcleo". Os princípios aos quais ele se refere são: a Web como plataforma; o aproveitamento da inteligência coletiva; os dados são o próximo Intel Inside; o fim do ciclo de lançamentos de softwares; os modelos leves de programação; o software em mais de um dispositivo; e a experiência rica do usuário.

Segundo O’Reilly (2005, p.27-29), há padrões de design da Web 2.0 que devem ser observados por aqueles que queiram aproveitar as possibilidades, principalmente comerciais, que a Web oferece. Os padrões citados por O'Reilly são os que a seguir relatam-se:

- "a cauda longa", denominação dada a um conjunto composto por pequenos sites que representam a maior parte do conteúdo da Internet. Por isso o autosserviço do cliente e o 
gerenciamento algorítmico de dados para alcançar a Web em sua totalidade devem estar presentes nas aplicações;

- os aplicativos são cada vez mais baseados em dados. Ter uma base de dados única e difícil de ser recriada é sinônimo de vantagem competitiva;

- os usuários agregam valor quando acrescentam seus próprios dados àqueles que o software lhes fornece. Portanto, o envolvimento do usuário, tanto implícita como explicitamente, na adição de valor do aplicativo é fundamental. Como só uma pequena porcentagem de usuários adicionará valor ao aplicativo, há que criar padrões para agregar dados do usuário como efeito colateral ao uso do aplicativo;

- beta perpétuo - quando os dispositivos e programas estão conectados à Internet, seus aplicativos são serviços em andamento. Assim, é importante que os usuários possam ser os avaliadores em tempo real dos novos recursos, que não devem ser empacotados em lançamentos monolíticos, mas, sim, adicionados regularmente como parte da experiência diária do usuário;

- os aplicativos da Web 2.0 constroem-se a partir de uma rede cooperativa de serviços de dados que devem ser reutilizados. Devem ser disponibilizadas interfaces para os serviços Web e para a sindicalização de conteúdos. Modelos leves de programação que admitam sistemas levemente acoplados devem ser encorajados. A colaboração, portanto, sobrepõe-se ao controle;

- como o computador já não é mais o único meio de acesso aos aplicativos da Internet e o valor diminui para os aplicativos que podem ser ligados a um único dispositivo, é importante que os aplicativos sejam projetados para integrar serviços entre dispositivos portáteis, computadores e servidores de Internet;

- como a propriedade intelectual limita a reutilização e impede a experimentação, toda vez que houver benefícios decorrentes da apropriação coletiva e não de restrições particulares, 
devem usar-se as licenças com o menor número de limitações possíveis. Os projetos devem ser direcionados para a "hackeabilidade" e "remixabilidade".

Os conceitos atribuídos por O'Reilly como representativos de uma Web 2.0 podem ser observados em serviços e aplicações que, segundo Anderson (2007, p.7), surgiram baseados na própria Web a partir de componentes das tecnologias e dos padrões abertos sustentadores da Internet e da Web.

Estas não são propriamente tecnologias, mas serviços (nossos processos de usuário) construídos usando os blocos de construção das tecnologias e os padrões abertos que sustentam a Internet e a Web. Esses serviços incluem blogs, wikis, serviços de compartilhamento de multimídia, sindicalização de conteúdos, podscasting e serviços de marcação de conteúdo. Muitas dessas aplicações da tecnologia Web estão relativamente maduras, em uso há alguns anos, embora novas funcionalidades e capacidades estejam sendo adicionadas regularmente. É interessante observar que muitas dessas novas tecnologias são concatenações, ou seja, elas fazem uso dos serviços existentes. (tradução nossa $)^{16}$

Os princípios que O'Reilly considera representativos da transição da Web para o que ele denomina de Web 2.0 caracterizam uma Web Colaborativa: um ambiente informacional que por meio de serviços e tecnologias disponibilizados na Internet propicia interações sociais.

16 These are not really technologies as such, but services (our user processes) built using the building blocks of the technologies and open standards that underpin the Internet and the Web. These include blogs, wikis, multimedia sharing services, content syndication, podcasting and content tagging services. Many of these applications of Web technology are relatively mature, having been in use for a number of years, although new features and capabilities are being added on a regular basis. It is worth noting that many of these newer technologies are concatenations, i.e. they make use of existing services. 


\section{Web Semântica}

O sonho de Berners-Lee, embora em grande medida já esteja realizado, ainda não foi concluído. A Web que ele idealizou não está totalmente concretizada, pois ela foi concebida para ser um espaço de informação útil não só para a comunicação entre indivíduos, mas para que nele as máquinas também pudessem participar e ajudar. Em 1998, Tim Berners-Lee escreveu um plano (Semantic Web Roadmap) destinado à realização de um conjunto de aplicações conectadas para dados na Web, de modo que se formasse uma rede lógica e consistente de dados: a Web Semântica. Berners-Lee (1998, p.1) explica que uma das dificuldades encontradas para concretizar seu projeto está no fato de que a maioria das informações na Web é delineada para o consumo humano, assim a abordagem da Web Semântica desenvolve linguagens para expressar informação de forma processável por uma máquina. Em entrevista dada ao jornalista Ethirajan Anbarasan, de El Correo de la Unesco, em setembro de 2000, Berners-Lee relata o que espera de uma Web Semântica, identificada como a segunda parte de seu sonho ainda não concretizado:

[...] na segunda parte, os computadores cooperam. As máquinas passam a ser capazes de analisar todos os dados que circulam na rede: conteúdos, enlaces e transações entre pessoas e computadores. A Web Semântica buscará a informação em diversas bases de dados, tanto em catálogos em linha quanto nos sítios meteorológicos ou da bolsa, e permitirá que toda essa informação seja tratada pelos computadores. Hoje não é possível porque os dados em linha não são compatíveis nem têm o formato necessário para serem analisados diretamente pelas máquinas. As páginas da Web somente estão pensadas para a leitura humana. A Web Semântica responderá também às aspirações de quem deseja contar com um programa de busca que ofereça sólidos resultados. Os atuais entregam milhares de páginas em resposta a uma única pergunta. Agora, bem, é impossível estudar o conteúdo de todas essas páginas. Com 
a Web Semântica, o robô buscador lhe dirá "Eis aí um objeto que responde ao critério desejado, algo que posso garantir matematicamente”. Em resumo, os robôs de pesquisa se tornarão mais fiáveis e mais eficazes. Quando meu sonho for uma realidade, a Web será um universo em que a fantasia do ser humano e a lógica da máquina poderão coexistir para formar uma combinação ideal e poderosa. $(\text { tradução nossa })^{17}$

Liyang Yu, especialista em Web Semântica, passados sete anos da declaração de Berners-Lee, refere-se a ela como a procura por condições que permitam estender a Web atual pela adição de semântica nos documentos Web. Essa semântica, ao ser expressa como informação estruturada, poderá ser lida e compreendida pelas máquinas. "[...] cada página Web conterá não somente informação para instruir máquinas sobre como exibir essa página, mas também dados estruturados para ajudar as máquinas a compreendê-la” (Yu, 2007, p.16, tradução nossa). ${ }^{18}$

17 (...) en la segunda parte, las computadoras cooperan. Las máquinas pasan a ser capaces de analizar todos los datos que circulan en la red: contenidos, enlaces y transacciones entre personas y computadoras. La Red semántica irá a buscar la información a diversas bases de datos, tanto en catálogos en línea como en los sitios meteorológicos o bursátiles, y permitirá que toda esa información sea tratada por las computadoras. Hoy no es posible porque los datos en línea no son compatibles ni tienen el formato necesario para ser analizados directamente por las máquinas. Las páginas de la Red sólo están pensadas para la lectura humana. La Red semántica responderá también a las aspiraciones de quienes desean contar con un programa de búsqueda que dé sólidos resultados. Los actuales entregan miles de páginas en respuesta a una sola pregunta. Ahora bien, es imposible estudiar el contenido de todas esas páginas. Con la Red semántica, el robot buscador te dirá: "He ahí un objeto que responde al criterio deseado, cosa que puedo garantizar matemáticamente." En resumen, los robots de investigación se tornarán más fiables y más eficaces. Cuando mi sueño sea una realidad, la Red será un universo en el que la fantasía del ser humano y la lógica de la máquina podrán coexistir para formar una combinación ideal y poderosa.

18 (...) each Web page will contain not only information to instruct machines about how to display it, but also structured data to help machines to understand it. 
O usuário da Internet, explica ainda Yu, utiliza a rede basicamente para pesquisa, integração e mineração na Web. Na pesquisa, o usuário procura localizar e acessar informações ou recursos na Web. Essa prática muitas vezes torna-se frustrante devido ao fato de que a enorme quantidade de informações recuperada dificilmente atende às necessidades específicas do usuário. A razão disso: as ferramentas de busca fazem suas pesquisas baseadas no que os documentos contêm de acordo com as palavras-chave atribuídas a esses documentos. A integração refere-se a combinar e agrupar recursos na Web para que eles possam ser coletivamente úteis. Realiza-se um processo de integração quando, por exemplo, o usuário procura por algum restaurante especializado em algum tipo de comida em particular. Ele primeiro acessa a informação que lhe dá a localização do restaurante e, em seguida, usa essa informação para obter mais informação: saber como chegar até o local (são essas informações que o ajudam a desfrutar de um ótimo jantar fora). A mineração na Web (considerando a Internet como uma enorme base de dados distribuída) refere-se à atividade de obter informação útil da Internet.

Para cada um dos usos - pesquisa, integração e mineração na Web -, Yu aponta que algo necessita ser melhorado. Para a pesquisa, os resultados deveriam ser os mais relevantes, a integração deveria ser mais automatizada e a mineração na Web deveria ser menos custosa. As razões para todos esses problemas aparentemente diferentes são idênticas: a construção da Internet é feita de tal modo que seus documentos só contêm a informação suficiente para que os computadores os apresentem, não para que os compreendam (ibidem).

O maior desafio para a concretização de uma Web Semântica, destacam Faria \& Girardi (2002), é

criar uma linguagem que seja capaz de expressar ao mesmo tempo o significado dos dados e definir regras para raciocinar sobre os mesmos, de forma a deduzir novos dados e regras e permitir que 
regras existentes em sistemas de conhecimento possam ser exportadas para a Web.

É preciso, no entanto, que os agentes de softwares tenham acesso não somente às definições estabelecidas nas ontologias, mas também a uma coleção de recursos informacionais devidamente estruturados e representados. Nesse sentido, há no W3C uma comunidade de pesquisadores pensando soluções para os naturais problemas que emergem das novidades e para melhorar, estender e padronizar o sistema a partir de reflexões de especialistas sobre a automação das ações agregadoras de informação realizadas por humanos: um novo passo na evolução da Web, uma Web Semântica que busca embutir inteligência e contexto na Web para propiciar a recuperação e o uso melhorado da informação em uma rede de conhecimento interligado. Para isso, a proposta é um novo modo de organização dos recursos informacionais na Web baseado na implantação de ferramentas tecnológicas e técnicas de representação do conteúdo informacional.

O projeto Web Semântica, destacam Jorente et al. (2009, p.19), trata da construção de possibilidades pautadas no conceito de serem as redes compostas por nós conectados (links) de maneira semelhante a como as pontes ligam as ilhas; as rotas comerciais, os mercados; as linhas telefônicas, os computadores; e os relacionamentos, as pessoas.

Um link hipertextual pode ligar tudo entre si, não reconhecendo hierarquias e discriminação entre categorias informacionais. Por meio de lógicas descritivas que conduzem a sistemas de ontologias, a criação de metalinguagens de recuperação na Web Semântica procura padrões, cria designs, automatiza para realizar complexidades. (idem, p.17)

É necessário compreender as observações de Morville (2005) sobre as ontologias, as taxonomias e as folksonomias como estruturas não mutuamente excludentes, mas cuja utilização depende do 
contexto informacional. Ao serem potencializadas por tecnologias semânticas (RDF e OWL), elas poderiam propiciar as condições adicionais para a organização de dados, a interoperabilidade e a recuperação de conteúdos informacionais, fatores estes de fragilidade na Internet, consequência da adição de uma dimensão inexplorada da representação do conhecimento feita por criadores de etiquetas que se auto-organizam organicamente nas redes sociais e, assim, cria-se idealisticamente uma recuperação da informação aberta, que amplia sua metodologia no modelo hipertópico (Jorente et al., 2009, p.19).

Juntas, taxonomias, folksonomias e ontologias propiciam maiores capacidades de interoperabilidade em relação aos cruzamentos de domínios e ao compartilhamento de conhecimento.

\section{Web Colaborativa}

$\mathrm{O}$ advento da Internet, como relatado anteriormente, propiciou o surgimento da Web e sua evolução para o que Tim O'Really denomina Web 2.0. Uma Web que modifica as rotinas dos indivíduos na hora de navegar e gera uma sociotecnologia da informação que deve constituir-se em assunto vital na contemporaneidade para a compreensão dos efeitos sobre as constituições sociais, dos comportamentos humanos e de suas atividades, bem como para o estudo e a formalização do entorno gerado por essas tecnologias.

O momento atual oferece a possibilidade de caminhar pela construção de um saber colaborativo marcado pela inteligência coletiva, em ações sociais de apropriação da informação, com o olhar para as redes sociais como ambiente antropológico de possibilidades. A apropriação da informação presume a existência de um valor da informação partilhado pelos participantes. Aponta-se nesse aspecto que as ações sociais de transferência da informação requisitam a utilização de procedimentos técnicos, expressivos ou normativos de dimensões cognitivas e comunicacionais no con- 
texto de formação e preservação de memórias e na socialização do conhecimento. As condições pragmáticas de aceitação e reconhecimento do valor da informação são dimensões do sucesso das ações de transferência de informação com ênfase no conceito de relação intrínseco na teoria social de redes. (Jorente et al., 2009, p.10)

Essa Web 2.0 constitui um ambiente informacional em que uma parcela importante da humanidade deixa de ser mero consumidor de bens simbólicos e, por práticas de colaboração e remix, passa a ser produtora de informação. Barreto (1998, p.122), em Mudança estrutural no fluxo do conhecimento: a comunicação eletrônica, cita como as relações entre o fluxo de informação e o público a quem o conhecimento é dirigido vêm se modificando e como modificam as bases conceituais da geração de conhecimento no indivíduo e em seu espaço de convivência, agregando competência na transmissão da informação e intensificando relações de interação.

No contexto da Web 2.0, em especial na cibercultura, autoria não se relaciona mais àquele autor que surge a partir do século XIII com a imprensa de Gutenberg e o capitalismo. Ele já não é uma fonte de originalidade, um ser privilegiado capaz de criar obras de arte e literatura a partir de uma inspiração espontânea.

O pesquisador da faculdade de Comunicação da Universidade Federal da Bahia Lemos (2005, p.2) destaca as modificações às noções de autor, de autoria e de propriedade que acontecem na pós-modernidade (meados do século XX), quando o artista quis romper fronteiras e passou a usar o processo de recombinação utilizando trabalhos de outros artistas, e também como esse processo influencia a sociedade contemporânea após o advento das tecnologias digitais.

A arte entra em crise e junto com ela a noção de obra, autor, autoria, propriedade. Na crise da criação pós-moderna ("a arte morreu!”) só é possível apropriações sob o signo da recriação. Não há mais autor, original e obra, apenas processos abertos, coletivos e livres. A tecnologia digital vai reforçar essas características da arte 
do pós-modernismo, já que "digital technology has made copyrightand the conventional notion of authorship - obsolete" (Murphie \& Potts, 2003, p.71). Na cibercultura, novos critérios de criação, criatividade e obra emergem consolidando, a partir das últimas décadas do século XX, essa cultura remix. Por remix compreendemos as possibilidades de apropriação, desvios e criação livre (que começam com a música, com os DJs no hip-hop e os Sound Systems) a partir de outros formatos, modalidades ou tecnologias, potencializados pelas características das ferramentas digitais e pela dinâmica da sociedade contemporânea. (Lemos, 2005, p.2)

Nesse ambiente informacional que denominamos Web Colaborativa, colaboração refere-se ao que Spyer, em Conectado (2007, p.23), define como sendo um processo dinâmico cujo objetivo consiste em chegar a um resultado novo partindo das competências particulares dos grupos ou indivíduos envolvidos: “[...] na colaboração, existe uma relação de interdependência entre indivíduo e grupo, entre metas pessoais e coletivas, o ganho de um ao mesmo tempo depende e influencia o resultado do conjunto". Quanto à remixagem, corresponde ao que Lemos (2005, p.1) denomina como o "conjunto de práticas sociais e comunicacionais de combinações, colagens, cut-up de informação a partir das tecnologias digitais".

$\mathrm{Na}$ Web Colaborativa observam-se também as três leis identificadas por Lemos como características da ciber-cultura-remix: uma nova configuração cultural fruto da alteração nos processos de comunicação, de produção, de criação e de circulação de bens e serviços no início de século XXI:

[...] a liberação do polo da emissão, o princípio de conexão em rede e a reconfiguração de formatos midiáticos e práticas sociais. Essas leis vão nortear os processos de "remixagem" contemporâneos. Sob o prisma de uma fenomenologia do social, esse tripé (emissão, conexão, reconfiguração) tem como corolário uma mudança social na vivência do espaço e do tempo. (ibidem). 
A informação já não corresponde unicamente ao que a mass media editava. A liberação do polo da emissão permite o expressivo aumento do fluxo informacional, composto agora de vozes, de discursos e de criações de indivíduos das mais diversas esferas sociais. A conectividade generalizada (tudo está em rede), a ubiquidade que esses indivíduos podem alcançar e a constante necessidade de reconfiguração de formatos mediáticos e das práticas sociais que são articulados na Web 2.0 evidenciam seu aspecto colaborativo (Araya \& Vidotti, 2009, p.40).

A reconfiguração cultural referida, em que princípios de colaboração e remixagem modificam as formas de criar, recriar, usar, reusar, compartilhar e disseminar conteúdos informacionais, explicita-se em blogs e wikis e em websites como Flickr e YouTube, entre outros. No entanto, cabe destacar que essas práticas, embora modificadas, continuam condicionadas a uma legislação de direitos autorais estabelecida para um contexto anterior à criação da Web.

\section{Blog}

Um website de representativa presença em diversas áreas e de fácil funcionamento é o web log ou blog, uma reprodução dos diários pessoais privados que desde 1994 popularizou-se na Web quando adolescentes e jovens passaram a usá-lo para o compartilhamento de opiniões e como fonte de informação. As ofertas de serviços gratuitos que propiciavam criá-lo e divulgá-lo permitiram que sua presença alcançasse qualquer atividade profissional. Na atualidade (2010), ele constitui fonte de informação não só informal, sobre ciência, tecnologia, literatura, arte, cultura e outros diversos assuntos, mas também, como destaca Lemos (2005 p.6), é "um grande instrumento de divulgação de informação fora do esquema do mass media, aumentando a possibilidade de escolha de fontes de informação por parte do cidadão comum”. Silva Filho (2006, p.1) publicava na revista Espaço Acadêmico, que em março de 2006 havia mais de 35 milhões de blogs e previa-se que esse número 
excederia os cem milhões até julho de 2007. Em 2008, o motor de busca de blogs em Internet, Technorati, ${ }^{19}$ indicava que o número de blogs registrados no mundo correspondia a 133 milhões. O portal Terra (2009) informava que somente na China o número de blogs alcançava os cem milhões.

Os blogs potencializam a inteligência global como filtro e reverberador simultaneamente, e a rede, acrescenta O'Reilly (2005, p.9), tem o poder de tirar partido da inteligência coletiva.

À medida que os usuários adicionam conteúdo e sites novos, esses passam a integrar a estrutura da rede à medida que outros usuários descobrem o conteúdo e se conectam com ele. Do mesmo modo que se formam sinapses no cérebro - com as associações fortalecendo-se em função da repetição ou da intensidade - a rede de conexões cresce organicamente, como resultado da atividade coletiva de todos os usuários da rede.

O blog, destaca Anderson (2007, p.7), além da simplicidade de operação tanto de quem o atualiza quanto de quem lê seu conteúdo, apresenta características bastante particulares:

- o material disponibilizado aparece em uma sequência de publicação cronológica invertida, em que a publicação mais recente fica sendo a primeira da lista, no estilo de um jornal on-line;

- a leitura é feita de forma linear por meio de uma barra de rolagem;

- a atualização (post) é simplificada: após publicar textos ou imagens, a organização da publicação acontece automática e rapidamente;

- é comum que o blog disponha de um blogroll, lista de enlaces a outros blogs de que o blogueiro gosta ou que considera úteis;

$19<$ http://technorati.com/>. 
- dispõe de uma entrada para que visitantes possam adicionar comentários, estabelecendo uma via de comunicação com o autor sobre o assunto publicado;

- sugere uma ideia de imediatez, pois permite que os indivíduos escrevam em tempo jornalístico - de hora em hora, diariamente, semanalmente -, com estilo mais próximo de uma reportagem do que de um ensaio;

- favorece interligações de todos os blogs, criando comunidades ou redes sociais, uma blogosfera interconectada em que blogueiros leem-se mutuamente, fazem links e referenciamse uns aos outros em suas publicações.

Os blogs também contam com recursos que lhes garantem o dinamismo necessário para torná-los uma rede viva, diferenciando-os de uma página comum da rede. Entre esses recursos, cabe destacar o RSS ou RSS feed (RDF Site Summary ou Really Simple Syndication), o permalink e o trackback ou link de retorno.

O RSS é uma tecnologia de formato de arquivo padronizado que surge em 1997 como fruto da confluência da tecnologia Really Simple Syndication, usada para enviar atualizações de blog, e o Rich Site Summary, da Netscape, que possibilitava aos usuários criar homepages personalizadas do Netscape, com fluxos de dados regularmente atualizados (O'Reilly, 2005, p.13). O RSS contém os detalhes sobre as publicações mais recentes do website e propicia a sindicalização de seu conteúdo, isto é, disponibiliza parte do conteúdo para leitores especializados ou para que outros websites usem e publiquem-no gratuitamente. A sindicalização mais frequente é apenas do título - que ficará disponível para que o leitor do blog possa acompanhar novas publicações e outros conteúdos - e, via um link hipertexto, esse título o levará para o blog de origem da publicação do texto. O RSS permite que o indivíduo não apenas acesse uma página, mas faça uma assinatura, sendo notificado cada vez que haja mudança na página.

O permalink é um endereço permanente da Internet (URI-Uniform Resource Identifiers) gerado pelo sistema de blogging para cada um dos posts (atualizações) publicados em um blog. O permalink, 
destaca O'Reilly (idem, p.14), "foi a primeira e mais bem-sucedida tentativa de se construir pontes entre blogs", pois ele permitia apontar e discutir sobre algum post específico em algum site pessoal. As homepages da maioria dos blogs têm várias entradas ou posts listados nelas, e, como a tendência é a de serem frequentemente atualizados, é bem provável que os artigos que o usuário encontra em um blog hoje não estejam lá dentro de uma semana ou um mês, por exemplo. O permalink, como identificador permanente de post ou artigos específicos do blog, facilitará o acesso a esse conteúdo informativo.

O Trackback ou link de retorno é um recurso que cria links automáticos de notificação. Se o usuário cria um post referindo-se a um post de outro blog e insere a URI de trackback desse outro blog, é gerada automaticamente uma notificação para esse blog indicando que seu post foi citado e, também automaticamente, o usuário passa a constar na lista de comentários desse blog sem necessidade de visitá-lo e incluir qualquer referência diretamente.

Os blogs representam uma mudança radical na dinâmica de criação de conteúdo. A participação coletiva gera resultados melhores do que a análise de qualquer documento individual. Por serem os blogueiros os mais produtivos e atualizados usuários de links, e pelo fato de os mecanismos de busca usarem a estrutura de links para predizer páginas importantes, os blogs exercem um papel desproporcional nos resultados das buscas, além de aumentar a visibilidade e poder dos próprios blogs, pois é prática da comunidade de blogueiros a autorreferência. Spyer (2007, p.53) acrescenta: "da mesma forma como uma formiga não existiria sem o formigueiro, o blog não faz sentido sem a blogosfera".

$\mathrm{Na}$ narrativa de um famoso blogueiro português, se de um lado pode-se perceber o aspecto legal/ilegal do uso da informação, de outro observa-se o uso do blog como efetiva fonte de informação. Paulo Faustino conta em artigo publicado em seu blog Fique Rico ${ }^{20}$

20 <http://www.escoladinheiro.com/2008/07/18/cuidado-com-as-imagensque-usa-explicacao-sobre-os-direitos-de-autor $/>$. 
como ele foi procurado pela autora de uma das imagens utilizadas em uma postagem que fez em seu blog. A imagem em questão foi retirada do Flickr e, como explica Faustino, por desconhecer os aspectos relativos ao direito autoral, publicou a imagem em seu blog sem autorização de sua criadora, para quem ele próprio enviou o link de seu blog. Ao se informar do uso indevido da imagem, a autora exigiu o pagamento pela obra.

A essa narrativa pode ser somada a contribuição de outro blogueiro que a comenta: "[...] pesquisando comecei a entender que somente dar o crédito devido ao autor da imagem não é o suficiente, é preciso também saber se o autor permite, ou não, que eu disponibilize o trabalho dele em meu blog (assim como é feito com os artigos dos blogs)" (Freitas, 2008).

Como utilizar as imagens então? É o que se pergunta o comentador antes de disponibilizar uma tecnologia apropriada para atribuir, já na codificação, os créditos e fazer o link com o local original das fotos: o Photo Dropper, recurso que usa as imagens do Flickr exibidas sob uma licença flexível que permite seu uso em blogs.

As modificações tecnológicas também têm possibilitado variações do blog como os Videologs ou Vlogs, cujo conteúdo consiste em vídeos, e os Photologs, com fotos em vez de textos. Em todos eles, a raiz de sua evolução, como destaca Lemos (2005, p.5), está na liberação do polo da emissão (qualquer pessoa pode dispor de um deles), no evidente princípio de conectividade em rede (blogs que fazem referência a outros blogs, por exemplo) e na reconfiguração da indústria midiática e de suas práticas de produção de informação (surgem novos formatos de diários, de publicações jornalísticas, de emissões sonoras e de vídeo, de literatura etc.).

\section{Wiki}

Em 1994 Ward Cunningham criou o software WikiWikiWeb (na língua havaiana significa "web ágil"). O objetivo de Cunningham era possibilitar que os usuários participassem no processo de 
edição do próprio conteúdo usando apenas um navegador Internet. Em 1995, ele o adicionou ao website PortlandPatternRepository, um repositório de padrões de projeto de software. Em entrevista ao website InternetNews.com ${ }^{21}$ em dezembro de 2006, Cunningham disse que ele pensou patentear sua invenção, porém, após entender que para poder comercializá-la teria de sair e vender essa ideia e que parecia pouco provável que alguém quisesse pagar por ela, resolveu disponibilizá-la para sua comunidade, a de desenvolvedores de software, o que, segundo ele, representaria um cartão de apresentação e uma forma de ser reconhecido (Araya \& Vidotti, 2009, p.41).

O website wiki, criado com contribuição de Cunningham, também é chamado de wiki e caracteriza-se por fomentar o trabalho anônimo, por permitir que qualquer pessoa agregue conteúdo informacional e modifique as informações enviadas por outro autor e por possibilitar que todos os rascunhos de textos possam ser visualizados. O trabalho realizado com a contribuição de diferentes pontos de vista, destaca Valzacchi (2006, p.1), é um bem precioso, difícil de ser conseguido nos claustros.

O periódico Arquivos Brasileiros de Oftalmologia, de acesso via SciELO-Scientific Electronic Libray Online, publicou em setembro/outubro de 2007 a carta do médico Kjaer (2007)²2, usuário do sistema wiki, na qual ele destacava a importância que a comunidade médica deveria atribuir à ferramenta wiki pela "capacidade de gerenciar a atualização das informações, por facilitar a produção intelectual coletiva e diminuir custos para a educação continuada e publicação de revisões bibliográficas". No texto explica-se detalhadamente como um wiki funciona para em seguida sugerir a criação do Wiki Brasileiro de Oftalmologia, enfatizando que, embora o wiki não substitua a revista científica ou a documentação histórica, ele pode se tornar enciclopédia com atualizações permanentes e de uti-

21 <http://www.internetnews.com/dev-news/article.php/3648131>.

22 <http://www.scielo.br/scielo.php? pid=S0004-27492007000500031\&script =sci_arttext>. 
lidade para a educação continuada e para a centralização da revisão bibliográfica de qualidade.

Depreendem-se, facilmente, os usos desse repositório dinâmico de informações para a gestão do conhecimento médico, em contínua e rápida evolução. A qualidade do texto permanentemente aprimorado tende à otimização. Por outro lado, livros e tradicionais artigos de revisão bibliográfica são estáticos, mais propensos a falhas e tornam-se rapidamente anacrônicos. (ibidem)

Um importante exemplo de modelo wiki, sem fins lucrativos, gerido e operado pela Wikimedia Foundation desde janeiro de 2001 e cada vez mais presente na vida dos internautas -, é a enciclopédia multilíngue on-line Wikipédia. Ela é escrita voluntariamente por pessoas comuns com acesso à Internet de diversas partes do mundo. Os artigos com as mais diversas informações, em 257 idiomas ou dialetos, são transcritos, modificados e ampliados por qualquer pessoa por meio de navegadores como o Internet Explorer, Mozilla Firefox, Netscape, Opera, Safári ou outro programa capaz de ler páginas em HTML e imagens. Em outubro de 2009, a Wikipédia registrava a existência de 515.407 verbetes em língua portuguesa, e, em abril de 2010, $586354 .{ }^{23}$

Em dezembro de 2005, o website BBCBrasil.com ${ }^{24}$ publicava um artigo com resultados de uma pesquisa feita pela revista científica Nature em que apontava a Wikipédia como sendo tão precisa quanto a Enciclopédia Britânica, contudo destacando também ter sido criticada devido às falhas de correção de seus verbetes: "A revista Nature examinou uma série de verbetes científicos nas duas fontes e encontrou poucas diferenças na precisão das definições" (BBCBrasil.com, 2005, p.1). O termo wiki, após a divulgação do estudo, popularizou-se entre os internautas.

23 <http://pt.wikipedia.org/wiki/Wikipedia:Estat\%C3\%ADsticas>.

24 <http://www.bbc.co.uk/portuguese/ciencia/story/2005/12/051215_wikipediacomparacaofn.shtml $>$. 
O sucesso da Wikipédia é comentado na revista Época de janeiro de 2006. Ele era atribuído à atualidade das informações e à pluralidade dos temas tratados por leitores que no contexto da Wikipédia transformam-se em editores de conteúdo: "Ao contrário das enciclopédias tradicionais, a Wikipédia muda a todo instante, captura tendências e modismos na velocidade em que surgem, registra feitos em tempo real, é viva, é ágil, é pop (Amorim \& Vicária, 2006, p.1). Em março de 2006, cita o artigo, o verbete referente a Michelle Bachelet registrava a notícia sobre a vitória de Bachelet nas eleições do Chile momentos após ser feito o anúncio oficial.

No panorama brasileiro, o projeto WikiCrimes, ${ }^{25}$ criado em dezembro de 2007 pelo professor Vasco Furtado, da Universidade de Fortaleza, com o intuito de mapear os crimes no país, permite que qualquer pessoa marque em um mapa do Brasil disponibilizado no website o local em que foi vítima de um crime. O usuário também pode optar por receber e-mails com alertas de crimes que aconteçam em regiões de seu próprio interesse. OWikiCrimes, que em junho de 2010 registrava 13.928 ocorrências, foi tema do artigo Wiki pinpoints Brazilian crime, publicado na BBC News ${ }^{26}$ em abril de 2008 e escrito por uma de suas repórteres, Helen Clegg, que, vítima de um assalto no Rio de Janeiro, usou o wiki para reportar o crime. Clegg conta a experiência e explica o porquê da criação do WikiCrimes, bem como de que forma ele tem sido encarado por segmentos da sociedade preocupados em combater a violência (comunidade e polícia, por exemplo).

\section{Flickr}

A conceituação de uma Web 2.0 colaborativa corrobora-se no website de hospedagem e partilha de imagens fotográficas Flickr, criado em 2004 (desde 2005 pertence à Yahoo!Inc.). Na página ini-

25 <http://www.wikicrimes.org/main.html;jsessionid=E69957904953D3D90 C1A483130125930\#>.

26 <http://news.bbc.co.uk/1/hi/technology/7347101.stm>. 
cial do próprio website, sob o título $O$ que é Flickr?, o usuário encontra a definição de ser a melhor aplicação de compartilhamento e gerenciamento de fotos do mundo. Assim como os ambientes colaborativos blogs e wikis, o Flickr também é gratuito.

No website, o usuário encontra as instruções necessárias para o uso e o aproveitamento adequado dos diferentes recursos oferecidos nesse ambiente da web colaborativa. As orientações são apresentadas em uma série de oito itens que compreendem, além da apresentação, instruções quanto:

- ao upload das imagens, que pode ser feito tanto por computador quanto por telefone celular;

- à edição, em que o aplicativo permite a correção de olhos vermelhos, recortes e efeitos que favorecem a criatividade;

- à organização, que pode ser feita em álbuns, coleções (agrupamento de álbuns);

- ao compartilhamento, que pode ser entre grupos de usuários, públicos ou particulares, e à definição do grau de privacidade que o usuário quer;

- ao mapeamento, que permite localizar geograficamente locais em que as fotos e os vídeos foram feitos e também navegar por um mapa-múndi e conhecer os locais que outras pessoas visitaram e registraram;

- a criar coisas a partir das imagens, como cartões de visita, livros de fotos, selos postais etc.;

- a manter contatos e atualizações ubíquas e simultâneas entre pessoas que se relacionam por laços familiares ou de amizade.

Tim O'Reilly (2005, p.11) enfatiza ser o Flickr uma das companhias que inauguraram o conceito de folksonomia (em oposição a taxonomia) para referir-se a um estilo de categorização colaborativa de sites em que o usuário usa como palavras-chave termos escolhidos livremente (tags).

O uso de tags permite associações múltiplas e superpostas como as que o próprio cérebro usa ao invés de categorias rígidas. No 
exemplo típico, uma fotografia de um filhote de cachorro no Flickr pode ser etiquetada tanto como "filhote" ou como "fofinho" - permitindo ser localizada através de eixos de atividade de usuário que foram naturalmente gerados.

Em abril de 2008, o website do Ministério da Cultura publicava um artigo sob o título "Flickr: deleite virtual para os olhos", postado por José Murilo destacando o alcance mundial do Flickr com 24 milhões de usuários e até cinco mil fotos cadastradas por minuto diariamente: "[...] este que saltou da aparente condição de álbum virtual para o status de maior vitrine da fotografia contemporânea, fenômeno bem recente" (Murilo, 2008, p.1). Já em junho de 2010, o próprio website $e^{27}$ divulgava ter 103.795.979 itens georreferenciados e que em um minuto o número de uploads feitos era de 6.997.

Desde abril de 2009 a Casa Branca tem sua própria conta no Flickr. ${ }^{28}$ As fotos da rotina do escritório do presidente Barack Obama são disponibilizadas para a visita dos internautas e também para os usuários deixarem seus comentários. Obama, desde que foi eleito, tem mantido a postura de conectividade pela Internet com seus eleitores.

Em maio de 2009, o Flickr ${ }^{29}$ recebeu o troféu na categoria "melhor comunidade", outorgado na 13a edição do Webby Awards, premiação internacional que homenageia os melhores projetos na Internet. O Webby Awards é promovido pela International Academy of Digital Arts and Sciences, ${ }^{30}$ fundada em 1998 com a proposta de ajudar a conduzir o progresso criativo, técnico e profissional da Internet e as formas de evolução da mídia interativa. As premiações dividem-se em cerca de setenta categorias, que incluem websites, publicidades interativas, vídeos on-line e aplicativos para celulares.

O The Commons ${ }^{31}$ também está no Flickr. Trata-se de um projeto em que coleções de imagens dos acervos de diversas instituições

$27<$ http://www.flickr.com/map/>.

$28<$ http://www.flickr.com/photos/whitehouse/>.

$29<$ http://blog.flickr.net/pt/2009/05/11/se-sentindo/>.

$30<$ http://iadas.net/>.

$31<$ http://www.flickr.com/commons/>. 
são disponibilizadas com o propósito de "mostrar aos usuários os tesouros escondidos nos arquivos de fotografias públicas mundiais e, [...] mostrar como a sua edição e o seu conhecimento podem ajudar a enriquecer ainda mais essas coleções" (The Commons, 2009).

O The Commons surge em janeiro de 2008 como projeto piloto em parceria com a Biblioteca do Congresso Americano e, como o sugere o título do texto postado por Soares (2008, p.1) no blog institucional do Flickr, propõe-se, ao convidar o usuário a descrever imagens adicionando tags ou deixando comentários, formar um "exército tagger para o bem comum":

Por acaso você já "taggeou" uma foto de outra pessoa? Eu já, e antecipo que não há coisa mais fácil. Pode ser uma palavra descritiva, algo que funcione como um laço para reunir fotos de um evento, duas palavras coladas em uma única ou até termos que identifiquem uma característica da foto, como a cor, a época...

O que muitos não sabem é que todo esse trabalho que alguns se dispõem a fazer está ajudando a construir algo muito mais importante do que um simples apanhado de palavras. Estou falando de um sistema orgânico de informação, resultado da interação dos termos e frases descritivas.

Em junho de 2010, O The Commons disponibilizava álbuns dos acervos de: Australian National Maritime Museum on the Commons, Australian War Memorial Collection, Bergen Public Library, Biblioteca De Arte-Fundação Calouste Gulbenkian, Biblioteque De Toulouse, Brooklin Museum, Center for Jewish History-NYC, Cornell University Library, DC Public Library Commons, Fylkesarkivet I Sogn Og Fjordane, Galt Museum E Archives on the Commons, George Eastman House, Getty Research Institute, Imperial War Museum Collections, Jewish Historical Society of the Upper Midwest, JWA Commons, LLGC-NLW, LSE Library, Musée McCord Museum, National Archief, National Galleries of Scotland Commons, National Libray NZ on the Commons, National Maritime Museum, National Media Museum, New York Public Library, NHA Library, 
Oregon State University Archives, Powerhouse Museum Collection, Smithsonian Institution, SMU Central University Libraries, State Library and Archives of Florida, State Libray of New South Wales Collection, State Libray of Queensland-Austrália, Swedish National Heritage Board, Texas State Archives, The Field Museum Library, The Library of Congress, The Library of Virginia, The National Archives UK, The U. S. National Archives, UA Archives | Upper Arlington History e UW Digital Collections.

Para o depósito institucional de imagens no The Commons, o Flickr pede uma declaração indicando que as imagens estão livres das restrições de direitos autorais conhecidas. Para determinar o que se denomina "sem restrições de direitos autorais", a instituição depositária do material fotográfico deve observar se as imagens estão em domínio público e por qual motivo (prazos de proteção expirados, por exemplo) ou se detêm os direitos autorais e não deseja exercer controle sobre eles, ou ainda se possui direitos jurídicos suficientes para autorizar terceiros a utilizarem a obra sem restrições.

Cada instituição participante publica sua declaração em uma interface do projeto e indica os dados relativos ao histórico de produção, bem como a informação necessária sobre as condições do depósito, garantindo assim o uso legal das imagens. Cabe destacar que o Flickr, neste aspecto, procura precaver-se exigindo ampla documentação para evitar possibilidades de as imagens em questão pertencerem a um quadro de direito autoral reservado, cuidado este que também se observa em qualquer tipo de imagem disponibilizada pelo aplicativo. As imagens do The Commons são um bem comum, mas aquelas depositadas por autores, fotógrafos ou produtores de imagens em geral também passam por processos que visam garantir os direitos autorais usando, por exemplo, o instrumental fornecido pelo Creative Commons, projeto sem fins lucrativos que disponibiliza licenças que permitem ao autor da obra escolher sob que condições seu trabalho pode ser utilizado.

O Flickr constitui também elemento representativo no ambiente informacional da Web Colaborativa, favorecendo as práticas de colaboração tanto de profissionais que procuram formas de expor 
seu trabalho quanto de indivíduos comuns que veem no compartilhamento e na recriação características já comuns à sua época.

\section{YouTube}

No website do YouTube, fundado em fevereiro de 2005 e desde outubro de 2006 propriedade do Google, os usuários podem carregar e compartilhar vídeos em formato digital. Apresenta-se como a comunidade de vídeos on-line de maior popularidade do planeta, que permite a milhões de pessoas descobrir, olhar e compartilhar vídeos criados originalmente. $\mathrm{O}$ website oferece fóruns de conexão entre usuários e atua como plataforma de distribuição para criadores de conteúdos originais e de propagandas, tanto em pequena quanto em grande escala.

A página inicial do website, à primeira vista, não contém muitas explicações sobre o website e sua proposta. Do lado esquerdo da página há imagens-ícones de acesso aos vídeos. Do lado direito, propaganda institucional ou de empresas conveniadas e avisos sobre o aplicativo, entre eles o link para o blog do YouTube Brasil, e, na parte inferior da página, links que direcionam para páginas diversas sobre a conta do usuário, ajuda e informações sobre o próprio website. Em alguns desses links o usuário pode efetivamente evidenciar as características de colaboração e compartilhamento que incluem o YouTube também como parte do ambiente informacional da Web Colaborativa.

Ao clicar no link TestTube, acessa-se a incubadora de ideias em que o usuário e convidado a testar recursos que ainda não foram implementados totalmente e a comentar sobre eles. Em 2009, o TestTube disponibilizava os recursos de: Anotações de Vídeo, um sistema interativo de comentários nos vídeos; Compartilhamento Ativo, que permite ao usuário mostrar os vídeos a que ele está assistindo a outros usuários do YouTube; Warp, em que a navegação é feita em tela inteira; e Canais em que o usuário pode bater papo com outras pessoas que estejam assistindo ao mesmo vídeo. 
Como é característico dos ambientes colaborativos, o YouTube também disponibiliza um fórum para que os usuários possam solicitar e fornecer ajuda a outros usuários sobre o próprio YouTube, bem como trocar opiniões, sugestões e críticas "construtivas" (destaca o próprio website) sobre as funcionalidades do produto.

Na seção Imprensa, por exemplo, um link de janeiro de 2009 conduz para um canal que liga o YouTube ao Congresso Americano em que o usuário poderá acompanhar ao vivo sessões do Senado e da Câmara dos Deputados dos Estados Unidos. "Esses canais irão permitir às pessoas obter uma visão de dentro e observar o trabalho de seus representantes no Congresso em Washington", afirmou Steve Grove, diretor de notícias e políticas do YouTube. "Eles também permitem aos cidadãos e aos seus líderes ter um dialogo direto sobre os assuntos enfrentados pelo país." Nancy Pelosi, portavoz da Casa Branca, afirma que os americanos agora, mais do que nunca, procuram a Web para assistir a notícias, com os canais do YouTube servindo como uma linha direta para o que está acontecendo no Congresso. Por outro lado, o líder da minoria no Senado, Mitch McConnell, afirma que a Internet representa a maior oportunidade de comunicações para o Capitólio desde a televisão e da ascensão dos canais a cabo especializados em política. O líder republicano John Boehner também concorda que o YouTube e outras ferramentas de comunicação ajudam a criar um nível de acesso e transparência que jamais foi visto antes no governo (YouTube ${ }^{32}, 2009$, p.1).

Em janeiro de 2009, o YouTube bateu recorde e atingiu cem milhões de usuários, que assistiram a 6,4 bilhões de vídeos em uma média de 62 vídeos, segundo noticiou o website Globo.com. ${ }^{33} \mathrm{O}$ site também informava que o Google, proprietário do YouTube, possui $43 \%$ do total de vídeos que circulam pela rede. Barifouse (2009, p.1) em maio de 2009 destacava, no site Época Negócios de maio

$32<$ http://www.youtube.com/press_room_entry?entry=FsRXSG0CCTg>.

33 <http://g1.globo.com/Noticias/Mundo/0,,MUL1031052-5602,00-YOU TUBE+BATE+RECORDE+E+ATINGE+MILHOES+DE+USUARIO $\mathrm{S}+\mathrm{EM}+\mathrm{JANEIRO} \cdot \mathrm{html}>$. 
de 2009, o fato de o YouTube colocar na rede vinte novas horas de vídeo a cada minuto - o equivalente a lançar 114 mil novos filmes a cada semana.

As práticas caracterizadoras de uma Web Colaborativa, em 2002, foram enfatizadas na conferência Social Software Summit, em Nova York, evento definido por seu organizador, C. Shirky, como um programa que apoia as comunicações em grupo e busca a interoperabilidade entre sistemas. Na ocasião, tratou-se da necessidade de um software construído e constituído por ferramentas que facilitassem a interação e a colaboração coletiva. Ele deveria ser definido sob condições que dessem o suporte necessário à interação conversacional entre indivíduos e grupos, abrissem espaços de colaboração e de realimentação social e criassem redes sociais gestoras do conhecimento (Jorente et al., 2009, p.12).

No contexto da nova configuração cultural, em que a participação do usuário na criação, na recriação, no compartilhamento, no uso, no reúso e na disseminação da produção intelectual registrada é crescente em virtude das facilidades providas pelas TIC, a preocupação quanto a aspectos legais relativos a tais práticas deve estar presente. É relevante que a sociedade, em geral, e o profissional da informação, em especial, saibam sob que condições elas podem ser realizadas em benefício da construção do saber compartilhado. 


\section{2 \\ Autoria E LEGISLAÇÃo DE CONTEÚDO INTELECTUAL}

O percurso deste capítulo corresponde ao espaço de tempo compreendido entre o século I a.C. (época da qual se encontram vestígios registrados úteis para ilustrar a interpretação dada ao conceito de autoria e uso da produção intelectual humana) e a contemporaneidade (2010), quando a rede mundial de computadores Internet já faz parte do mundo como uma nova tecnologia de comunicação e informação possibilitadora de modificações significativas na sociedade no âmbito da criação, do uso e da disseminação de conteúdos informacionais.

Em um breve relato, primeiro procura-se mostrar aspectos relacionados com autoria e uso da produção intelectual antes da era da palavra impressa e após a invenção da prensa com tipos móveis. Segundo, tratam-se dos primórdios da primeira legislação relativa à proteção da obra intelectual. Finalmente, trata-se da Lei de Copyright, sua equivalente no Brasil - a Lei n ${ }^{\circ}$ 9.610, de 19.2.98, de Direitos Autorais -, e dos acordos internacionais sobre proteção à obra fruto do intelecto humano.

\section{A produção intelectual anterior à era da palavra impressa}

A produção intelectual ao longo da história tem estado baseada em conhecimentos anteriormente construídos, mas o conceito de 
autoria não tem acompanhado a produção intelectual com a mesma significação dada na contemporaneidade.

$\mathrm{Na}$ Antiguidade, (século I a.C.), o arquiteto, escritor, engenheiro e tratadista romano Marco Vitrúvio Polião enaltecia o esforço daqueles que tinham deixado registradas em seus escritos as informações necessárias para o desenvolvimento das futuras gerações.

Útil e sabiamente dedicaram-se os antigos a deixar para a posteridade suas descobertas por meio dos livros, para que nunca se perdessem; pelo contrário, aumentando-os de tempos em tempos com novas reflexões, para que chegassem finalmente as ciências ao estado mais perfeito. Devemos, portanto, agradecer infinitamente não ter, com um invejoso silêncio, deixado cair no esquecimento suas invenções, e de tê-las deixado às idades em seus escritos. Se assim não o tivessem feito, mal saberíamos agora os acontecimentos de Troia, as opiniões de Thales, Demócrito, Anaxágoras, Xenophanes ou outros Físicos em referência à natureza das coisas. (Vitrúvio Polião, 1787, p.161, tradução nossa $)^{1}$

Também na Antiguidade encontram-se evidências da importância atribuída ao fato de que tais criações deveriam ser reconhecidas como bens de seus autores. Na obra de Vitrúvio Polião, o autor critica aqueles que se atreviam a publicar, como sendo próprias, obras de outros, "e assim como a estes devemos agradecer, devem, pelo contrário, ser vituperados, os que roubando as obras daqueles atreveram-se a publicá-las como sendo próprias" (ibidem, tradução nossa). ${ }^{2}$

1 Útil y sabiamente se dedicaron los antiguos á dexar á la posteridad sus hallazgos por medio de los libros, para que nunca se perdiesen; antes aumentandolos de tiempo en tiempo con nuevas reflexiones, llegasen finalmente as ciencias al estado mas perfecto. Debemos por tanto darles infinitas gracias de no haber, con un envidioso silencio, dado sus invenciones al olvido, y de haberlas dexado á las edades en sus escritos. Si asi no lo hubiesen ejecutado, mas sabriamos ahora los sucesos de roya, las opiniones de Thales, Demócrito, Anaxágoras, Xenóphanes y otros Fisicos en orden á la naturaleza de las cosas.

$2 Y$ así como á estos debemos dar las gracias, deben al contrario ser vituperados los que robando las obras de aquellos, se atrevieron á publicarlas como propias (...). 
No século I d.C., o poeta espanhol Marco Valerio Marcial (40 d.C.-104 d.C.), no Livro I, manifesta sua desaprovação àqueles que indevidamente atribuem como sendo sua a criação poética de outros.

\section{Epigrama LIII}

\section{Ladrão de poemas}

Em meus livros há, Fidentino, uma página tua, uma só, mas assinalada com a marca inconfundível de seu autor, que converte teus poemas em roubo manifesto.

[...] Meus livros não necessitam nem de comprovação nem de juiz, tua página se levanta contra ti e te diz: "Tu és um ladrão". (Marcial, 2004, p.99, tradução nossa) ${ }^{3}$

Confere-se assim a Marcial ser o primeiro a ter associado a noção do crime de plágio do Direito Romano à apresentação da obra intelectual alheia como sendo própria. Marcial chamava de plagiário a quem apresentasse como sua a obra de outra pessoa, comparando-o por analogia com aquele que a Lei Fábia de Plagiariis, do final do século II a. C., "declarava réu de plagio a quem, deliberadamente, comprasse ou vendesse um homem livre, o ocultasse, doasse, permutasse ou o desse como dote" (Puente \& Días, 1840, p.54-5, tradução nossa). ${ }^{4}$

\section{Epigrama XXIX}

Um plagiário

Corre o boato de que tu, Fidentino, lês meus versos ao público como se fossem teus. Se tu quiseres que se diga que são meus, enviar-te-ei grátis os poemas (...);

\section{Ladrón de poemas.}

En mis libritos hay, Fidentino, una página tuya, una sola, pero señalada con la impronta inconfundible de su autor, que convierte tus poemas en robo manifiesto. (...) Mis libros no necesitan ni contraste ni juez; tu página se levanta contra ti y te dice: "Eres un ladrón".

4 Declaraba reos de plagio al que á sabiendas comprase ó vendiera un hombre libre, lo ocultase, donase, permutara ó diese en dote (...). 


\section{Epigrama XXXVIII}

Além de plagiador mal declamador

O livro que declamas, Fidentino, é meu; mas quando o declamas mal, começa a ser teu.

\section{Epigrama LII}

Meus versos são meus, defende-os

Encomendo-te, Quinciano, meus versos. Se é que posso chamar de meus os que declama um poeta amigo teu. Se eles se queixam de sua dolorosa escravidão, vá a ajudá-los. E quando aquele se proclame seu dono, dize que são meus e que foram liberados. Se o disseres bem alto três ou quatro vezes, farás que se envergonhe o plagiário. (Marcial, 2004, p.89-98, tradução nossa) ${ }^{5}$

A reprodução da obra intelectual do século $\mathrm{V}$ a.C. até o século XV d.C. era feita pelos escribas ou copistas, indivíduos responsáveis por copiar caligraficamente manuscritos de todos os tipos. $\mathrm{O}$ número de livros antigos ou medievais era extremamente limitado.

$\mathrm{Na}$ Idade Média, a cultura manuscrita era orientada para o produtor, e o conteúdo informacional não se considerava um processo original de criatividade. $\mathrm{O}$ interesse por autores e títulos de autenticidade não existia, pois a produção intelectual refletia o conhecimento de alguns, adquirido ao longo do tempo, baseado sempre no conhecimento de outros anteriores a eles (McLuhan, 1977, p.185).

Estaremos sendo vítimas de um anacronismo, se imaginamos que o estudioso medieval considerava o conteúdo dos livros que lia como expressão da personalidade e opinião de outro homem. Ele o

5 Epigrama XXIX - Un plagiario: Corre el rumor de que tú, Fidentino, lees mis versos al público como si fueran tuyos. Si quieres que se diga que son míos, te enviaré gratis los poemas; / Epigrama XXXVIII - Además de plagiario, mal recitador: El libro que recitas, Fidentino, es mio; pero cuando lo recitas mal, empieza a ser tuyo. / Epigrama LII - Mis versos son míos, defiéndelos: Te encomiendo, Quinciano, mis libritos. Si es que puedo llamar míos los que recita un poeta amigo tuyo. Si ellos se quejan de su dolorosa esclavitud, acude en su ayuda por entero. $Y$ cuando aquél se proclame su dueño, di que son míos y que han sido liberados. Si lo dices bien alto tres o cuatro veces, harás que se avergüence el plagiario. 
considerava como parte daquele grande corpo total de conhecimentos a Scientia de omni acibili, que havia sido outrora propriedade dos antigos sábios. O que quer que lia num livro venerável não considerava como asserção de alguém, mas como pequena parcela de conhecimentos adquirida por alguém, havia muito tempo, de outrem ainda mais antigo. (Goldschmidt apud McLuhan, 1977, p.188)

Não era somente o usuário de manuscritos que mostrava indiferença quanto à autoria ou ao período exato em que a obra tinha sido escrita. $\mathrm{O}$ autor nem sempre se manifestava explicitamente em sua obra. Ele próprio não lhe atribuía originalidade, pois ela era somente o espelho do conhecimento registrado no passado. Assim, era frequente o anonimato da produção medieval.

[...] há muito mais escritores que evidentemente pensavam que era desnecessário, se não inconsequente, anexar seus nomes em seus poemas, romances e estudos. As razões para esse predominante e aparentemente tranquilo anonimato eram, sem dúvida, complexas. Um fator importante foi seguramente o que poderia ser chamado de complexo de inferioridade linguística e cultural que as línguas vernáculas sofreram com a presença do Latim, pois a Europa medieval viu-se no fim de uma degeneração linguística e cultural que começara no Éden e diminuiria somente no início da era Cristã. Um autor, etimologicamente, é alguém que acrescenta, e na Idade Média isso era prerrogativa e poder de somente aqueles escritores latinos cujas composições tornaram-se veneráveis por sua antiguidade e permanentes pela sua língua. (MacHan, 1999, p.3, tradução nossa) ${ }^{6}$

6 (...) there are many more writers who evidently thought it was unnecessary, if not inconsequential, to attach their names to their lyrics, romances and treatises. The reasons for this prevailing and apparently unproblematic anonymity are, no doubt, complex. A significant factor was surely what might be called the cultural and linguistic inferiority complex which the vernaculars suffered in the presence of Latin, inasmuch as medieval Europe saw itself at the end of a cultural and linguistic degeneration which began in Eden and experienced remission only in the early Christian era. An author, etymologically, is one who increases, and in the Middle Ages this was the prerogative and power of only those Latin writers whose compositions were made venerable by their antiquity and enduring by their language. 
O significado do conceito de autoria no período medieval evidentemente difere do atribuído na modernidade. McLuhan, comentando Goldschmidt, cita o momento em que este procura demonstrar que na Idade Média por várias razões não se dava ao conceito de "autoria" exatamente o mesmo sentido atribuído na modernidade, quando passou a ser considerada por meio de um filtro de fascínio e fetichização do ser humano por trás dos textos e livros - como se ele fosse um ser superior ao restante dos mortais. Na Idade Média, a autoria não era de maneira alguma importante, inclusive para os escritores, que

nem sempre se davam ao trabalho de "por entre aspas" aquilo que extraíam de outros livros ou de indicar a fonte de onde haviam citado o trecho; hesitavam em assinar de maneira clara e inconfundível até mesmo o que evidentemente era trabalho deles próprios. (Goldschmidt apud McLuhan, 1977, p.188)

A questão da autoria na cultura manuscrita medieval, também dados os métodos pelos quais era elaborado um livro, deixava de ser um componente relevante.

Qualquer que fosse o método adotado, um volume que encerrasse vinte trabalhos diferentes de dez autores diferentes teria forçosamente que ser relacionado sob um só nome, independentemente do que o bibliotecário decidisse fazer acerca dos outro nove nomes. E, se o primeiro trecho no volume fosse de S. Agostinho, o volume, figuraria sob o nome de S. Agostinho. Se se desejasse ver o volume ter-se-ia que solicitá-lo pelo nome de S. Agostinho, mesmo que fosse o quinto tratado no volume que se desejava consultar, que podia ser de Hugo de Santo Caro. Se se pedia a um amigo em outra abadia para copiar algo que se tinha notado numa visita anterior, ter-se-ia que escrever-lhe: "Queira copiar o tratado de fls. 50 a 70 em seu Augustinus". Isso não implicava necessariamente que o missivista ignorava que o autor daquele tratado não era Agostinho; julgasse-o ou não, teria que pedir o livro "ex-Agostinho". Em 
outra biblioteca, esse mesmo texto, digamos o De Duodecim abusivis, seria o terceiro num volume encadernado que começava com algum trabalho de S. Cipriano. Ali, esse mesmo tratado seria "exCipriano”. Essa é apenas uma fonte prolífica das características de "autoria" que fazia com que um só e mesmo texto fosse citado por vários nomes. (ibidem, p.187)

A partir do século XII, o surgimento das universidades possibilitou um campo novo de publicações alimentado pelos estudantes que copiavam os livros ditados por seus mestres. Essas publicações, levadas pelos próprios estudantes quando concluíam seus estudos, acabavam nas bibliotecas dos mosteiros, mais uma prática que ilustra a importância atribuída à construção de conhecimento embasado na produção intelectual produzida anteriormente e que muitas vezes reduz o significado de autoria à atividade realizada pelo copista. McLuhan cita os estudos de Goldschmidt para lembrar que na Idade Média referir-se a quem escreveu o livro não necessariamente significaria quem compôs o livro. Podia estar se referindo a que copista o teria escrito, pergunta está não difícil de responder, pois em qualquer abadia a letra de um bom copista seria reconhecida durante muitas gerações. As culturas que antecederam a era da palavra impressa buscavam transmitir às gerações sua produção intelectual, no entanto a autoria da obra não era o que lhe garantia o respeito, e sim o valor de seu tempo acumulado, de sua antiguidade (Nunes, 2007, p.76).

\section{A invenção de Gutenberg: primeiros passos rumo a uma legislação}

Na Idade Moderna, século XV, a imprensa com tipos móveis inventada pelo alemão Johann Gensfleisch Gutenberg, durante a década de 1440 a 1450, gerou o primeiro bem de comércio reproduzido de maneira uniforme em grande escala. 
Veremos que, do mesmo modo que a palavra impressa foi a primeira coisa produzida em massa, foi também o primeiro "bem" ou artigo de comércio a repetir-se ou reproduzir-se uniformemente. A linha de montagem de tipos móveis tornou possível um produto que era uniforme e podia repetir-se tanto quanto um experimento científico.

[... A A palavra impressa criara a economia de mercado e o sistema de preços. Pois enquanto as mercadorias não fossem uniformemente idênticas, o preço de qualquer artigo estaria sujeito a regateio e ajuste. (McLuhan, 1977, p.177- 227)

A cultura da palavra impressa imperante após a invenção da prensa com tipos móveis vivenciou modificações não só nas formas de registrar e disseminar a produção intelectual, mas também modificou os conceitos de originalidade e de autoria. McLuhan destaca que foi a publicação impressa o primeiro meio direto para conduzir à fama e perpetuação do nome de um homem privado. Na modernidade, o autor passa a ser visto como uma fonte de originalidade, um indivíduo privilegiado capaz de criar obras de arte e literatura a partir de uma inspiração espontânea.

[...] a associação e o hábito com a palavra impressa modificaram nosso modo de pensar sobre a arte literária e respectivos estilos, fez nascer ideias a respeito da originalidade e propriedade literária, praticamente inexistentes na era do manuscrito, e modificou o processo psicológico [...]. Na época do manuscrito, podia ser considerado como ação meritória copiar o livro de um homem e fazê-lo circular; na era da palavra impressa, tal ação resulta em processos e prejuízos. (Chaytor apud McLuhan, 1977, p.129)

A produção das obras feita em grande escala exigiu, por motivos políticos ou religiosos, a ação dos governantes no sentido de censurar as ideias que poderiam ser disseminadas naquelas obras e que, graças à nova tecnologia, poderiam chegar a um maior número de indivíduos. $\mathrm{O}$ advento da imprensa de Gutenberg impulsionou 
a necessidade de legislar sobre a publicação, principalmente das obras literárias.

As primeiras medidas tomadas para atender às exigências emergentes nesse novo contexto social, explica Abrão (2002, p.28-29), incluíam a concessão de privilégios por parte dos governantes para os editores - não para os autores - por prazos determinados, sempre passíveis de serem revogados. Tais privilégios garantiam a comercialização dos escritos a esses editores e o controle da produção impressa às autoridades. Em 1495, o Senado de Veneza foi provavelmente um dos primeiros a outorgar um desses privilégios. $\mathrm{O}$ editor Aldo Manúcio, criador da Imprensa Aldina, obteve a concessão de um monopólio que lhe permitiria imprimir durante vinte anos livros em grego. Em 1533, Henrique VIII proibiu a importação para a Inglaterra de publicações estrangeiras e, para garantir o controle das publicações locais, em 1538 ordenou que todos os novos livros impressos na Inglaterra fossem antes aprovados pelo Conselho Privado.

\section{Produção intelectual: primeira legislação}

Em 1557, na Inglaterra, Felipe e Maria Tudor concederam para a English Stationer'Company - associação de donos de papelaria e livreiros - um monopólio real para a comercialização das obras. A associação garantia a censura para a publicação de obras consideradas sediciosas. A esse privilégio no controle dos escritos, assegurado aos livreiros e não aos autores (indivíduos estes a quem se continuava a não atribuir importância), chamou-se de copyright. $\mathrm{O}$ vínculo estabelecido entre governo e associação lhes assegurava o lucro econômico. O governo recebia os royalties pela concessão do monopólio e pela cobrança dos impostos e os livreiros tinham seu mercado garantido (Abrão, 2002, p.28).

Em 1586, e com o intuito de combater o surgimento da pirataria, que prejudicava os interesses econômicos dos livreiros ingleses, estes conseguiram um decreto que era praticamente uma consolida- 
ção e ampliação da legislação prévia e que estabelecia que: a) todas as imprensas existentes na época, e também as futuras, deveriam reportar-se à English Stationer'Company; b) nenhuma imprensa seria estabelecida fora de Londres, exceto nas universidades de Cambridge e Oxford, onde somente uma imprensa em cada um desses lugares seria permitida; c) para diminuir a excessiva quantidade de impressores estabelecidos, nenhuma imprensa adicional poderia ser instalada até que, por morte ou por outro motivo, eles fossem reduzidos a um número que o arcebispo de Canterbury e o bispo de Londres considerassem necessário para atender o reino. Se houvesse vagas, a English Stationer'Company poderia nomear livreiros para preenchimento delas e, para serem licenciados, ela deveria apresentá-los aos comissários eclesiásticos (Ward \& Trent et al., 2000).

Em 1662, o Parlamento Inglês aprovou o Licensig of Press Act, dirigido ao controle de escritos considerados políticos e sediciosos. Com esse decreto, os editores passaram a ter um ainda maior controle do monopólio sobre as publicações e a Coroa passou a exercer de maneira mais ampla a censura na imprensa e nos livros importados, publicações estas que eram as únicas fontes de textos que reprovavam a conduta da realeza (Abrão, 2002, p.29).

Em 1665, com o fim da censura legal e do monopólio, os livreiros enfraquecidos começaram a sentir os efeitos da concorrência estrangeira. Na época, surgiram debates sobre quem poderia reclamar a propriedade literária. Os livreiros usaram a linguagem habitual de propriedade para arrancar o controle do comércio, enquanto ingleses como o filósofo John Locke e o escritor Daniel Defoe pressionaram para o reconhecimento legal do status do autor como proprietário de sua obra.

Em 10 de abril de 1710, o Parlamento inglês aprovou o Statute of Anne, a primeira norma sobre copyright da história, cujo aspecto talvez mais revolucionário fosse precisamente o fato de ter proclamado os autores, e não os editores, como os proprietários de suas obras. Essa primeira legislação restringia o prazo de proteção para 14 anos, no caso de livros novos e se o autor estivesse ainda vivo, o 
prazo poderia ser renovado por uma única vez (isto é, um máximo de 28 anos de proteção). As obras publicadas antes de 1710 receberam a proteção por um prazo único de 21 anos (Ward \& Trent et al., 2000).

Ao Statute of Anne, segundo Abrão (2002, p.29), são atribuídos especialmente três méritos:

a) transformou o direito de cópia dos livreiros (monopólio e censura) em um conceito de regulação comercial, mais voltado à promoção do conhecimento e à diminuição dos respectivos poderes (limitação no tempo, liberdade de cessão do copyright e controle de preços);

b) criou o domínio público para a literatura (cada livro poderia ser explorado por 14 anos, podendo esse prazo ser prorrogado por uma única vez), acabando com a perpetuidade, porque, no velho sistema, toda literatura pertencia a algum livreiro para sempre, e somente a literatura que se enquadrasse nos padrões sensórios deles poderia ser impressa;

c) permitiu que os autores depositassem livros em seu nome pessoal, tirando-os, por um lado, do anonimato e, por outro, criando a memória intelectual do país com a doação de livros às universidades e bibliotecas públicas.

Com a aprovação do Statute of Anne pretendia-se equilibrar o poder exercido pelos livreiros sobre a difusão de conteúdo informacional principalmente por contrariar o ideal defendido nessa época em que o Iluminismo apontava para a importância da educação e da disseminação do conhecimento. A aprovação do Statute of Anne garantiu que os livros valiosos ficassem livres para que qualquer editor os publicasse após a extinção do prazo de proteção do $c o$ pyright. A limitação dos prazos foi uma forma indireta de garantir a concorrência entre livreiros e, consequentemente, a produção e a difusão da cultura (Lessig, 2004, p.89).

Lessig (advogado, professor e escritor norte-americano) lembra: "[...] O copyright nasceu como um conjunto específico de res- 
trições: proibia que outros reimprimissem um livro. Em 1710, o ‘direito de cópia' era um direito para usar uma máquina específica para a duplicação de uma obra específica. Não ia além desse direito tão restrito" (idem, p.87, tradução nossa). ${ }^{7}$

Assim, por exemplo, mesmo que o copyright das obras de Shakespeare fosse à perpetuidade, tudo o que isso teria significado sob o significado original do termo seria que ninguém poderia reimprimir a obra de Shakespeare sem a autorização dos herdeiros de Shakespeare. Não haveria controle de nada relacionado com, por exemplo, de que forma se podia representar a obra, se a obra podia ser traduzida, ou se seria permitido que Kenneth Branagh fizesse seus filmes. O "direito de cópia” era somente um direito exclusivo para imprimir - nada mais, mas é claro, também nada menos. (idem, p.88, tradução nossa) $)^{8}$

A partir de 1731, os escoceses, favorecidos pelas determinações do Statute of Anne, começaram a republicar obras clássicas, provocando a manifestação dos editores londrinos a favor de uma lei de copyright perpétuo. Em 1769, no caso denominado Millar vs. Taylor, o editor londrino ganhou um veredicto que confirmava um direito de common law, estabelecendo, segundo a jurisprudência, essa perpetuidade. Em 1729, Millar tinha comprado, de acordo com os requerimentos estabelecidos pelo Statute of Anne, os direitos do poema The seasons, do escocês James Thomson. Quando o

7 The copyright was born as a very specific set of restrictions: It forbade others from reprinting a book. In 1710, the "copy-right" was a right to use a particular machine to replicate a particular work. It did not go beyond that that very narrow right.

8 So, for example, even if the copyright to Shakespeare's works were perpetual, all that would have meant under the original meaning of the term was that no one could reprint Shakespeare's work without the permission of the Shakespeare state. It would not have controlled anything, for example, about how the work could be performed, whether the work could be translated, or whether Kenneth Branagh would be allowed to make his films. The "copy-right" was only an exclusive right to print-no less, of course, but also no more. 
prazo do copyright desse poema expirou, Roberth Taylor passou a imprimi-lo, fazendo concorrência a Millar.

A conquista do editor Millar durou somente cinco anos. Em 1774, no caso conhecido como Donaldson vs. Beckett, a sentença favorável ao livreiro escocês Donaldson rejeitou o argumento em favor de um copyright perpétuo e manteve os limites estabelecidos no Statute of Anne. Depois de 1774, o domínio público efetivamente concretiza-se. Quando o prazo de proteção da obra intelectual expirasse, as obras deixariam de pertencer ao "domínio privado" de seus titulares e passariam a ser de uso da sociedade em geral, pertenceriam ao “domínio público". Pela primeira vez na história, as obras de Shakespeare, Bacon, Milton, Johnson e Bunyan, por exemplo, não estariam mais sob controle do monopólio dos editores. O resultado: cultura liberada (idem, p.89-91).

A cultura na Inglaterra era depois disso livre [... livre no sentido de que a cultura e seu desenvolvimento já não estariam controlados por um pequeno grupo de editores. Como faz todo mercado livre, este mercado livre de cultura livre cresceria conforme os consumidores e produtores escolhessem. A cultura inglesa se desenvolveria conforme os muitos leitores ingleses escolhessem deixar que ela se desenvolvesse - na escolha de livros que comprassem e escrevessem; na escolha de ideias que repetissem e apoiassem. Escolheriam em um contexto competitivo, não em um contexto em que as escolhas sobre que cultura estão à disposição das pessoas e como essas pessoas têm acesso a ela são feitas pela minoria, apesar dos desejos da maioria. (idem, p.94, tradução nossa) ${ }^{9}$

9 Culture in England was thereafter free (...) free in the sense that the culture and its growth would no longer be controlled by a small group of publishers. As every free market does, this free market of free culture would grow as the consumers and producers chose. English culture would develop as the many English readers chose to let it develop -chose in the books they bought and wrote; chose in the memes they repeated and endorsed. Chose in a competitive context, not a context in which the choices about what culture is available to people and how they get access to it are made by the few despite the wishes of the many. 
O copyright é baseado no sistema jurídico originado na Inglaterra, o Common Law, e, pela colonização, espalhou-se aos países de língua inglesa, como é o caso dos Estados Unidos. O Common Law caracteriza-se pela valorização da jurisprudência (aplicação de estudo de casos jurídicos na tomada de decisões judiciais). Os conceitos jurídicos são elaborados por indução da experiência jurídica do passado; são construídos pela amálgama de inúmeros casos que, juntos, delimitam campos de ações.

\section{Copyright: legislação norte-americana}

Os princípios do copyright estabelecidos na Inglaterra foram levados para os Estados Unidos, mas somente em 31 de maio 1790 o Congresso americano passou a primeira lei federal do copyright restringindo os direitos de terceiros de publicarem a obra. A proteção era por 14 anos, renováveis por mais 14 anos, se no fim do período o autor estivesse vivo. Se não houvesse renovação, a obra passava a domínio público.

Os legisladores norte-americanos criaram, assim, um equilíbrio que permitia alimentar o domínio público, pois um número significativo de obras não seria registrado nos primeiros dez anos de vigência da lei de copyright e, provavelmente, uma grande parte das obras registradas também não seria renovada após vencer o prazo de proteção de 14 anos.

O copyright constituía uma minúscula regulação para uma minúscula parte do mercado criativo representada pelos editores, pois somente a publicação estava sob controle do copyright e haveria violação do direito se a obra fosse impressa sem a permissão do autor. O copyright protegia somente mapas, cartas de navegação e livros; não protegia obras musicais ou de arquitetura; não havia regulamentação para obras derivadas; traduções ou adaptações do texto eram permitidas. Todos os processos de recriação a partir da obra original permaneciam livres de regulamentação (Lessig, 2004, p.133-159). 
Os Estados Unidos tiveram essa configuração durante 41 anos. Em 1831, houve a primeira revisão da lei de copyright e o período de proteção mudou de 14 para 28 anos, renováveis por mais 14 anos, totalizando um prazo de proteção de 42 anos, e a proteção estendeuse às obras musicais. Em 1856, a lei incluiu as composições dramáticas; em 1865, as fotografias; e, partir de 1870, na segunda revisão geral da lei, a proteção passou a incluir pinturas, estátuas e obras derivadas. As obras derivadas, se publicadas, isto é, oferecidas comercialmente, eram regulamentadas pela lei de copyright. A publicação e a transformação não comercial ainda eram essencialmente livres (Araya \& Vidotti, 2009, p.44).

[...] o direito garantido por um copyright dava ao autor o direito exclusivo de "publicar" obras protegidas por copyright. Isso significa que alguém violava o copyright somente se republicasse a obra sem a permissão do dono do copyright. Finalmente, o direito garantido pelo copyright era um direito exclusivo para esse livro em particular. O direito não se estendia ao que os advogados chamam de "obras derivadas". Portanto, não interferiria no direito de qualquer pessoa que não fosse o autor de traduzir um livro com copyright, ou de adaptar a história para uma forma diferente (como um drama baseado em um livro publicado). (Lessig, 2004, p.136, tradução nossa $)^{10}$

Como o copyright regulamentava apenas a publicação e era atrelado ao registro, somente aqueles autores que esperavam obter algum proveito financeiro registravam as obras. A cópia daquelas

10 (...) the right granted by a copyright gave the author the exclusive right to "publish" copyrighted works. That means someone else violated the copyright only if he republished the work without the copyright owner's permission. Finally, the right granted by a copyright was an exclusive right to that particular book. The right did not extend to what lawyers call "derivative works." It would not, therefore, interfere with the right of someone other than the author to translate a copyrighted book, or to adapt the story to a different form (such as a drama based on a published book). 
consideradas não comerciais era livre. Em 1909, na terceira revisão geral da lei de copyright, o Congresso ampliou o período de renovação de 14 para mais 28 anos, configurando um período máximo de 56 anos, após o qual a obra passaria ao domínio público. Nessa revisão, passou-se a regulamentar a cópia, não a publicação, e a partir desse momento o escopo da lei ficou atrelado à tecnologia.

Em 1912, a lei protegia também os filmes. E foi sob essa legislação que o cineasta estadunidense Walt Disney criou suas obras. Ele pode usufruir de uma cultura já existente, porém relativamente fresca, pois o domínio público nessa época não era muito antigo. Disney baseou-se no passado para criar o Mickey Mouse, um dos seus mais famosos personagens. Lessig (2004, p.22-3) relata como uma sequência de processos criativos de diferentes pessoas contribuiu para isso: em 1927, o som sincronizado foi introduzido no filme The jazz singer, dirigido por Alan Crosland. No ano seguinte, Buster Keaton, importante comediante e cineasta norte-americano, criou o filme mudo Steamboat Bill Jr, produzido de forma independente e inspirado na canção "Steamboat Bill”, de Ren Shields e irmãos Leighton. Em maio de 1928, apareceu pela primeira vez, em um desenho mudo chamado Plane crazy, a personagem Steamboat Willie, uma paródia do filme de Keaton. Em novembro do mesmo ano, no Colony Theater, em Nova York, no primeiro desenho animado com som sincronizado, Steamboat Willie trouxe à vida Mickey.

Em 1928, o domínio público não representava uma área conflitante. As obras passavam ao domínio público ao finalizar o prazo de proteção do copyright e podiam ser usadas livremente. Podia-se se basear nelas para criar obras derivadas. Obras como Branca de Neve e Cinderela, dos alemães Jacob e Wilhelm Grimm, também foram usadas no processo criativo de Walt Disney. Ele usou elementos da criatividade cultural existente e mesclou-os ao seu próprio talento, transformando-os em algo diferente. Disney recontou os contos dos irmãos Grimm sob a forma de desenhos animados, mas não eliminou completamente os aspectos simbólicos de medo e perigo das obras originais (idem, . p.23-4). 
Isso era cultura, na que você não necessitava da permissão de mais alguém para tomar e construir sobre ela. Esse era o caráter da criatividade do início do século passado. Era construída sobre um requisito constitucional de que a proteção fosse por períodos limitados. (idem, 2002, p.1, tradução nossa) $)^{11}$

A exigência de renovação do copyright após o vencimento do primeiro prazo havia propiciado o equilíbrio necessário entre o aspecto comercial, que envolve a publicação de uma obra, e o aspecto social, que se refere à sua disponibilização para o domínio público. Como somente faria sentido renovar o copyright das obras que continuassem tendo um valor comercial (o que representava uma pequena parte do conteúdo protegido), o domínio público estaria constantemente sendo alimentado.

A partir de 1962 a situação mudaria. O Congresso norte-americano aprovaria 11 modificações que ampliariam o período dos copyrights já existentes e duas que estenderiam o prazo dos futuros copyrights. Na quarta revisão geral da lei de copyright, em 1976, os copyrights existentes foram ampliados em 19 anos, e para todas as obras criadas após 1978 haveria um período único de proteção: para os autores da obra, durante a sua vida mais cinquenta anos, e, para corporações, 75 anos (idem, 2004, p.156).

Quando, em 1990, o governo dos Estados Unidos confiou a administração da rede mundial de computadores Internet à National Science Foundation, os norte-americanos tinham no copyright uma forma de proteção amparada pela Constituição dos Estados Unidos e concedida para trabalhos de autoria original, como obras literárias, dramáticas, musicais e artísticas, softwares e obras de arquitetura. Esses trabalhos deviam estar fixados em um meio de expressão tangível que os tornasse perceptíveis diretamente ou com a ajuda de uma máquina ou dispositivo. A publicação ou o registro

11 It was culture, which you didn't need the permission of someone else to take and build upon. That was the character of creativity at the birth of the last century. It was built upon a constitutional requirement that protection be for limited times (...). 
das obras não era requisito obrigatório para a obtenção da proteção, que se iniciava no momento da criação e fixação em qualquer meio de expressão tangível. $\mathrm{O}$ prazo de proteção correspondia a toda a vida de seu autor mais cinquenta anos. No caso das corporações, o prazo estipulava uma validade de 75 anos.

Em 1992, a exigência de registro de renovação para todas as obras criadas antes de 1978 foi abandonada, e, em 1998, na Lei de Extensão do Período de Copyright Sonny Bono (Sonny Bono Copyright Term Extension Act $)^{12}$, os períodos dos copyrights existentes e futuros foram ampliados em vinte anos, isto é, a vida do autor mais setenta anos após sua morte. Resultado: nenhuma obra sob copyright passará para o domínio público até 2018 (idem, p.134-6 ). As famosas criações de Walt Disney, Mickey Mouse, Pluto, Pateta e Pato Donald, previstas para cair no domínio público em 2003, 2005, 2007 e 2009, respectivamente, foram favorecidas pela Lei Sonny Bonno.

A lei de copyright norte-americana inclui o conceito do fair use (uso justo), que permite o uso de material protegido para uso educacional (incluindo múltiplas cópias para uso em sala de aula), para crítica, para comentário, para divulgação de notícia e para pesquisa. A doutrina do fair use segue um teste de quatro fatores para definir as possibilidades de uso de conteúdo sob proteção do copyright: 1) a finalidade e as características do uso, verificando-se se tal uso é de natureza comercial ou para finalidades educacionais não lucrativas; 2) a natureza da obra reproduzida; 3 ) a quantidade e substancialidade da porção usada em relação à obra reproduzida como um todo; 4 ) o efeito do uso sobre o mercado potencial ou o valor da obra reproduzida.

O copyright tem mudado drasticamente desde 1790, data em que o Congresso norte-americano aprovou a primeira lei federal a

12 Nome dado em homenagem a Salvatore Phillip "Sonny" Bono, produtor discográfico, cantor, ator e político norte-americano eleito deputado na Câmara dos Representantes em 1994 representando o 44 Distrito Congressional da Califórnia. Durante seu mandato, introduziu o Sonny Bono Copyright Term Extension Act. 
respeito. Nesse contexto, Lessig (idem, p.36) destaca que o alcance da lei de copyright nessa época era muito pequeno. Limitava-se à proteção de mapas, cartas de navegação e livros e dava ao proprietário do copyright o direito exclusivo de publicar. Hoje o copyright cobre também música, arquitetura, teatro e programas informáticos. O detentor do direito de copyright tem, além do direito exclusivo da publicação da obra, o direito exclusivo de controlar a "cópia" dessa obra, bem como o direito sobre qualquer "obra derivada" que possa surgir a partir da obra original. "Deste modo, o direito cobre mais obras derivadas, protege a obra criativa de uma maneira mais ampla e protege obras que estão baseadas de uma forma significativa na obra criativa inicial" (idem, p.136, tradução nossa). ${ }^{13} \mathrm{E}$, como a conjugação das TIC com a Internet tem facilitado a produção de obras originais, a derivação de obras e de cópias, bem como a circulação de tudo isso. Consequentemente, a violação da lei de copyright tem-se tornado uma prática constante.

Com a proposta de combater a facilidade de copiar conteúdo sob proteção do copyright e limitar sua divulgação, os Estados Unidos vêm buscando novas possibilidades legais, e em outubro de 1998 adotaram a Lei dos Direitos Autorais do Milênio Digital (Digital Millenium Copyright Act - DMCA).${ }^{14}$ Essa lei foi aprovada para a implementação de dois tratados assinados em 1996 na Organização Mundial da Propriedade Intelectual (OMPI ou, na versão inglesa, WIPO - organismo das Nações Unidas criado em 1967): o Tratado de Direito de Autor (WCT - WIPO Copyright Treaty) e o Tratado sobre Interpretações e Fonogramas (WPPT - WIPO Performances and Phonograms Treaty).

A lei do DMCA, além de proteger os direitos de autor, trata não só da infração do copyright em si, mas também da produção e da distribuição de qualquer tecnologia ou de qualquer serviço con-

13 In this way, the right covers more creative work, protects the creative work more broadly, and protects works that are based in a significant way on the initial creative work.

14 <http://www.copyright.gov/legislation/dmca.pdf>. 
cebido para evitar medidas e mecanismos de proteção dos direitos de autor.

Lemos (2005), em entrevista ao Jornal do Brasil, observava que os Estados Unidos foram o primeiro país a adotar uma lei para decidir o futuro da tecnologia e retirar conteúdo da Internet.

Durante todo o século 20, a propriedade intelectual foi equilibrada pelo conflito entre detentores da tecnologia e usuários, com vitória da liberdade do desenvolvimento da tecnologia. A partir da década de 1990 isso mudou: os detentores começaram a ter poder para decidir os caminhos da tecnologia. A marca dessa mudança na legislação é o DMCA - os EUA foram o primeiro país a adotar uma lei para decidir o futuro da tecnologia e retirar conteúdo do ar.

A Lei dos Direitos Autorais do Milênio Digital, salienta ainda Lemos (idem), tem funcionado em muitos países como modelo de legislação para criar dispositivos legais de responsabilização de provedores de conteúdo sob proteção das legislações de direitos autorais.

\section{Direitos autorais: normas brasileira e internacionais}

O direito autoral brasileiro refere-se ao conjunto de prerrogativas de ordem patrimonial e moral atribuído ao autor (pessoa física criadora) de uma obra intelectual (criação do espírito) de natureza literária, artística ou científica. Ele surge inspirado nos princípios individualistas da Revolução Francesa, os quais acabaram irradiando-se primeiro pela Europa e posteriormente pela América Latina.

Na França, no século XVI, já se manifestava nos autores a consciência de que teriam direitos sobre suas criações, embora, assim como na Inglaterra, somente o rei concedesse o direito a publicações. Foi a Revolução Francesa, destaca Abrão (2002, p.30), paralela à Revolução Industrial, que propiciou o desenvolvimento e a estruturação nos países de origem latina de outra fase do direito 
autoral, mais humanista e com predominância dos aspectos morais e éticos de respeito ao indivíduo e às suas ideias.

Foi a jurisprudência francesa, então, que começou a disciplinar as relações entre escritores e editores, e os laços perpétuos que os uniam, obrigando, em histórica decisão, que das futuras transações desses direitos participassem os herdeiros de grandes escritores como La Fontaine e Fénelon.

Em 30/8/1777 novas regras foram estabelecidas na França entre autores, editores e livreiros. Embora mantidos os privilégios na comercialização, reconheceram ao autor o direito de editar e de vender as suas obras.

A lei brasileira baseia-se no sistema jurídico romano-germânico Civil Law e caracteriza-se pela predominância do Direito Positivo (sistema de normas vigentes, obrigatórias, aplicáveis coercitivamente por órgãos institucionalizados, tendo a forma de lei, costume ou de tratado). Os tribunais fundamentam as sentenças nas disposições de códigos e leis, a partir dos quais se originam as soluções de cada caso.

No Brasil, a obra protegida pela legislação corresponde à exteriorização de uma determinada manifestação intelectual, expressa por qualquer meio ou fixada em qualquer suporte, tangível ou intangível, conhecido ou que se invente no futuro. A proteção constitui-se de um direito moral (criação) e de um direito patrimonial (pecuniário). Essa proteção é regulada pela Lei n. 9.610, de 19.2.98,15 de direitos autorais, e seu foco está na pessoa do direito (o autor), diferente da lei de copyright, cujo foco está na obra e na prerrogativa patrimonial de poder copiá-la. O direito patrimonial refere-se ao conjunto de prerrogativas que permitem ao seu titular a utilização econômica da obra intelectual. O direito moral é de pertinência estritamente pessoal e visa dar ao autor, ou a seus herdeiros, poderes para zelar por sua qualidade de criador da obra, para promover o

15 <http://www.planalto.gov.br/ccivil/leis/19610.htm>. 
respeito à forma que lhe foi dada pelo seu criador (Brasil, Ministério da Cultura, 2006, p.220).

O processo de criação que o autor desenvolve para gerar uma obra passível de proteção autoral é relatado pela advogada Abrão (2002, p.74):

No início, criação e ideia se confundem no intelecto do autor, etapa inicial de um longo processo que vai resultar na obra. Do intelecto passa para um papel, uma fita magnética, uma tela ou outro suporte, mas ainda não passa de um projeto, de um esboço, de um ensaio. Até esse momento a obra só existe na órbita privada do autor: uma espécie de nascituro, gestado longa e cuidadosamente até o momento do nascimento, isto é, de sua publicação. A publicação marca a etapa final do processo de criação, é o momento de a obra vir ao conhecimento de uma ou mais pessoas, com as mesmas características com que vai ganhar o grande público. A partir daí, autor é um nome, porque a obra passa a ter vida própria.

Para a efetiva concretização do processo de criação de conteúdo intelectual, outro advogado, $\operatorname{Bittar}(2000$, p.70), lembra que o autor deverá alimentar esse processo com informação e conhecimento retirado de elementos do acervo cultural preexistente, informação e conhecimento que Gama (2008, p.34) destaca serem bens culturais que, enriquecidos pelo intercâmbio, transformam-se em informação e conhecimento compartilhado.

Um requisito básico para que o autor possa garantir a proteção legal de sua obra é a originalidade, isto é, sua obra deve ser integrada de componentes individualizadores para não ser confundida com outra preexistente. Ela deve ser intrínseca e extrinsecamente diferente de outras anteriormente materializadas e deve revestir-se de traços ou de caracteres próprios, distintos de outros já componentes da realidade (Bittar, 2000, p.23).

São obras protegidas pela Lei de Direitos Autorais a obra literária, artística ou científica; as conferências, alocuções, sermões e outras obras da mesma natureza; as obras dramáticas e dramático- 
musicais; as obras coreográficas e pantomímicas, cuja execução cênica se fixe por escrito ou por outra qualquer forma; as composições musicais, tenham ou não letra; as obras audiovisuais, sonorizadas ou não, inclusive as cinematográficas; as obras fotográficas e as produzidas por qualquer processo análogo ao da fotografia; as obras de desenho, pintura, gravura, escultura, litografia e arte cinética; as ilustrações, cartas geográficas e outras obras da mesma natureza; os projetos, esboços e obras plásticas concernentes à Geografia, à Engenharia, à Topografia, à Arquitetura, ao Paisagismo, à Cenografia e à Ciência; as adaptações, traduções e outras transformações de obras originais, apresentadas como criação intelectual nova; os programas de computador; as coletâneas ou compilações, antologias, enciclopédias, dicionários, bases de dados e outras obras que, por sua seleção, organização ou disposição de seu conteúdo, constituam uma criação intelectual.

Não são objeto de proteção da Lei de Direitos Autorais ideias, procedimentos normativos, sistemas, métodos, projetos ou conceitos matemáticos; esquemas, planos ou regras para realizar atos mentais, jogos ou negócios; formulários em branco para serem preenchidos por qualquer tipo de informação, científica ou não, e suas instruções; textos de tratados ou convenções, leis, decretos, regulamentos, decisões judiciais e atos oficiais; informações de uso comum, como calendários, agendas, cadastros ou legendas; nomes e títulos isolados; aproveitamento industrial ou comercial das ideias contidas nas obras.

A proteção aos direitos de que trata a lei brasileira independe de registro da obra, e a duração da proteção às obras artísticas, literárias e científicas permanece por toda a vida do autor e é transmissível a seus herdeiros por setenta anos a partir de $1^{\circ}$ de janeiro do ano subsequente à morte do autor. Para as obras fotográficas e audiovisuais, fonogramas e emissões das obras por empresas de radiodifusão e as interpretações, a proteção corresponde a setenta anos a partir da publicação das obras. Passado esse período, a obra passa ao domínio público, podendo ser utilizada sem autorização, desde que não fira os direitos morais do autor. 
A utilização da obra intelectual depende de autorização prévia e expressa do autor, e não constitui ofensa aos direitos autorais a reprodução: a) na imprensa diária ou periódica de notícia ou de artigo informativo, de discursos pronunciados em reuniões públicas de qualquer natureza, com a menção do nome do autor, se assinados, e da publicação de onde foram transcritos; b) de retratos, ou de outra forma de representação da imagem, feitos sob encomenda, quando realizada pelo proprietário do objeto encomendado, não havendo a oposição da pessoa neles representada ou de seus herdeiros; c) de obras literárias, artísticas ou científicas para uso exclusivo de deficientes visuais, sempre que a reprodução, sem fins comerciais, seja feita mediante o sistema Braille ou outro procedimento em qualquer suporte para esses destinatários.

Segundo a Lei de Direitos Autorais, é lícito também: a) a reprodução, em um só exemplar, de pequenos trechos para uso privado do copista, desde que feita por este sem intuito de lucro; b) citar em livros, jornais e revistas ou qualquer outro meio de comunicação trechos de qualquer obra, para fins de estudo, crítica ou polêmica, na medida justificada para se atingir determinada finalidade, desde que se indique o nome do autor e as fontes bibliográficas da obra; c) o apanhado de lições em estabelecimentos de ensino por aqueles a quem elas se dirigem, vedada sua publicação, integral ou parcial, sem autorização prévia e expressa de quem as ministrou; d) o uso de obras literárias, artísticas ou científicas, fonogramas e transmissão de rádio e televisão em estabelecimentos comerciais, desde que exclusivamente para demonstração à clientela, e que esses estabelecimentos comercializem os suportes ou equipamentos que permitam sua utilização; e) a representação teatral e a execução musical, quando no recinto familiar ou, para fins exclusivamente didáticos, nos estabelecimentos de ensino, desde que não haja em nenhum caso o intuito de obter lucros; f) a reprodução, em quaisquer obras, de pequenos trechos de obras preexistentes, de qualquer natureza, ou de obra integral, quando de artes plásticas, sempre que a reprodução em si não seja o objetivo principal da nova obra e não prejudique a 
exploração normal da obra reproduzida nem cause prejuízo injustificado aos legítimos interesses dos autores.

$\mathrm{Na}$ contemporaneidade, a multiplicação dos meios de comunicação e a transposição de fronteiras impedem que autores e usuários possam manter contato pessoal para negociação dos direitos autorais. Portanto, a OMPI reconhece e estimula a gestão coletiva do direito autoral por intermédio de organizações que atuem representando os titulares dos direitos e em defensa de seus interesses.

No Brasil existem várias entidades de gestão coletiva. Na área da música, há 12 associações de titulares relacionadas a obras e profissionais da música e um escritório central - Escritório Central de Arrecadação e Distribuição (ECAD) - que unifica o sistema de arrecadação e de distribuição dos direitos relativos à execução musical. A fiscalização de reprodução de obras literárias é controlada pela Associação Brasileira de Direitos Reprográficos (ABDR). No que diz respeito às obras teatrais, existe a Sociedade Brasileira de Artistas de Teatro (SBAT). No campo da informática, atua a Associação Brasileira das Empresas de Software (Abes), que fiscaliza a utilização de programas de computador (Brasil, Ministério da Cultura, 2006, p.45-6).

Os direitos de autor têm sido também alvo de ampla mobilização internacional, com a preocupação tanto pela proteção da integridade quanto com a garantia dos direitos de exploração econômica das obras literárias e científicas para seus legítimos titulares (Abrão, 2002, p.43). Neste sentido, foram consensuadas uniões no intuito de traçar metas e disciplinar a defesa do direito de autor e dos direitos conexos, editando normas de aplicação internacional. Entre elas cabe destacar: a) Convenção de Berna para a Proteção das Obras Literárias e Artísticas, ${ }^{16}$ estabelecida na Suíça em 1886 e administrada e secretariada pela OMPI (WIPO); b) Convenção Universal de Genebra, ${ }^{17}$ administrada pela Unesco (United Nations

16 <http://www.wipo.int/treaties/en/ip/berne/trtdocs_wo001.html>.

17 <http://portal.unesco.org/en/ev.php-URL_ID=13646\&URL_DO=DO_ TOPIC\&URL_SECTION=201.html>. 
Educational, Scientific and Cultural Organization), adotada internacionalmente a partir de setembro de 1952 e revista pela última vez em 1971; c) Convenção de Roma, que trata da proteção de intérpretes, produtores de fonogramas e organismos de radiodifusão; d) tratados da OMPI) WIPO Copyright Treaty, ou WCT, ${ }^{18}$ e WIPO Performances and Phonograms Treaty, ou WPPT. ${ }^{19}$

$\mathrm{Na}$ modernidade, a imprensa de Gutenberg possibilitou a publicação da produção literária em grande escala e modificou significativamente o fluxo de conteúdo intelectual. Segmentos da sociedade, tanto por motivos econômicos quanto políticos ou religiosos, passaram a exigir uma proteção para as obras intelectuais. Já na cultura pós-moderna, exige-se o reequilíbrio entre os dois extremos o da produção e o da recepção -, rearquitetados na interatividade.

[... ] a informação é um bem cultural e social, um valor de progresso e cultura e, bem como o conhecimento, enriquece-se mediante intercâmbio. O direito que a regulamenta não deve refletir somente os interesses comerciais e de curto prazo, nem assimilá-la de maneira simplista, como bem de consumo, a que reduz a simples objeto comercializável. O direito à informação busca o sutil equilíbrio entre os titulares dos direitos (o benefício da criação e/ou do investimento econômico) e os possíveis usuários da informação. (Gama, 2008, p.34)

Os professores e pesquisadores da Ciência da Informação Rafael Capurro e Birger Hjorland, em O conceito de informação, propõem que o foco dos profissionais da informação especificamente deve ter em vista "uma abordagem sociológica e epistemológica para a geração, coleta, organização, interpretação, armazenamento, recuperação, disseminação, transformação e uso da informação", e ainda destacam:

18 <http://www.wipo.int/treaties/en/ip/wct/trtdocs_wo033.html>.

19 <http://www.wipo.int/treaties/en/ip/wppt/trtdocs_wo034.html>. 
Os cientistas da informação - pela própria natureza de seu campo - devem trabalhar de modo de cima para baixo, ou seja, do campo geral do conhecimento e suas fontes de informação para o específico, enquanto os especialistas do domínio devem trabalhar de baixo para cima, do específico para o geral. [...] Na prática, contudo, informação deve ser definida em relação às necessidades dos grupos-alvo servidos pelos especialistas em informação, não de modo universal ou individualista, mas, em vez disso, de modo coletivo ou particular. Informação é o que pode responder às questões importantes relacionadas às atividades do grupo-alvo. A geração, coleta, organização, interpretação, armazenamento, recuperação, disseminação e transformação da informação devem, portanto, ser baseados em visões/teorias sobre os problemas, questões e objetivos que a informação deverá satisfazer (Capurro \& Hjorland, 2007, p.187).

A definição de Capurro \& Hjorland implica que os novos paradigmas da Ciência da Informação devem levar em conta o contexto específico em cada um dos aspectos levantados; devem também levar em conta a coletividade para a qual servirá como conhecimento. Capurro \& Hjorland (idem, p.193) concluem que essas condições são necessárias inclusive para a própria redefinição do campo da Ciência da Informação, que deve considerar não somente o documento ou o aspecto puro e simplesmente cognitivo perante ele.

Devemos tentar esclarecer melhor nossa identidade, nossos objetivos específicos e fortalecer a continuidade histórica no campo. Não deveríamos considerar o conceito de informação isoladamente, mas vê-lo em relação a outros conceitos como, por exemplo, documentos e mídia.

No que diz respeito aos direitos autorais, a conceituação que Capurro \& Hjorland dão para informação no campo da Ciência da Informação torna imprescindível que os profissionais nele envolvidos conheçam os limites que a legislação impõe e estejam atentos às 
alternativas que favoreçam o fluxo de informação no contexto que a contemporaneidade vivencia. Neste, a conjunção do desenvolvimento tecnológico - o aumento da capacidade dos computadores de armazenar e processar dados, amplamente reforçado pela interligação via Internet - e as estipulações legais vigentes que tratam da propriedade intelectual geram conflitos e contradições. 


\section{3 \\ Alternativas EMERGENTES PARA CRIAÇÃO, DISSEMINAÇÃO E USO LEGAL DE INFORMAÇÃO NO CONTEXTO DA WEB}

O desenvolvimento e o uso das tecnologias de informação e comunicação, em especial a Internet - base tecnológica computacional para a forma de organização em rede disponibilizada pelo ambiente informacional Web -, têm provocado mudanças significativas nas formas de criar, recriar, usar, reusar, compartilhar, preservar e disseminar conteúdo intelectual. Contudo, é paradoxal a situação que o indivíduo do século XXI vive. Se por um lado tem o privilégio de usufruir as tecnologias que o induzem a criar e compartilhar e que, consequentemente, alteram o fluxo de produção intelectual, aumentando-o significativamente e transformando-o em um bem passível de ser mais democraticamente alcançado, por outro sua criatividade é cerceada pela legislação estabelecida anteriormente ao advento dessas tecnologias.

Apesar do desenvolvimento tecnológico que fez surgir, por exemplo, a tecnologia digital e a Internet, as principais instituições do direito de propriedade intelectual, forjadas no século XIX com base em uma realidade social completamente distinta da que hoje presenciamos, permanecem praticamente inalteradas. (Lemos, 2005, p.8) 
Ainda mais sério é observar que o fluxo da comunicação científica, que poderia ser favorecido no panorama de um ambiente Web Colaborativa, vê-se afetado, entre outros, por motivos relacionados com a não titularidade do direito autoral do criador, prejudicando assim a viabilização de possibilidades de disseminação da informação científica para constituir-se em um bem de valor eminentemente social.

O capítulo anterior tratou sobre a legislação de proteção à obra intelectual desde seus primórdios. Neste capítulo serão apresentadas algumas das, provavelmente muitas, manifestações da sociedade na Web que refletem os conflitos emergentes do antagonismo, entre o que as TIC propiciam e o que a lei estabelece, bem como as ações e alternativas que vislumbram a proposta de oferecer condições para, dentro dos padrões que a legislação permite, poder usufruir da colaboração e da remixagem propiciadas na Web Colaborativa.

\section{Ilicitude digital}

Um momento de grande evidência do embate entre as TIC e a legislação vigente sobre proteção aos direitos do autor se deu na Campus Party 2009, segunda edição no Brasil. Sobre o evento, o jornal O Estado de S.Paulo do dia 2.2.2009 publicou, no caderno "Links", que a Campus Party "[...] escancarou uma realidade urgente: os novos hábitos de consumo de cultura, conhecimento e diversão não cabem mais na legislação de direitos autorais e antipirataria em vigor no Brasil e no mundo" (Pretti \& Martins, 2009, p.L1). As pessoas que participaram da Campus Party trocaram arquivos digitais dos mais diversos tipos, baixando e subindo conteúdo informacional em grande quantidade e que em grande parte, segundo a lei de direitos autorais, era ilegal.

Desde 1997 a Campus Party é realizada anualmente na Espanha. Durante uma semana, reúnem-se milhares de estudantes,

$1<$ http://www.campus-party.com.br/index.php/oevento.html>. 
professores, cientistas, jornalistas, entre outros e, principalmente, líderes de comunidades on-line "extremamente ativas na sociedade em rede, com enorme poder de formar opinião e criar tendências: os trendsetters” (Campus Party ${ }^{\mathrm{TM}}$, 2009) de diversos países, cada um com seus próprios computadores e com o intuito de compartilhar experiências relacionadas às últimas inovações tecnológicas e de entretenimento eletrônico em rede no mundo e que agem em distintas áreas, desde novas tecnologias de informação até economia e finanças. O Brasil, como porta de entrada do evento que pretende se expandir na América Latina, no encontro realizado em janeiro de 2009 recebeu 6.655 campuseiros e mais de 118 mil visitantes da área Expo e Lazer.

O conjunto arquitetônico da Fundação Bienal de São Paulo forneceu infraestrutura com oficinas, conferências, palestras, shows e atividades dos campistas em pelo menos 11 áreas temáticas: CampusBlog, Games, Simulação, Modding, Música, Design, Fotografia, Vídeo, Desenvolvimento, Software Livre, Campus Futuro. Estavam também no evento fabricantes de produtos relacionados às áreas temáticas para fazer circular suas novidades, garantindo um mercado cativo: uma combinação de cultura e de negócios. Outro aspecto que demonstra visual e espacialmente a importância atribuída ao encontro é o fato de ele ser realizado na edificação que abriga também as bienais em São Paulo. O prédio - pertencente ao conjunto de obras projetado pelo arquiteto Oscar Niemeyer para o Parque do Ibirapuera - esteve sempre relacionado à porta de entrada do novo no Brasil, seja nas artes, na indústria, em bienais de livros etc.

Em 2009, o Ministério da Cultura foi um dos patrocinadores da Campus Party, em conjunto com órgãos governamentais, como a prefeitura e o governo de São Paulo, além da Telefônica, do Flickr, do YouTube, do Orkut e do Twitter, entre outros. Isso mostra a relevância atribuída ao evento, repetido em 2010 sem grandes modificações quanto às atividades nele desenvolvidas.

A edição do jornal O Estado de S.Paulo que descreve a Campus Party apresenta informações preliminares que contextualizam a magnitude das práticas informacionais desregradas no Brasil. Cita- 
se que, segundo a Federação Internacional da Indústria Fonográfica, 95\% dos downloads na rede mundial são ilegais; dados do Ibope/ NetRatings apontam que $46 \%$ dos internautas brasileiros acessam sites e serviços de downloads ilegais; e, para a Federação do Comércio do Estado do Rio de Janeiro (Fecomércio-RJ), apenas 5\% dos brasileiros não recorrem à "pirataria" por medo de serem punidos (ibidem). A pequena percentagem citada evidencia que, para os outros $95 \%$, tais práticas não são consideradas ilegais ou simplesmente não interessa se são ilegais.

O jornal O Estado de S.Paulo apresenta cinco páginas avaliando as práticas que se tornaram habituais via Internet: a troca e o compartilhamento de arquivos que, na maioria das vezes, compõem-se de grandes quantidades de informação protegida pela legislação de direitos autorais, sendo, portanto, práticas ilegais. Pretti \& Martins (idem, p.L8) citam que a preocupação do especialista em legislação sobre direitos autorais Lawrence Lessig vai além da especificidade do assunto em questão; trata-se de uma geração de garotos que vê na lei algo "chato" e por isso a ignora. Será difícil, portanto, fazer que esses jovens obedeçam as leis fiscais ou outras leis. Lessig alerta que o centro da questão deve fixar-se na mudança da relação das leis com a sociedade. A incorporação da cultura do remix deve acontecer não só nos negócios, mas também na produção de conteúdo, isto é, uma nova cultura: a da hibridização, uma cultura que não pode ser criminalizada e que no Brasil Lemos (2005, p.1) denomina de ciber-cultura-remix, caracterizando-a pela remixagem, conjunto de práticas sociais e comunicacionais de combinações, colagens, cut-up de informação a partir das tecnologias digitais.

Os problemas, entretanto, não estão somente em situações tão evidentes como a destacada na Campus Party. Menos concentrados, mas tão relevantes, estão também no ambiente informacional Web Colaborativa. E o que se questiona no caderno "Link" do jornal O Estado de S.Paulo é: de quem é o erro? Das pessoas ou da lei? Qualquer pessoa que disponha de um aparato que permita o acesso à Internet pode incorrer em algum crime previsto pela lei de proteção dos direitos autorais. $\mathrm{O}$ exponencial aumento de 
downloads ilegais de 8\% em um ano, de 2007 a 2008, aquece o debate sobre um desequilíbrio entre a realidade e a escrita da lei, que no Brasil é extremamente rígida para um país que não é produtor de informação a ser protegida, e sim consumidor. O resultado dessa extrema rigidez manifesta-se na coerção dos cidadãos a situações de ilegalidade, muitas vezes sem que sequer o saibam.

O upload e/ou o download de conteúdos protegidos por direitos autorais são ilegais. Evidentemente, no Brasil já há um expressivo número de indivíduos usando conteúdos disponibilizados, por exemplo, pelo YouTube. Para ter uma ideia da expressiva quantidade de informação que circula na Web Colaborativa cabe citar novamente o artigo do site Época Negócios ${ }^{2}$ de maio de 2009, destacando que o portal de vídeos do Google, o YouTube, colocava no ar vinte novas horas de vídeo a cada minuto - o equivalente a lançar 114 mil novos filmes a cada semana. O site também salientava que, em meados de 2007, o índice era de seis horas por minuto, e, em janeiro de 2009, esse índice correspondia a 15 horas por minuto (Barifouse, 2009, p.1).

$\mathrm{O} \mathrm{MP} 3$ player ou um telefone celular que toca música podem constituir-se na ponte para o acesso ilegal de conteúdo informacional por meio de programas que permitem o compartilhamento de arquivos pela Internet. O título da matéria de O Estado de S. Paulo do caderno "Link" ilustra como a maioria das pessoas conectadas à Internet, muitas vezes sem sabê-lo, estão à margem da lei: "Você baixa músicas, filmes e jogos? Coloca música no iPod? Ripa CDs para ouvir no computador? Coloca música como toque de celular? Copia DVDs? Troca músicas com celulares Bluetooth? Então você é pirata!” (Pretti \& Martins, 2009, p.L1).

A Lei de Direitos Autorais também protege as obras fotográficas e as produzidas por qualquer processo análogo ao da fotografia. As novas tecnologias digitais propiciam que tanto a criação quanto o fluxo das imagens aumentem exponencialmente a cada dia. $\mathrm{O}$ número de comunidades que compartilham fotos pela Internet é expressivo. Porém, também na maioria das vezes sem sabê-lo, as

$2<\mathrm{http}$ ///colunas.epocanegocios.globo.com/tecneira/tag/youtube/>. 
pessoas utilizam-se dessas imagens sem respeitar as regras de uso impostas pela legislação. Isto é, para a utilização de uma foto é necessária a prévia e expressa autorização do fotógrafo, porque "atrás de toda fotografia haverá um dedo humano acionando um botão, e neurônios comandando um cérebro portador das ideias que se exteriorizem" (Abrão, 2002, p.113).

A contemporaneidade, como se procurou mostrar com as situações citadas, evidentemente vê-se envolvida em um paradoxo. Se por um lado ela dispõe de condições tecnológicas que possibilitam práticas de colaboração e remixagem, por outro tais práticas ficam condicionadas pelo que a legislação sobre produção intelectual estabelece e colocam o seu indivíduo em situações de ilicitude que sugerem novos olhares na procura do equilíbrio necessário para o favorecimento do fluxo informacional.

Como Lessig (2001, p.2-3) destaca, a Internet é construída em três camadas. A camada intermediária, denominada camada lógica ou de código, corresponde ao núcleo da Internet. Ela, em razão do seu design end-to-end (princípio desenhado que os arquitetos da rede começaram a articular no começo dos anos 1980 e que traz a ideia da necessidade de colocar a inteligência à margem da rede, mantendo-a simples), é efetivamente um bem comum, um "commons", isto é, recurso que não é dividido em partes individuais de propriedade, mas mantido junto para que todos possam utilizá-lo sem uma permissão especial. Ninguém controla os recursos à inovação que são disponibilizados na camada lógica. Mas as camadas física (camada inferior à do código, que corresponde aos computadores e à fiação utilizados na conexão) e de conteúdo (camada superior, que corresponde ao material que é exibido na rede) não foram organizadas como bens comuns. $\mathrm{Na}$ camada física, os computadores, por exemplo, não são livres, no sentido de públicos, e, na camada do conteúdo, grande parte do conteúdo disponibilizado na rede é protegida por direitos autorais.

No contexto da Web há uma parcela da sociedade que procura sustentar os padrões que lhe garantam o domínio econômico sobre a disseminação do conhecimento. Ela age na camada física e, prin- 
cipalmente, na camada de conteúdo: são os titulares dos direitos autorais, que na maioria das vezes não são os próprios autores. Lessig (idem) alerta que, se tais direitos, criados anteriormente ao advento da Internet, surgiram para garantir aos artistas o controle sobre seus "escritos" por um tempo determinado e para estimulá-los à produção de novos trabalhos, na contemporaneidade, os efeitos dessa legislação têm sido os de transferir o controle para as novas tecnologias de distribuição.

Surgem, nesse sentido, medidas para prevenir a infração à legislação em questão, como as tomadas pelo YouTube após fracassarem, em dezembro de 2008, suas negociações contratuais com o Warner Music Group, a terceira maior gravadora do mundo. Após expirar um acordo assinado com o YouTube em 2006, que permitia a transmissão de clipes de música de grupos e artistas como Red Hot Chili Peppers, a gravadora quis aumentar o valor cobrado pelos direitos de tais transmissões, mas o YouTube recusou-se a abandonar os termos negociados anteriormente. O Warner Music Group decidiu retirar milhares de vídeos de música do YouTube. Outras formas de conteúdo também começaram a ser observadas em consequência dessa disputa. Para evitar a infração à lei, o YouTube passou a remover milhares de vídeos feitos por amadores e que violassem a lei de direitos autorais: "vídeos caseiros familiares que continham um trecho de uma canção tocando ao fundo também foram removidos, bem como diversos vídeos que usam música de maneira brincalhona, em mash-ups e montagens"(Portal Terra, 2009). ${ }^{3}$ Em janeiro de 2009, o YouTube também passou a remover, ao serem postas on-line, as faixas de áudios dos videoclipes com copyright. Para isso, usa uma ferramenta que varre trilhas e as compara com um banco de obras protegidas. Quando encontra alguma infração, o detentor dos direitos é informado e, se ele quiser, o vídeo é retirado ou mantido on-line completo, mas com a indicação de tratar-se de um clipe infrator (Chacksfield, 2009, p.1).

$3<$ http://tecnologia.terra.com.br/interna/0,,OI3450527-EI4802,00-YouTub e+remove+audio+de+videoclipes + para+ proteger+copyright.html $>$. 
Outra ação que ilustra como as empresas detentoras de direitos autorais passam a agir para manter o controle sobre seus patrimônios foi noticiada em julho de 2008 na revista Época. ${ }^{4}$ Publicava-se que o Google (proprietário do YouTube), por determinação de um tribunal federal norte-americano em Nova York, deveria divulgar para o grupo de mídia Viacom, dono da MTV e da Paramount Pictures, a lista de vídeos e o endereço de IP (Internet Protocol) de cada usuário do YouTube do mundo. A intenção da Viacom é provar com esses dados que o acesso a vídeos ilegais é maior do que o acesso gerado por filmes criados pelos próprios usuários. Segundo a empresa Viacom, existiam na época 160 mil vídeos de sua propriedade no YouTube, vistos 1,5 bilhão de vezes pelos usuários do site. O YouTube, após esse incidente, para prevenir a divulgação de filmes com proteção de direitos autorais, passou a filtrar a inserção de vídeos no site.

O MIT Free Culture, um grupo de estudantes do MIT (Massachusetts Institute of Technology) preocupados com a determinação do YouTube de usar tecnologia de filtragem para fazer a varredura dos vídeos e áudios protegidos por copyright, criou o projeto de pesquisa YouTomb. ${ }^{5} \mathrm{O}$ objetivo do projeto é investigar que tipo de vídeos hospedados pelo YouTube estão sendo removidos. O MIT Free Culture entende que, embora a automatização facilite o processo de remoção de conteúdo protegido, ela também representa uma ameaça para aqueles conteúdos considerados exceções pela doutrina do fair use e, inclusive, para vídeos que podem ser removidos erroneamente. A proposta do MIT Free Culture consiste em identificar como o YouTube reconhece potenciais violações de copyright e reunir dados dos erros feitos pelo algoritmo. Em julho de 2009 , o site do projeto informava que estavam sendo monitorados 358.791 vídeos e identificava-se a remoção de somente 3.269 por violação do copyright (menos de 1\%) e 34.972 por outras razões ainda não identificadas. Em junho de 2010, os números correspon-

4 <http://revistaepoca.globo.com/Revista/Epoca/0,,EMI7299-15275,00. html>.

$5<$ http://youtomb.mit.edu/about $>$. 
diam a 440.036 vídeos monitorados, 9.760 vídeos removidos por violação do copyright e 212.711 vídeos removidos por outras razões.

Em 12 de maio de 2009, o governo francês lança uma proposta cuja amplitude de ação resulta ainda maior. O Senado da França aprovou a primeira lei específica contra a utilização ilegal de conteúdos na Internet e que previa pena para os usuários que fizessem downloads ilegais de músicas e filmes. A lei determina o corte do serviço de acesso à Web a quem ferir o dispositivo legal (Portal Terra). ${ }^{6}$ Em junho de 2009, o Conselho Constitucional da França declarou inconstitucionais os dispositivos que garantiam ao órgão administrativo Hadopi (Haute Autorité pour la diffusion des œuvres et la protection des droits sur Internet) a competência para suspender o acesso à Internet dos usuários. Em 15 de setembro de 2009, a Assembleia Nacional francesa votou e aprovou um projeto de lei complementar conhecido como Lei Hadopi 2, criado pelo governo francês como resposta à declaração de junho do Conselho Constitucional da França.

Richard Stallman, Lawrence Lessig e Ronaldo Lemos, entre outros, têm focado seu trabalho no cenário de uma Web predominantemente colaborativa, porém não com a intenção de cercear o indivíduo em seu processo criativo, mas de contribuir para que essa criatividade, significativamente aguçada e propiciada pelo advento das TIC, possa fluir amparada na legalidade. Assim, fruto de seus esforços, nascem as licenças flexíveis como alternativas para que a sociedade em geral possa interagir no ambiente informacional da Web Colaborativa dentro dos padrões que a lei estabelece.

\section{Copyleft}

Nos anos de 1980, quando a grande maioria dos softwares já era privativa e seus proprietários impediam a colaboração entre usuá-

6 <http://tecnologia.terra.com.br/interna/0,,OI3765365-EI4802,00-Franca + aprova+lei+antipirataria + e+ pode+desconectar+internautas.html $>$. 
rios, o norte-americano Richard Matthew Stallman viu a necessidade de resgatar o espírito cooperativo que prevalecia inicialmente na comunidade computacional em que o uso do software livre e a colaboração entre programadores era prática comum. Assim, após a American Telephone and Telegraph (AT\&T) proibir o acesso amplo ao sistema operacional Unix, Stallman criou o Projeto GNU com o intuito de desenvolver um sistema operacional completo de software livre que tivesse a lógica do sistema Unix. Em 1984, Stallman lançou o GNU (sigla recursiva para GNU's Not Unix) compatível com o sistema operacional Unix (Stallman, 1994).

A principal organização patrocinadora do Projeto GNU é a Free Software Foundation (FSF), ${ }^{7}$ criada por Stallman em 1985. Com sede em Boston, Massachusetts, a FSF dedica-se a promover os direitos dos usuários de computador para usar, estudar, copiar, modificar e redistribuir programas de computador. Defende as liberdades de expressão, de divulgação e de associação na Internet, o direito de usar programas de criptografia para comunicações privadas e o direito de escrever software sem empecilhos com monopólios privados. Assim, as chamadas quatro liberdades fundamentais do software livre são: a liberdade de executar o programa para qualquer propósito; a liberdade de estudar como o programa funciona e adaptá-lo às suas necessidades; a liberdade de redistribuir cópias, de modo que você possa ajudar ao seu próximo; e a liberdade de aperfeiçoar o programa e liberar seus aperfeiçoamentos, de modo que toda a comunidade se beneficie.

A difusão da Internet favoreceu a divulgação do movimento de software livre pelo mundo, e em 1991 a combinação do GNU com o software programado pelo finlandês Linus Benedict Torvalds gerou o sistema operacional livre, completo e multifuncional GNU/Linux. Torvalds conseguiu compilar todos os programas e ferramentas do movimento GNU em um kernel, um núcleo central, que ele denominou de Linux, ou seja, Linus for Unix.

$7<$ http://www.fsf.org/>. 
A FSF promove o desenvolvimento e uso de software livre - em especial do sistema de operação GNU e suas variantes GNU/Linux. O sociólogo brasileiro Sérgio Amadeu refere-se ao movimento de software livre como sendo a maior expressão de "[...] uma sociedade que busca mais do que a sua mercantilização. Trata-se de um movimento baseado no princípio do compartilhamento do conhecimento e na solidariedade praticada pela inteligência coletiva conectada na rede mundial de computadores" (Amadeu, s. d., p.16).

Stallman, para concretizar seu ideal de software livre, também idealizou a licença GNU General Public License (GNU GPL ou GPL), uma licença livre que garante ao usuário do software GNU a liberdade de copiá-lo, redistribuí-lo e mudá-lo, desde que aquele que o modifique subsequentemente também o mantenha livre. Essa licença consolidou o conceito de Copyleft para se referir a uma forma de usar a legislação de proteção dos direitos autorais que permitisse eliminar os direitos reservados impostos pela lei de copyright quanto à utilização, difusão e modificação de obras criativas, mas diferente do domínio público, em que não existem restrições. O Copyleft significa liberdade para copiar, distribuir e modificar, porém tudo o que for agregado ao que já está produzido também deverá continuar da mesma forma livre. O Linux, principal sistema operacional gratuito no mercado, foi criado de acordo com os conceitos do Copyleft.

A maneira mais simples de tornar um programa livre é disponibilizá-lo no domínio público, sem direitos reservados. Isso permite compartilhar o programa e suas melhorias com as pessoas, se assim o desejarem. Mas permite a pessoas não colaboradoras converter o programa em software privativo. Elas podem fazer mudanças, muitas ou poucas, e distribuir o resultado como um produto privativo. As pessoas que recebem o programa com essas modificações não têm a liberdade que o autor original lhes outorgou; o intermediário tirou-a. [...] Copyleft diz que qualquer um que redistribui o software, com ou sem modificações, deve dar a liberdade de copiá-lo ou mo- 
dificá-lo ainda mais. O Copyleft garante a cada usuário essa liberdade. (GNU Operating Systems, p.3, tradução nossa) ${ }^{8}$

No website do GNU Operating Systems, na página relativa a licenças, explicam-se os procedimentos para que um programa esteja sob a proteção do Copyleft: primeiro, o programa em questão deve ter o copyright atribuído para em seguida poder adicionar as cláusulas de distribuição. Elas equivalem a um instrumento legal que outorga a qualquer indivíduo o direito de poder usar, modificar e redistribuir o código fonte do programa ou de qualquer programa derivado dele, mas somente se os termos de distribuição atribuídos originalmente não são modificados. Código e liberdades tornam-se assim legalmente inseparáveis. Copylefté um conceito geral presente nas licenças GNU GPL, GNU LGPL (Licença Pública Geral Reduzida) e GNU FDL (Licença de Documentação Livre).

Durante a palestra Software libre, educación libre y cultura compartible, no Congresso Internacional Software Livre e Governo Eletrônico (Consegi 2009), na Escola de Administração Fazendária (Esaf), em Brasília (DF) -, Richard Stallman defendeu a plataforma aberta como condição imprescindível para manter as garantias individuais e coletivas na sociedade contemporânea e destacou que o software livre garante as liberdades de conhecer, criar, compartilhar e distribuir sem limites (Serpro, 2009, p.1). Stallman e seus seguidores defendem que a sociedade necessita de informação e que os indivíduos deveriam ter um direito fundamental: o direito de apropriação de trabalhos criativos. Para tanto, a sociedade contem-

8 La forma más simple de hacer que un programa sea libre es ponerlo en el dominio público, sin derechos reservados. Esto le permite compartir el programa y sus mejoras a la gente, si asi lo desean. Pero le permite a gente no cooperativa convertir el programa en software privativo. Ellos pueden hacer cambios, muchos o pocos, $y$ distribuir el resultado como un producto privativo. Las personas que reciben el programa con esas modificaciones no tienen la libertad que el autor original les dio; el intermediario se las ha quitado. (...) Copyleft dice que cualquiera que redistribuye el software, con o sin cambios, debe dar la libertad de copiarlo y modificarlo más. Copyleft garantiza que cada usuario tiene libertad. 
porânea necessita incentivar o espírito de colaboração entre seus cidadãos e, nesse contexto, o copyright não favorece a participação coletiva e colaborativa do indivíduo em benefício do desenvolvimento de uma cultura global.

\section{Creative Commons}

O Creative Commons é um projeto sem fins lucrativos, de adesão voluntária, sediado na Universidade Stanford, nos Estados Unidos. Ele é responsável por uma nova forma de direito autoral, pois disponibiliza um conjunto de licenças para áudio, imagem, vídeo, texto e educação que permite a autores e criadores de conteúdo intelectual, como músicos, cineastas, escritores, fotógrafos, blogueiros, jornalistas, cientistas, educadores e outros, indicar à sociedade, de maneira fácil, padronizada, com textos claros baseados na legislação vigente, sob que condições suas obras podem ser usadas, reusadas, remixadas ou compartilhadas legalmente.

Em 2002, Lawrence Lessig disponibiliza nos Estados Unidos o projeto de licenças flexíveis Creative Commons com a proposta de criar um sistema pelo qual todas as "criações do espírito" passem a ter "Alguns direitos reservados" - de acordo com os usos que o autor deseje permitir para essas criações - e em contraste com o que a lei de copyright estabelece: "Todos os direitos reservados".

Para o Creative Commons, uma ideia não é diminuída quando mais pessoas a utilizam, por isso o projeto "aspira cultivar um 'commons' onde as pessoas sintam-se livres para reutilizar não só ideias, mas também palavras, imagens e música sem pedir permissão - porque a permissão já foi concedida a todos" (Creative Commons, 2005).

Em junho de 2010, o site CC-Monitor, ${ }^{9}$ que contém dados coletados automaticamente sobre a adoção das licenças Creative Commons no mundo, registrava 257 milhões de obras licenciadas com

$9<$ http://monitor.creativecommons.org/Jurisdiction_Comparison>. 
Creative Commons. Dessa quantidade, a maior porcentagem, 37\%, corresponde às licenças "BY-SA", isto é, licenças que permitem a criação de obras derivadas, inclusive para fins comerciais, entretanto deve-se atribuir a autoria ao autor original e as obras derivadas devem ser licenciadas sob termos semelhantes. As cifras que o site CC-Monitor apresenta colocam a Espanha como o país que tem a maior quantidade de obras licenciadas com CC, seguida da Itália, dos Estados Unidos e do Japão. O Brasil ocupa o $10^{\circ}$ lugar, com 1.712.669 obras licenciadas.

Na ocasião, junho de 2010, os 53 países que faziam parte do projeto eram: África do Sul, Alemanha, Argentina, Austrália, Áustria, Bélgica, Brasil, Bulgária, Canadá, Chile, China, Colômbia, Coreia do Sul, Croácia, Dinamarca, Equador, Escócia, Eslovênia, Espanha, Estados Unidos, Filipinas, Finlândia, França, Grécia, Guatemala, Holanda, Hong-Kong, Hungria, Índia, Israel, Itália, Japão, Luxemburgo, Macedônia, Malásia, Malta, México, Nova Zelândia, Noruega, Peru, Polônia, Portugal, Porto Rico, República Checa, Reino Unido, Romênia, Sérvia, Singapura, Suécia, Suíça, Tailândia, Taiwan e Vietnâ. Países como Armênia, Azerbaijão, Egito, Estônia, Geórgia, Irlanda, Jordânia, Nigéria e Ucrânia estudavam a adesão ao Creative Commons.

O Creative Commons oferece seis modelos de licenças obtidas pela combinação das etiquetas: (i) (atribuição), (-) (uso não comercial), $\ominus$ (não a obras derivadas) e () (compartilhamento pela mesma licença).

A exigência de atribuição (dar crédito) ao autor da obra original é característica comum a todas as licenças Creative Commons. O termo relativo ao uso não comercial proíbe a venda ou a utilização da obra para fins lucrativos. O termo não a obras derivadas autoriza a livre cópia, a distribuição e a utilização da obra, entretanto, o autor não autoriza modificações nem o uso da obra para a criação de obras derivadas. Com o termo compartilhamento pela mesma licença, o autor autoriza a livre cópia, a distribuição e a utilização da obra, entretanto, ele impõe a condição de que, se a obra for utilizada para a criação de obras derivadas, a obra resultante deve ser necessa- 
riamente compartilhada pela mesma licença. Os seis modelos de licenças Creative Commons são:

(i) $(-)$ Atribuição/Uso Não Comercial/Vedada a Criação de Obras Derivadas (Attribution Non-commercial No Derivatives/ BY-NC-ND). Esta licença é a mais restritiva dentre as seis licenças principais. Ela é comumente chamada "propaganda grátis", pois permite que outros façam download das obras e as compartilhem, contanto que mencionem e façam o link ao autor original. Esta licença não permite modificar a obra de nenhuma forma nem utilizála para fins comerciais.

(i)(2) Atribuição/Uso Não Comercial, ompartilhamento pela mesma Licença (Attribution Non-commercial Share Alike/BY-NC$\mathrm{SA})$. Esta licença permite que outros remixem, adaptem e criem obras derivadas da obra original com fins não comerciais, contanto que atribuam crédito ao autor original e licenciem as novas criações sob os mesmos parâmetros. Outros podem fazer o download ou redistribuir a obra da mesma forma que na licença anterior, mas eles também podem traduzir, fazer remixes e elaborar novas histórias com base na obra original, porém o conteúdo produzido deverá ser licenciado com a mesma licença, de modo que qualquer obra derivada consequentemente não poderá ser usada para fins comerciais.

(i) Atribuição/Uso Não Comercial (Attribution Non-commercial/BY-NC). Esta licença permite que outros remixem, adaptem e criem obras derivadas da obra original, mas é vedado o uso com fins comerciais. As novas obras devem conter menção ao autor original nos créditos e também não podem ser usadas com fins comerciais, porém elas não precisam ser licenciadas sob os mesmos termos desta licença.

(i) $\Theta$ Atribuição/Vedada a Criação de Obras Derivadas (Attribution No Derivatives/BY-ND). Esta licença permite a redistribuição e o uso para fins comerciais e não comerciais, contanto que a obra seja redistribuída sem modificações e completa, e que os créditos sejam atribuídos ao autor original. 
(1)( Atribuição/Compartilhamento pela mesma Licença (Attribution Share Alike/BY-SA). Esta licença permite que outros remixem, adaptem e criem obras derivadas, inclusive para fins comerciais, contanto que o crédito seja atribuído ao autor original e que essas obras sejam licenciadas sob os mesmos termos. Esta licença é geralmente comparada a licenças de software livre. Dessa forma, as obras derivadas também poderão ser usadas para fins comerciais.

(i) Atribuição (Attribution/BY). Esta licença permite que outros distribuam, remixem, adaptem ou criem obras derivadas, inclusive para uso com fins comerciais, contanto que seja dado o crédito pela criação original.

Além das licenças obtidas pela combinação das etiquetas, o Creative Commons oferece opções de:

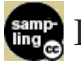

Licença de Sampling (recombinação). Esta permite que pequenos pedaços de qualquer tipo de obra (música, imagens, filme etc.) sejam remixados em obras novas, com modificações relevantes que caracterizem uma produção nova, ainda que para uso com fins comerciais. A distribuição das obras derivadas fica automaticamente autorizada para o autor que recriou a obra do autor original;

share Licença de Compartilhamento de Música, para músicos que queiram compartilhar suas obras com seus fãs. Estes poderão fazer o download, copiar e compartilhar o arquivo, porém não poderão vender, alterar ou fazer qualquer uso comercial da obra;

(ationg Licença Nações em Desenvolvimento. Esta permite que o autor disponibilize sua obra sob condições menos restritivas para países que não sejam considerados como de alta renda pelo Banco Mundial;

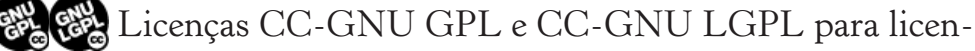
ciamento de softwares. Estas licenças, como explicado no próprio site do projeto, foram criadas para atender às necessidades específicas do governo brasileiro no que tange ao incentivo à adoção do software livre no país; 
(0) CC0-CCZero. Licença que permite somente ao autor ou proprietário da obra intelectual abrir mão dos direitos autorais e direitos conexos (direitos dos artistas, intérpretes e executantes) em toda a extensão permitida pela lei, bem como disponibilizar seu trabalho para que qualquer pessoa possa usá-lo de qualquer forma e para qualquer finalidade, incluindo para fins comerciais. A licença CC0 corresponde à opção "nenhum direito reservado" e é universal em sua aplicabilidade, diferente da Licença de Dedicação ao Domínio Público, que se baseia na legislação estadunidense e sua aplicação não é garantida em todos os países. Após optar pela licença CC0, não há nenhuma possibilidade de retornar à proteção anterior. $\mathrm{O}$ site norte-americano Digg $^{10}$ reúne links para notícias, podcasts e vídeos enviados e avaliados pelos próprios usuários. Desde maio de 2009, tudo o que é publicado no site (títulos, notícias e comentários) é de domínio público sob licença Creative Commons Zero (CC0).

Em janeiro de 2010, foram apresentadas no Brasil as licenças CC 3.0 em sua versão para o português. As modificações que essas licenças apresentam referem-se principalmente aos processos de tradução e de internacionalização para os que procuraram garantir o tratamento uniforme e consistente de temas relativos a direitos morais e à gestão coletiva de direitos. As principais modificações são relatadas no próprio website do Creative Commons Brasil. ${ }^{11}$

A partir da versão 3.0, as seis licenças CC passam a ser traduzidas de um conjunto genérico e internacional de licenças chamado Unported, em alusão ao termo port e à portabilidade entre licenças de diferentes países, redigido com base no texto de tratados internacionais como a Convenção de Berna e TRIPs. Todos os países envolvidos no projeto agora derivam suas licenças dos termos das licenças Unported, ao invés de simplesmente adaptar o texto das licenças americanas ao direito doméstico, como ocorria anteriormente.

$10<$ http://digg.com/about/>.

11 <http://www.creativecommons.org.br/index.php?option=com_content\&ta $\mathrm{sk}=$ view $\& \mathrm{id}=133 \&$ Itemid $=1>$. 
O rol de definições foi ampliado e reescrito para conferir maior precisão ao alcance das licenças e eliminar ao máximo a possibilidade de interpretações equivocadas dos termos.

As cláusulas relativas a direitos morais foram redigidas de modo a tornar mais claros direitos que já se encontravam respaldados pelas versões anteriores das licenças. Os direitos e obrigações existentes entre o autor e os criadores de obras derivadas da obra licenciada, quanto ao direito de paternidade (atribuição), ficam mais explícitos.

A licença Atribuição-Compartilhamento pela mesma licença agora tem uma cláusula de "licença compatível", o que facilita futuras conversões para licenças similares [...]. (Creative Commons Brasil, 2010)

As licenças Creative Commons apresentam-se com links para textos em três tipologias diferentes: a) um resumo da licença em uma linguagem simples (Commons deed) contendo os itens relevantes para a compreensão do usuário; b) outro texto apresenta a licença detalhada (Legal code) com termos jurídicos que garantem sua validade perante o judiciário; c) e um terceiro texto (Digital code) referente à versão da licença com a linguagem que permite aos computadores fazer a leitura e que ajuda os mecanismos de busca e outras aplicações a identificar a obra e seus termos de uso.

O processo de licenciamento de conteúdo intelectual no Creative Commons é muito simples. Basta acessar a página onde estão disponíveis as licenças do projeto e responder às perguntas que permitirão a atribuição da licença considerada adequada às necessidades do usuário. A partir daí, há instruções detalhadas sobre como aplicar o símbolo "CC - Alguns Direitos Reservados" na obra indicando qual é a licença aplicável. Se o trabalho estiver na Internet, basta colocar o símbolo do Creative Commons da respectiva licença no site. Para isso, o próprio site disponibiliza um trecho de código em HTML para ser copiado e colado no site em que está a obra. A validade do licenciamento se inicia no momento de inserir o código do Creative Commons no site. Caso a obra seja um livro, um CD, 
um DVD ou outra obra "física", basta inserir na própria obra (capa, contracapa, no próprio CD ou na caixinha) o símbolo do Creative Commons de "Alguns direitos reservados" especificando qual é a licença escolhida.

As licenças Creative Commons apresentam-se como um instrumento legal para a proteção do conteúdo intelectual cuja eficácia pode ser confirmada no resultado de uma ação judicial pelo uso indevido de uma obra sob a proteção de uma dessas licenças. Em abril de 2007, no Chile, o desenhista Armando Torrealba criou, para a divulgação da banda Marlou, da qual faz parte, a imagem de um urso panda ${ }^{12}$ usando um cabelo de estilo punk. O sucesso de seu desenho (muitos dos fãs da banda quiseram ter camisetas e outros adereços estampados com a imagem) levou o jovem a procurar uma licença Creative Commons para proteger seus direitos de autor e de uso comercial e também para permitir que as pessoas usassem a imagem. A licença estabelecia que além de atribuição da autoria, a obra não poderia ser usada para fins comerciais e qualquer obra derivada deveria ser compartilhada por uma licença semelhante. Contudo, uma grande loja de departamentos usou a imagem em uma campanha publicitária sem respeitar os direitos de seu criador e as condições que ele exigia para seu uso. $\mathrm{O}$ autor procurou a $\mathrm{ONG}$ Derechos Digitales ${ }^{13}$ para entrar com uma ação judicial exigindo que a imagem deixasse de ser usada na campanha. A empresa cumpriu a ordem e a agência responsável pela campanha indenizou Armando Torrealba (ONG Derechos Digitales, 2007, p.1).

O terceiro país a aderir ao projeto Creative Commons (após Japão e Finlândia) foi o Brasil. Desde 2003, é o advogado e professor de direito da Fundação Getúlio Vargas do Rio de Janeiro Ronaldo Lemos quem coordena o modelo no Brasil. Para Lemos (2005), uma das características do povo brasileiro é transformar criativamente elementos culturais próprios e de outras culturas. O Creative Com-

$12<$ http://www.flickr.com/photos/iamperegrino/250854500/>.

13 <http://www.derechosdigitales.org/2007/11/13/inauguran-en-chillanprimer-laboratorio-patrocinado-por-creative-commons $/>$. 
mons favorece esse tipo de liberdade criativa, de acesso, de diálogo e de transformação da cultura. Alguns dos órgãos governamentais que no Brasil já usam as licenças Creative Commons são: Banco Internacional de Objetos Educacionais, do Ministério da Educação e Cultura; Ministério da Cultura; Centro Nacional de Folclore e Cultura Popular; Cultura Digital; Programa de Pesquisa em Biodiversidade; Departamento de Controle do Espaço Aéreo; Biblioteca Digital (BDJur) do Superior Tribunal de Justiça; LexML; Casa Brasil; Radiobrás/Agência Brasil. ${ }^{14}$

As revistas disponibilizadas no Portal de Periódicos - campus de Rio Claro - Unesp, ${ }^{15}$ o Repositório Institucional da $\mathrm{UnB}^{16}$ (um conjunto de serviços oferecidos pela Biblioteca Central para a gestão e disseminação da produção científica e acadêmica da Universidade de Brasília) e a revista Ciência da Informação ${ }^{17}$ (uma das principais publicações da área da Ciência da Informação) utilizam as licenças Creative Commons para garantir a disponibilização de conteúdos intelectuais em condições que favoreçam o acesso aberto à produção científica.

O Creative Commons Brasil já é bastante conhecido, discutido e utilizado também em diversos segmentos da sociedade. Entre muitos outros que usam as licenças, destaca-se o site colaborativo, coletivo virtual, Overmundo, ${ }^{18}$ que, como referido no próprio

14 <http://www.cultura.gov.br/site/wp-content/uploads/2009/01/livro-direito-autoral.pdf $>$.

$<$ http://objetoseducacionais2.mec.gov.br/>.

$<$ http://www.cultura.gov.br/site/>.

$<$ http://www.cnfcp.gov.br/>.

$<$ http://culturadigital.br/blog/2008/02/27/creative-commons/>.

$<$ http://www.decea.gov.br/>.

$<$ http://bdjur.stj.gov.br/jspui/sobre.jsp $>$.

$<$ http://projeto.lexml.gov.br/>.

$<$ http://www.casabrasil.gov.br/>.

$<$ http://agenciabrasil.ebc.com.br/>.

$15<$ http://cecemca.rc.unesp.br/ojs/>.

$16<$ http://repositorio.bce.unb.br/>.

17 <http://revista.ibict.br/index.php/ciinf/index>.

$18<$ http://www.overmundo.com.br/>. 
site, pelas possibilidades colaborativas da Internet e da Web, pode tornar visível, em toda sua diversidade, a produção cultural das inúmeras vertentes da arte contemporânea tanto do Brasil como das comunidades de brasileiros que vivem no exterior. O Overmundo garante seu funcionamento com a ampla participação da comunidade de usuários que produzem conteúdos e votam para selecionar os conteúdos que serão editados, disponibilizam músicas, filmes e textos e comentam e trocam informações - uma nova forma de gerar conhecimento. Qualquer conteúdo no website é automaticamente licenciado sob uma licença Creative Commons, beneficiando toda a sociedade, que poderá usá-lo e compartilhá-lo livremente.

O Creative Commons está à disposição da sociedade há mais de seis anos e tem sido amplamente divulgado. Segmentos que lidam diretamente com a legislação da propriedade intelectual destacam a necessidade de conhecer o projeto. A Ata da $9^{a}$ reunião ordinária da Comissão de Direito da Propriedade Imaterial da OAB SP, realizada dia $16.12 .2008,{ }^{19}$ registra a aprovação para que na primeira reunião do ano de 2009 o Creative Commons, considerado um novo sistema, seja debatido por uma das comissões. O pedido de estudo foi sugerido após um dos membros ter recebido uma consulta no Conar (Conselho de Autorregulamentação Publicitária) sobre as licenças Creative Commons e este ter entendido que o assunto era inédito para a comissão, porém de alto interesse.

No âmbito internacional, o Change.gov, ${ }^{20}$ website presidencial dos Estados Unidos e espécie de gabinete virtual do presidente Barack Obama, adota uma licença Creative Commons para todo seu conteúdo (exceto quando houver alguma ressalva), que permite compartilhar, copiar, distribuir e transmitir a obra nele contida, porém sempre atribuindo o crédito ao autor. O website, que também inclui um blog, ${ }^{21}$ mantém um espaço para que os cidadãos possam

19 <http://www2.oabsp.org.br/asp/comissoes/propriedade_imaterial/atas/ ata92008_imaterial.pdf.>.

$20<$ http://change.gov/>.

$21<$ http://change.gov/newsroom/blog/>. 
compartilhar suas histórias e sentimentos. Sobre o assunto, o Creative Commons Brasil destaca que, embora o respeito pelo DMCA (Digital Millennium Copyright Act) e pelo tradicional copyright esteja explícito no Change.gov, quando Obama usa uma licença flexível, ele afirma sua política autoral. O Creative Commons Brasil salienta que as propostas tecnológicas relacionadas no website presidencial dos Estados Unidos, o Change.gov, revelam possibilidades promissoras para o futuro, e entre essas propostas destaca as seguintes:

a) Garantir a total e livre troca de ideias por uma Internet aberta e diversas outras mídias.

b) Proteger a liberdade da Internet apoiando o princípio da neutralidade na rede a fim de preservar os benefícios da livre concorrência no âmbito virtual.

c) Encorajar a diversidade na propriedade de mídia, promover o desenvolvimento de novas saídas de mídia para a expressão de diversos pontos de vista.

d) Proteger a Propriedade Intelectual atualizando e reformando os sistemas de direitos autorais e patentes para incentivar a discussão cívica, a inovação e o investimento, assim como garantir o tratamento justo aos proprietários de propriedade intelectual. (Creative Commons Brasil, 2008)

Também no cenário internacional, em junho de 2009, a enciclopédia coletiva de conteúdo livre Wikipédia adotou como padrão a licença Creative Commons BY-SA (Atribuição-Compartilhamento pela mesma Licença). Antes, a Wikipédia utilizava a licença GNU Free Documentation License (GFDL), a qual ainda será mantida em alguns casos. A mudança foi aprovada pelo Conselho Administrador da Wikimedia Foundation (organização sem fins lucrativos dedicada a incentivar a produção e a distribuição de conteúdo livre) depois de uma pesquisa com mais de vinte mil usuários comprovar que $76 \%$ eram a favor da nova licença por estar mais voltada para material autoral (Amaro, 2009, p.1).

Em julho de 2009, o Google passou a disponibilizar um novo serviço para seus usuários. A ferramenta de pesquisa de imagens 
(image search tool) oferece filtros para a localização de imagens que tenham sido marcadas com as licenças Creative Commons. O usuário pode restringir sua busca por imagens na Web marcadas com essas licenças e assim poderá compartilhá-las, usá-las e, inclusive, modificá-las. Para acessar o filtro, basta clicar no botão de Pesquisa Avançada de imagens e selecionar as opções desejadas na seção de "direitos de utilização". Os resultados serão restritos às imagens marcadas com licenças Creative Commons ou outras licenças compatíveis, tais como a GNU Free Documentation License, ou imagens que estão em domínio público (Creative Commons, 2009).

O Flickr ${ }^{22}$ também possibilita a localização de imagens marcadas com as licenças Creative Commons. Em junho de 2010, o site informava conter um total de 147.340.828 imagens sob proteção das licenças Creative Commons.

As licenças Creative Commons têm-se constituído em ferramentas importantes para o Movimento de Acesso Aberto à literatura científica. São consideradas como adequadas para proteger os direitos autorais e ao mesmo tempo garantir o acesso e uso da produção científica, pois o autor pode reter o direito de impedir a distribuição de cópias modificadas, não autorizadas ou com propósito de uso comercial. "Essencialmente, isso impede legalmente o plágio, a deturpação e o reúso comercial da obra. Ademais, permite todos os tipos de uso requeridos pelo uso acadêmico legítimo, inclusive as facilidades de pesquisa e consulta" (Acesso Aberto Brasil, s. d., p.1).

A Public Libray of Science (PLoS), projeto sem fins lucrativos de cientistas e médicos preocupados em fazer da literatura médica e científica do mundo um recurso público, dentro do modelo de acesso aberto, usa as licenças Creative Commons para a efetivação de sua proposta.

Em contexto semelhante, cabe citar a Scholarly Publishing $\mathcal{E}$ Academic Resources Coalition (Sparc), uma aliança internacional de bibliotecas acadêmicas e de pesquisa e organizações que trabalham para corrigir disfunções no mercado da publicação científica. Seu

$22<$ http://www.flickr.com/creativecommons/>. 
principal objetivo é facilitar a emergência de um novo sistema em rede para disseminar trabalhos científicos, combater preços abusivos em revistas e apoiar o acesso aberto, especialmente nas áreas de Ciência, Tecnologia e Medicina. Seu website e a maior parte do conteúdo nele disponibilizado também são licenciados com licenças Creative Commons. Também a Iniciativa de Código Aberto (Open Source Initiative - OSI), organização dedicada à promoção do código aberto, usa no seu website a licença Atribuição (Attribution/ $B Y)$, permitindo que outros distribuam, remixem, adaptem ou criem obras derivadas, mesmo que para uso com fins comerciais, contanto que seja dado o crédito pela criação original.

Em dezembro de 2007, a Nature Publishing Group (NPG), uma das mais conceituadas revistas científicas interdisciplinares do mundo, passou a disponibilizar todos os artigos sobre genoma humano com a licença Creative Commons Atribuição/Uso Não Comercial - Compartilhamento pela mesma Licença. Assim, a sociedade está livre para compartilhar (copiar, distribuir e transmitir) e remixar (adaptar) a contribuição, desde que atendendo a propósitos não comerciais sujeitos às mesmas ou a similares condições e atribuições da licença. Tal medida reflete a preocupação de tornar os artigos cada vez mais acessíveis e atende ao acordo que, em fevereiro de 1996, no Primeiro Encontro Internacional de Estratégia para o Sequenciamento do Genoma Humano, realizado nas Bermudas, estabelecia

[...] que toda informação sobre a sequência do genoma humano, gerada por centros financiados para sequenciamento humano em larga escala, deverá estar gratuitamente disponível e em domínio público, de forma a fomentar a pesquisa e o desenvolvimento e a maximizar seus benefícios à sociedade. (Creative Commons, 2007)

Além das licenças flexíveis, o Creative Commons tem lançado outros projetos destinados a apoiar e expandir o domínio público. São eles: CC International, CC Learns, CC Mixter e Science Commons. 
O Creative Commons International funciona como "porta" do núcleo Licenças Creative Commons às legislações de direitos autorais diferentes ao redor do mundo. O processo de portabilidade envolve traduzir tanto linguisticamente quanto legalmente as licenças e adaptá-las às jurisdições específicas.

O CC Mixter é um site de música da comunidade, com remixes sob licença Creative Commons, onde o usuário pode ouvir, adquirir amostras, fazer mash-up ou interagir com a música da maneira que quiser.

O CC Learns tem a proposta de utilizar o potencial da Internet para suportar os recursos de aprendizado e educacionais abertos para minimizar as barreiras legais (educando professores e educadores sobre os aspectos relativos ao copyright e sobre como usá-lo adequadamente na educação), as barreiras técnicas (promovendo padrões de interoperabilidade, ferramentas para facilitar alterações e reutilização) e as barreiras sociais (encorajando professores e educadores a reutilizar materiais educacionais disponíveis na Web).

Em junho de 2010, Alex Kozak, filósofo e especialista em política de informação, co-fundador da Students for Free Culture, em Berkeley, EUA, reportava que um grupo de desenvolvedores de software da Universidade do Estado de Michigan interessados em pesquisa e descobertas em educação apresentou ao Creative Commons o projeto DiscoverEd. Trata-se do protótipo de um mecanismo de pesquisa educacional que usa metadados para melhorar os resultados da pesquisa do texto completo. Fornece uma maneira de filtrar os resultados sobre recursos educacionais de uma pesquisa com base em características específicas, como as condições de compartilhamento estipuladas na licença, para qual nível de escolaridade o conteúdo é apropriado e o assunto. Esses metadados são recolhidos a partir de uma variedade de fontes, incluindo os protocolos OAIPMH (Open Archive Initiative-Protocol Metadata Harvesting), RSS feeds (Really Simple Syndication) e RDFa (Resource Description Framework - in-attributes).

Kozak recomenda que, para comprovar a utilidade do projeto, sejam comparados os resultados de uma pesquisa com o termo 
cell organelles, por exemplo, no Google, Yahoo ou Bing, com os resultados da ferramenta DiscoverEd. A constatação será de que o DiscoverEd proporcionará uma significativa diferença nos resultados, conduzindo o usuário a encontrar objetos/recursos com conteúdo educacional sob licenças Creative Commons justamente pelos metadados que acompanham as representações dos objetos educacionais.

Enquanto a maioria dos motores de busca depende exclusivamente de análises algorítmicas de recursos, o DiscoverEd pode incorporar dados fornecidos pelo editor ou responsável pelo recurso. Se os responsáveis e os editores seguirem alguns padrões básicos, os metadados podem ser capturados e exibidos pela DiscoverEd. Esses formatos (por exemplo, RDFa) permitem por outro lado que projetos educacionais não relacionados, responsáveis e repositórios expressem fatos sobre seus recursos no mesmo formato para que ferramentas (como DiscoverEd) possam usar aqueles dados para fins úteis (como pesquisa e descoberta). (Kozak, 2010, tradução nossa $)^{23}$

O Creative Commons acredita em uma Web Colaborativa que siga padrões abertos, permitindo melhores resultados para todos. A visão do Creative Commons, destaca ainda Kozak (idem), é que, seguindo todos os padrões interoperáveis, como as licenças Creative Commons, por exemplo, o resultado será uma plataforma que permita inovação técnica e social semelhante ao que aconteceu com HTTP e HTML.

23 While most search engines rely solely on algorithmic analyses of resources, DiscoverEd can incorporate data provided by the resource publisher or curator. As long as curators and publishers follow some basic standards, metadata can be consumed and displayed by DiscoverEd. These formats (e.g. RDFa) allow otherwise unrelated educational projects, curators, and repositories to express facts about their resources in the same format so that tools (like DiscoverEd) can use that data for useful purposes (like search and discovery). 


\section{Science Commons}

Baseado no conceito de livre acesso à informação e à literatura acadêmica, o Creative Commons desenvolveu o projeto Science Commons com o objetivo de promover a inovação e a colaboração científica por meio da remoção de barreiras legais e técnicas desnecessárias para fazer a pesquisa científica reútil. São inúmeros os cientistas que ainda hoje trabalham em relativo isolamento e há muitas investigações realizadas em duplicado. Os dados das pesquisas ficam presos a contratos ou perdidos em bases de dados que não podem ser acessadas ou integradas. Os benefícios que a comunidade científica pode oferecer para o desenvolvimento humano evidentemente são limitados.

O foco principal do projeto Science Commons está em desenvolver e promover políticas e ferramentas que ajudem indivíduos e organizações a abrir e marcar suas pesquisas e conjuntos de dados de tal modo que possam ser reusados. Diante disso, o Science Commons apresenta três iniciativas para acelerar o ciclo de investigação, isto é, para propiciar a produção contínua e a reutilização do conhecimento que está no cerne do método científico. São elas: a) tornar a pesquisa científica "reútil", ajudando pessoas e organizações a abrir e marcar suas pesquisas e dados de tal modo que possibilitem a reutilização; b) ativar o acesso a materiais de pesquisa com "um clique" para agilizar o processo de transferência de materiais para que os pesquisadores possam replicar facilmente, verificar e ampliar a investigação; c) integrar fontes de informação fragmentada para ajudar os pesquisadores a encontrar, analisar e utilizar dados de fontes diferentes, marcando e integrando as informações com uma língua comum, legível por computador. Juntas, essas iniciativas formam os blocos necessários para a construção de uma nova infraestrutura de colaboração para tornar propositalmente mais fácil a descoberta científica.

O Science Commons disponibiliza um protocolo de dados abertos para que a comunidade científica global possa usar dados criados sob diferentes regimes legais. Oferece também um conjunto 
de contratos padronizados para trazer eficiências e economias de escala do e-commerce para o mundo de ferramentas científicas, permitindo que pesquisadores possam replicar facilmente, verificar e ampliar suas pesquisas.

Entre os parceiros do projeto estão BioMed Central, publicação on-line de mais de 170 jornais de acesso aberto na área de pesquisa médica e biológica; MIT Open CourseWare, que disponibiliza material de conteúdo aberto e livre para estudantes, cientistas, educadores etc.; e da PLoS - Public Library of Science, organização sem fins lucrativos formada por cientistas e físicos que têm como objetivo tornar as informações científicas acessíveis livremente.

O conselho do Science Commons é formado por, entre outros, Sir John Sulston, ganhador do Prêmio Nobel de Fisiologia e conhecido por ser um dos responsáveis pelo sequenciamento genético do DNA; pelo professor James Boyle, da Faculdade de Direito da Universidade de Duke; e pelo professor Paul David, economista e professor da Universidade de Oxford. Em maio de 2007, no Centro de Tecnologia e Sociedade (CTS) da FGV Direito Rio, o diretor-executivo do Science Commons, John Wilbanks, ministrou a palestra-debate "Science Commons: promovendo a difusão do conhecimento científico".

No contexto do projeto Science Commons, torna-se oportuna a reflexão sobre a importância de entender a comunicação científica como um recurso de uso comum, no competitivo, um commons, conceito que remete a Charlotte Hess e Elinor Ostrom, esta última cientista política estadunidense detentora do Prêmio Nobel de Ciências Econômicas de 2009, juntamente com Oliver Williamson, pela análise da governança econômica, especialmente dos bens comuns.

Hess \& Ostrom (2003, p.114) destacam que, embora durante os últimos 15 a 20 anos a literatura interdisciplinar internacional sobre commons tenha crescido, refletindo as tentativas de chegar a uma compreensão unificada para a definição do conceito, a literatura legal recente não faz menção a essa produção e o termo commons é usado frequentemente como sinônimo de domínio público, entendendo domínio público como terra de propriedade do governo e 
como alguma coisa livre para qualquer pessoa usar ou como alguma coisa não protegida por patentes ou copyright. Quanto ao domínio público intelectual, um commons parece ser uma ideia sobre processos democráticos, liberdade de expressão e liberdade de trocar informação.

Estudiosos da área do direito, como Lawrence Lessig, Yochai Benkler e Jéssica Litman, por exemplo, entendem o conceito de commons como um acesso aberto universal, um conceito que envolve restrição legal contra regimes de controle e como um domínio público, respectivamente.

Hess \& Ostrom (idem, p.115) lembram, além disso, que o conceito commons carrega várias histórias que compreendem desde propriedade de espaços compartilhados a noções de ideais democráticos, e quase todos os usos do termo têm sido contestados, gerando debates que até hoje não foram completamente resolvidos e que se enquadram em uma perspectiva de questionamento sobre se proprietários de terras têm uma papel especial na sociedade que necessite de proteção e sobre a legitimidade de fechar propriedades comunalmente pertencentes.

Na conceituação de Hess \& Ostrom (idem, p.129-130), ${ }^{24}$ para que a informação e o domínio público intelectual possam ser efetivamente um commons, é importante desenvolver uma compreensão mais cuidadosa dos processos de fornecimento e de produção das informações e dos artefatos, de fornecimento e produção dos meios de informação, de distribuição dos artefatos para os meios e para os usuários e das várias formas de consumir e usar o conteúdo informacional desses artefatos.

Para essas autoras, artefato corresponde à representação observável e possível de ser citada de uma ideia ou de um conjunto delas. Os artefatos variam em sua durabilidade. Os artefatos físicos podem ser usados sequencialmente e, no caso da informação disseminada no ciberespaço, simultânea e obliquamente por diversos leitores. Por outro lado, muitos usuários de artefatos têm sido

24 <http://www.law.duke.edu/journals/66LCPHess>. 
historicamente excluídos de seu uso por razões diversas, porém acentuadas na medida do crescimento da complexidade dos processos de codificações. Assim, os processos de exclusão de usuários potenciais têm se tornado mais complexos e menos transparentes com os artefatos digitais. Os artefatos são considerados unidades físicas de fluxo de um meio de informação. Exemplos de artefatos são os artigos, as notas de pesquisas, os livros, as bases de dados, os mapas, os arquivos de computadores e as páginas Web.

Um meioé o sistema de recursos que armazena os artefatos e suas ideias. Antes do desenvolvimento dos artefatos digitais, os meios tradicionais eram as bibliotecas públicas e privadas e os arquivos que armazenavam artefatos físicos. Um meio tinha um limite físico no número e no tipo de artefatos que podiam ser armazenados. Enquanto os custos de excluir usuários não eram habitualmente muito altos, muitas bibliotecas e arquivos investiram no desenvolvimento de regras bem definidas sobre quem seria considerado usuário legítimo, sobre o tempo que os indivíduos poderiam legalmente remover artefatos de todas as instalações e sobre as práticas que deveriam ser seguidas dentro das instalações (permanecer em silêncio, por exemplo), sobre o uso dos artefatos (não destacar, arrancar páginas etc.), bem como sobre os indivíduos, para o acompanhamento e verificação dessas regras. Os próprios meios estavam sujeitos a deterioração se um investimento substancial não fosse feito em sua manutenção. Coleções privadas geralmente não eram abertas ao público. Na era digital, são também meios as bibliotecas digitais, os repositórios, as redes de computadores e a Internet (ibidem).

As ideias contidas em um artefato podem ser compreendidas como sendo a visão criativa, o conteúdo intangível, as informações inovadoras e o conhecimento. As ideias são as unidades de fluxo não físico contidas em um artefato. Esse é o elemento que o direito autoral não protege. Analiticamente, o uso individual de uma ideia não subtrai o corpus desta para o uso de outros. Pode, no entanto, ser possível excluir outros de conhecer uma ideia ao mantê-la em segredo. Na visão habitual da Ciência da Informação, as ideias cristalizariam-se em dados, informações e conhecimento. 
Hess \& Ostrom (idem, p.113) destacam também a dificuldade de uma definição do conceito de informação, mas referem-se à análise do economista austríaco Friedrich Hayek, que considera haver dois tipos de conhecimentos essenciais cuja compreensão continua crucialmente relevante na construção do conhecimento científico e das políticas de informação. Em 1945, Hayek citava o fato de estarmos acostumados a respeitar o conhecimento científico recolhido por peritos, porém esquecemos que é apenas em combinação com o "conhecimento local" que esse conhecimento assume um valor real.

As discussões entre acadêmicos focam-se na natureza das relações entre esses conceitos-chave e seus significados. Geralmente, os três conceitos são concebidos como parte de uma ordem sequencial: dados, informação e conhecimento. Dados (forma plural da palavra latina datum, que significa "os dados") são a matéria-prima para a informação, e informação é a matéria-prima para o conhecimento. No entanto, essa sequência parece problemática, pois ela é baseada no pressuposto de que informação é um elemento necessário, incorporado no conhecimento; um estágio intermediário entre dados e conhecimento.

Em função dessa complexidade, busca-se, entre as diversas definições atribuídas a dado, informação e conhecimento, a de Zins (2005, p.454), pesquisador israelense da Ciência da Informação. $\mathrm{O}$ autor traz uma diferença relevante para uma nova perspectiva em que a noção de commons e a regulamentação de novas formas de compartilhamento figuram como atores principais de um cenário inédito na configuração do conhecimento e dos saberes. Para ele, esses conceitos são inter-relacionados e podem ser observados sob dois aspectos: no domínio universal e no domínio subjetivo.

No domínio subjetivo, dado é o estímulo sensorial - seu significado -, isto é, a percepção empírica; informação corresponde ao conhecimento empírico; e o conhecimento refere-se ao pensamento na mente do indivíduo. Segundo Zins (idem, p.452, tradução nossa):

Para avaliar as definições dos três conceitos no domínio subjetivo, propriamente o leitor deveria estar atento para algumas discus- 
sões epistemológicas básicas. Observe que conhecimento - como um pensamento - é um produto de uma síntese. Esta asserção é baseada na literatura filosófica que se seguiu à Crítica da razão pura de Kant (1781). Kant argumentou que qualquer percepção empírica é produto de uma síntese de uma multiplicidade de dados significados/sensoriais. Ele identificou, em qualquer percepção, a priori, componentes que dão significado para a diversidade de matéria-prima e constroem-na como uma unidade. ${ }^{25}$

No domínio universal, dado, informação e conhecimento são representados por símbolos empíricos. Dados são jogos de símbolos que representam estímulos empíricos ou percepções. A informação corresponde a um conjunto determinado de símbolos que representa um conhecimento empírico, e conhecimento refere-se a um conjunto de símbolos que representa o significado dos pensamentos que o indivíduo, justificadamente, acredita serem verdadeiros. Nessa conceituação, Zins (idem, p.454, tradução nossa) destaca que informação é um tipo de conhecimento. Não é nem um estágio intermediário entre dados e conhecimento, nem sinônimo de conhecimento.

Dados, informação e conhecimento são representados, no domínio universal, por símbolos empíricos (isto é, símbolos que se podem perceber pelos sentidos). Eles podem assumir formas diversificadas, tais como sinais gravados, formas pintadas, palavras impressas, sinais digitais, fluxos luminosos, ondas sonoras, e semelhantes. Como observado, o conhecimento objetivo, ou melhor, o conhecimento universal é um produto de uma externalização

25 In order to evaluate the definitions of the three concepts in the subjective domain properly the reader should be aware of some basic epistemological discussions. Note that knowledge - as a thought - is a product of a synthesis. This assertion is based on the philosophical literature that followed Kant's (1781) Critique of Pure Reason. Kant argued that any empirical perception is the product of a synthesis of a multiplicity of sense/sensory data. He identified in any perception a priori components, which give meaning to the diversity of raw material and construct it as one unit. 
do conhecimento subjetivo. Consequentemente, dados objetivos, informação objetiva e conhecimento objetivo espelham as suas contrapartes cognitivas. ${ }^{26}$

Todas as pesquisas válidas em commons envolvem a combinação de conhecimento científico com o tempo e o lugar de análise. Hess \& Ostrom acrescentam que é importante lembrar que informação é um artefato humano, com acordos e regras, e fortemente atado às regras da própria linguagem. A informação tem um importante componente cultural, assim como funções intelectuais, econômicas e políticas. Como tal, é um recurso que deve ser passado de um indivíduo a outro para ter qualquer valor público.

$\mathrm{Na}$ análise de Hess \& Ostrom, a compreensão dos processos que envolvem as formas da informação possibilita visualizar que muitos dos entraves desses processos de comunicação científica que a impedem de ser efetivamente um commons são de ordem jurídica e relacionados com a propriedade intelectual (direitos autorais e patentes). No âmbito da produção científica, torna-se necessário o desenvolvimento de uma estrutura jurídica mais adequada para esses processos, que hoje são desafiados por novas tecnologias em um ambiente global.

Fica claro que para todos esses autores as emergentes formas sociais e suas interfaces tecnológicas determinam estruturas mentais distintas e, consequentemente, novas matrizes comportamentais e de inteligência coletiva.

A presença da tecnologia no cotidiano das pessoas formando opinião, criando necessidades e determinando comportamentos,

26 Data, information, and knowledge are represented, in the universal domain by empirical symbols (i.e. symbols that one can sense through his/her senses). They can take on diversified forms such as engraved signs, painted forms, printed words, digital signals, light beams, sound waves, and the like. As noted, objective knowledge, or rather universal knowledge, is a product of an externalization of subjective knowledge. Consequently, objective data, objective information, and objective knowledge mirror their cognitive counterparts. 
torna a investigação dessa temática na Ciência da Informação extremamente importante no processo de formação reflexiva dos sujeitos no que se refere ao uso de recursos informacionais alocados nos mais diversos suportes e ambientes. É investigação importante também no favorecimento das estratégias de empoderamento enquanto ação coletiva desenvolvida pelos indivíduos quando participam de espaços privilegiados de decisões e de consciência social e dos direitos sociais. (Jorente et al., 2009)

O bom resultado das investigações e dos diálogos com os diversos campos do conhecimento presentes na ecologia complexa que reúne sistemas de ambientes informacionais e de sujeitos autônomos conectados não deve ser prejudicado por dificuldades criadas por leis proprietárias que impeçam o referido empoderamento. $\mathrm{O}$ olhar contemporâneo, pelo contrário, deve considerar a colaboração e o remix como práticas recorrentes e favorecedoras da reflexão e da construção de um saber compartilhado como meio do referido empoderamento e inteligência coletivos.

\section{Acesso livre ao conhecimento científico}

Na comunidade científica, responsável pela produção de informações vitais ao desenvolvimento humano, as tecnologias de informação e comunicação, em particular a Web, também estão presentes em seu fazer científico, favorecendo práticas de colaboração que contribuem para o ideal de ter a informação científica como um efetivo recurso de uso comum, benéfico para a construção de um saber coletivo necessário ao desenvolvimento de um mundo humanitariamente mais justo. Contudo, observa-se que entraves que pareciam poder ser eliminados com o advento das TIC permanecem e, como é previsível quando novas tecnologias são incorporadas, outros surgem.

Em 2005, o bibliotecário, editor e livreiro Briquet de Lemos (2005, p.3-4), ao proferir a palestra "Periódicos eletrônicos: proble- 
ma ou solução?” no X Encontro Nacional de Editores Científicos, em São Paulo, discorreu sobre o surgimento e a evolução do periódico eletrônico que ele definiu como

um recurso eletrônico, com artigos completos, que pode incluir elementos de multimídia, disponível na Internet, e que é publicado sequencialmente, com uma designação numérica ou cronológica, e que pretende continuar indefinidamente. Pode ser a reprodução de uma revista impressa ou uma publicação exclusivamente em linha.

O primeiro periódico eletrônico de comunicação científica teria sido o Postmodern Culture, que surgiu em setembro de 1990, primeiro no formato de correio eletrônico, depois em disquete e, em janeiro de 1994, na sua versão em hipermídia na Internet. A publicação eletrônica parecia poder acabar com a insatisfação existente há muito tempo no âmbito da comunicação científica. Insatisfação que, em 1919, por exemplo, levou o inventor do aço-manganês, Sir Robert Abbott Hadfield, a propor a criação de uma central classificadora dos originais de artigos para posterior encaminhamento às revistas. Tal medida pretendia eliminar a dispersão de artigos por uma ampla gama de periódicos e evitar a demora em sua publicação e difusão para a comunidade científica. Houve também propostas para que as revistas fossem extintas, devido ao excessivo valor pago pelas assinaturas. Discutia-se que nem todos os artigos publicados no fascículo de uma revista eram de interesse dos cientistas, no entanto eles pagavam pela totalidade da publicação. A comunicação científica representava lucro certo para editoras e generosa fonte de recursos para as sociedades científicas (idem, p.1-2).

O surgimento do períodico eletrônico representava a libertação de uma prática considerada ineficiente para a divulgação do conteúdo informacional científico.

Rompiam-se os grilhões que amarravam o artigo científico contemporâneo a uma metodologia e tecnologia ultrapassadas, velhas de mais de 500 anos, e a um produto - a revista científica - com 
mais de 320 anos de idade, que estava aquém das necessidades de um mundo cada vez mais globalizado. [...] O periódico eletrônico seria também a libertação dos sistemas perversos impostos pelas editoras de periódicos científicos, inclusive as sociedades científicas, isoladamente, ou a elas associadas. Isso no mundo desenvolvido. No mundo subdesenvolvido a proposta seduzia principalmente pelo seu aparente baixo custo de produção. Era uma proposta que tinha tudo para dar certo. Finalmente a produção científica dos países da periferia poderia valer-se de um veículo de divulgação universal, principalmente agora que essa produção vinha redigida numa língua planetária. (idem, p.1)

A comunicação científica poderia usufruir das possibilidades propiciadas pelo avanço tecnológico, em especial a Internet e os ambientes informacionais da Web. Além de poder diminuir o custo de produção e favorecer a disseminação, há outras vantagens nos periódicos eletrônicos que merecem ser observadas:

[...] acessibilidade [acesso] - onde houver um microcomputador ligado à Internet, você terá acesso ao periódico; divulgação ilimitada: estaria garantida a distribuição em âmbito planetário, sem necessidade de embalagem, selos, correio, carteiro e atrasos; rapidez de publicação: redução do tempo entre a submissão dos originais e sua publicação; qualidade garantida pelos pares: manutenção da qualidade do sistema, pois continuaria sendo feita a revisão pelos pares; extensão ilimitada: não haveria limite para o tamanho dos artigos; ligação automática do artigo à rede de seus antecessores ou correlatos: isso seria assegurado pela vinculação (linking) do artigo com as referências citadas; utilização de cores sem nenhuma limitação; uso de diferentes métodos de indexação; buscas fáceis; utilização de multimídia; interatividade; remissivas para outros recursos disponíveis na rede; e o aumento da utilização de material antigo. (idem, p.4)

Entretanto, a disseminação e o acesso mais amplo e irrestrito ao conhecimento científico, possíveis de serem alcançados valendo-se 
das oportunidades propiciadas pelas TIC, principalmente a Internet e a Web, também têm encontrado entraves.

O cientista húngaro Harnad (2007, p.1) destaca que no mundo há a publicação de aproximadamente 24 mil periódicos científicos, avaliados pelos pares. Essas publicações, em diversas línguas, cobrem todas as áreas do conhecimento e geram cerca de 2,5 milhões de artigos científicos por ano. Contudo, grande parte das universidades e das instituições de pesquisa do mundo não tem os recursos financeiros suficientes para assinar pelo acesso a todos esses conteúdos. Somente uma pequena parcela dessa produção científica chega a ser disponibilizada para os usuários. Assim, os resultados das pesquisas desenvolvidas alcançam uma fração mínima de seu potencial de uso, de aplicações e de fator de impacto, e, consequentemente, destaca ainda Harnad (idem), não favorecem a produtividade na pesquisa e no progresso.

Um fator importante que também afeta a disseminação da publicação científica encontra-se no hábito arraigado da cessão de direitos autorais, prática em que o autor transfere seus direitos para a entidade que publica seu trabalho. A concentração dos direitos de autor e, por conseguinte, dos principais resultados das pesquisas em um editor não favorece a disseminação, pois ela pode ser influenciada pelos interesses e percepções do editor (Ferreira, 2008, p.111).

Cientistas no mundo inteiro, preocupados em incrementar a visibilidade e o acesso aos resultados de seus estudos e assim maximizar o progresso da ciência e da tecnologia, procuram mecanismos mais ágeis e econômicos que possibilitem a viabilização da maior troca de conteúdo científico usando os recursos que as TIC propiciam.

Em agosto de 1991, o físico Paul Ginsparg, do laboratório de Los Alamos, no Novo México, criou o ArXiv, sistema para armazenamento, recuperação e disseminação de documentos eletrônicos e primeiro repositório baseado na filosofia dos arquivos abertos. Nele, os usuários podiam (e ainda podem) recuperar ou submeter e publicar os artigos tanto por uma interface Web como via correio eletrônico. 
Atentos a essa nova alternativa que começava a se delinear para a publicação científica, em outubro de 1999, reuniram-se pesquisadores de diversas áreas e nacionalidades durante a Convenção de Santa Fé, realizada no Novo México, sob os auspícios do Council on Library and Information Resources (Clir), da Digital Library Federation (DLF), da Scholarly Publishing E Academic Resources Coalition (Sparc), da Association of Research Libraries (ARL) e do Los Alamos National Laboratory (LANL). No ano seguinte, surgia o movimento internacional conhecido como Iniciativa dos Arquivos Abertos (Open Archives Initiative - OAI) com o propósito de desenvolver padrões de interoperabilidade que facilitassem a disseminação eficiente de conteúdo. Para alcançar seu objetivo, a OAI estabeleceu como mecanismos: a definição de um conjunto mínimo de metadados com base no padrão Dublin Core; a adoção de uma sintaxe comum XML (Extensible Markup Language) para representar e transportar tanto o OAMS (Open Archives Metadata Set) como os conjuntos de metadados específicos de cada repositório; e implementou um protocolo comum de comunicação - OAI/ Protocol for Metadata Harvesting (PMH) - para permitir que todos os arquivos em conformidade com esse modelo possam expor os metadados dos registros neles depositados, possibilitando ser coletados por outro arquivo. "Esse processo permite que os conteúdos de um arquivo em conformidade como referido modelo sejam coletados, tratados e pesquisáveis, como se todos os conteúdos de todos os arquivos estivessem em um arquivo global" (Harnad, 2007, p.2).

Também com o olhar no desenvolvimento social da humanidade em geral, e no contexto do acesso aberto ao conhecimento, em dezembro de 2001, o Instituto Sociedade Aberta (Open Society Institute - OSI) convocou uma reunião em Budapeste, Hungria, com os principais defensores, de diferentes nações, do Movimento ao Acesso Aberto à literatura científica e aos periódicos acadêmicos. Os participantes representavam pontos de vista diversos, inseridos em muitas disciplinas acadêmicas e com experiência em iniciativas relativas a esse movimento. Os objetivos do encontro concentraram-se em explorar até que ponto poderiam ser combinadas as diversas iniciativas existentes para que os artigos de investigação 
em todas as áreas acadêmicas estivessem disponíveis gratuitamente na Internet, bem como identificar de que maneira o OSI poderia usar seus recursos para ajudar essa causa. Esse encontro resultou no documento Declaração de Budapeste (Budapest Open Access Initiative - Boai) e na consolidação do Movimento de Acesso Aberto à literatura científica (Open Access), apoiado pelos participantes de Budapeste e por indivíduos e organizações de todo o mundo representando pesquisadores, universidades, laboratórios, bibliotecas, fundações, publicações periódicas, editores, sociedades de especialistas e iniciativas semelhantes de acesso aberto. Aderiram à iniciativa: Bioline International, OSI, Public Library of Science (Plos), University Montreal, University Southampton/University Quebec-Montreal e Bio Med Central.

Para alcançar o efetivo acesso on-line à literatura científica que os pesquisadores oferecem à sociedade sem nenhuma expectativa de receber qualquer pagamento, a Boai incentiva como estratégias complementares tanto o acesso aberto a periódicos quanto o autoarquivamento. A literatura em questão inclui artigos submetidos a periódicos com revisão por pares, bem como preprints não revistos que o pesquisador deseje disponibilizar on-line para receber comentários ou alertar seus colegas para resultados importantes da sua investigação (Boai, 2002). A Declaração de Budapeste definiu que o termo "acesso aberto à literatura" deve ser entendido como

a disposição livre e pública na Internet, de forma a permitir a qualquer usuário a leitura, download, cópia, impressão, distribuição, busca ou o link com o conteúdo completo de artigos, bem como a indexação ou o uso para qualquer outro propósito legal. No entendimento das organizações que apoiam o acesso aberto, não deve haver barreiras financeiras, legais e técnicas outras que não aquelas necessárias para a conexão à Internet. $\mathrm{O}$ único constrangimento para a reprodução e distribuição deve ser o controle do autor sobre a integridade de seu trabalho e o direito à devida citação. (Acesso Aberto Brasil, ${ }^{27}$ s. d., p.1).

$27<$ http://www.acessoaberto.org/>. 
Além da Declaração de Budapeste, há mais duas declarações consideradas fundamentais para a consolidação do Movimento de Acesso Aberto: a Declaração de Bethesda (Bethesda Statement on Open Access Publishing) e a Declaração de Berlim sobre o Acesso Aberto ao Conhecimento nas Ciências e Humanidades.

A Declaração de Bethesda, realizada em 11.4.2003 na sede do Howard Hughes Medical Institute em Chevy Chase, Maryland, Estados Unidos, teve a proposta de estimular as discussões na comunidade de pesquisas biomédicas direcionadas à concretização efetiva do acesso aberto à literatura científica. Duas condições são indicadas pela Declaração de Bethesda para que a publicação científica possa ser considerada de acesso livre:

1. $\mathrm{O}(\mathrm{s})$ autor(es) e o(s) detentor(es) do copyright garantem a todos os usuários o direito de acesso gratuito, irrevogável, global e perpétuo; e uma licença para copiar, usar, distribuir, transmitir e exibir o trabalho publicamente e para fazer e distribuir obras derivadas, em qualquer meio digital para qualquer propósito responsável, sujeito à correta atribuição da autoria, bem como o direito de fazer um número pequeno de cópias para seu uso pessoal.

2. Uma versão completa da obra e todos os materiais suplementares, incluindo uma cópia da licença como estabelecido acima, em um formato eletrônico padrão adequado é depositado logo após a publicação inicial em pelo menos um repositório on-line mantido por uma instituição acadêmica, sociedade científica, agência governamental ou outra organização devidamente estabelecida que procure promover o acesso aberto, a distribuição irrestrita, a interoperabilidade e o arquivamento a longo prazo (a PubMed Central é um desses repositórios para as ciências biomédicas). (Bethesda Statement on Open Access Publishing, 2003, tradução nossa $)^{28}$

28 1. The author(s) and copyright holder(s) grant(s) to all users a free, irrevocable, worldwide, perpetual right of access to, and a license to copy, use, distribute, transmit and display the work publicly and to make and distribute derivative 
A Declaração de Berlim sobre Acesso Livre ao Conhecimento nas Ciências e Humanidades é fruto de uma conferência sobre acesso aberto organizada pela Sociedade Max Planck, em Berlim, em outubro de 2003, com o intuito de promover a Internet como instrumento funcional a serviço de uma base de conhecimento científico global e do pensamento humano. A Declaração de Berlim concretizou a adesão ao acesso aberto à literatura científica de representantes de várias instituições científicas europeias e estabeleceu como condição para o favorecimento do acesso livre o empenho de todo e qualquer indivíduo que produza conhecimento científico, ou seja, detentor de patrimônio cultural.

A Declaração de Berlim encoraja os investigadores/bolsistas à publicação de seus estudos de acordo com os princípios do paradigma de acesso livre. Consideram-se contribuições ao acesso livre resultados de investigações científicas originais, dados não processados e metadados, fontes originais, representações digitais de materiais pictóricos e gráficos e material acadêmico multimídia. Tais contribuições devem satisfazer as seguintes condições:

1. $\mathrm{O}(\mathrm{s})$ autor(es) e o(s) detentor(es) dos direitos de tais contribuições concede $(\mathrm{m})$ a todos os utilizadores o direito gratuito, irrevogável e mundial de lhes aceder, e uma licença para copiar, usar, distribuir, transmitir e exibir o trabalho publicamente e realizar e distribuir obras derivadas, em qualquer suporte digital para qualquer propósito responsável, sujeito à correta atribuição da autoria (as regras da comunidade continuarão a fornecer

works, in any digital medium for any responsible purpose, subject to proper attribution of authorship, as well as the right to make small numbers of printed copies for their personal use.

2. A complete version of the work and all supplemental materials, including a copy of the permission as stated above, in a suitable standard electronic format is deposited immediately upon initial publication in at least one online repository that is supported by an academic institution, scholarly society, government agency, or other well-established organization that seeks to enable open access, unrestricted distribution, interoperability, and long-term archiving (for the biomedical sciences, PubMed Central is such a repository). 
mecanismos para impor a atribuição e uso responsável dos trabalhos publicados, como acontece no presente), bem como o direito de fazer um pequeno número de cópias impressas para seu uso pessoal.

2. Uma versão completa da obra e todos os materiais suplementares, incluindo uma cópia da licença como acima definida, é depositada (e portanto publicada) num formato eletrônico normalizado e apropriado em pelo menos um repositório que utilize normas técnicas adequadas (como as definições Open Archive) que seja mantido por uma instituição acadêmica, sociedade científica, organismo governamental ou outra organização estabelecida que pretenda promover o acesso livre, a distribuição irrestrita, a interoperabilidade e o arquivo a longo prazo, (Declaração de Berlim, 2003)

Para o Movimento de Acesso Aberto, a literatura científica que deveria estar livremente acessível on-line é aquela oferecida ao mundo sem expectativas de pagamento e que abrange, principalmente, os artigos de periódicos revisados pelos pares, mas também inclui artigos preprints não revisados disponibilizados para serem comentados ou para alertar os colegas sobre importantes resultados de pesquisas. Para favorecer o efetivo acesso livre a esse conteúdo, Harnard (2004) e seus colaboradores propõem dois caminhos possíveis de serem adotados pelas editoras e revistas: a via verde, em que os autores podem autoarquivar seus artigos, já publicados ou autorizados para publicação, nos repositórios públicos de acesso aberto; e a via dourada, em que os próprios editores garantem o acesso livre ao conteúdo científico, bem como as condições para a publicação também em ambientes de acesso aberto.

Em setembro de 2009, o Doaj (Directory of Open Access Journal), serviço hospedado, mantido e financiado em parte pela Lund University Libraries Head Office e que permite acesso a textos completos de periódicos acadêmicos e científicos que usem um sistema de controle de qualidade adequado e disponibilizem seus conteúdos na condição de acesso aberto, citava que 1.648 dos 4.344 pe- 
riódicos que constam em seu diretório são pesquisáveis em nível de artigo. Assim, o total de artigos incluídos no serviço correspondia a 312.010 (Doaj, 2009).

Tanto a OAI quanto o Movimento de Acesso Aberto (AO) perpetuam os princípios básicos referendados pela comunidade científica, isto é: o da disseminação, da fidedignidade e do acesso. A disseminação dos resultados das pesquisas, destaca Ferreira (2008, p.114), é fundamental para a Ciência, pois, além de garantir maior visibilidade para a produção científica, garante também a possibilidade de uso e de aplicações desses resultados e, consequentemente, a evolução das pesquisas e o avanço social da humanidade. Para o cientista, representa, "além da visibilidade de sua produção e da consequente maximização de resultados, chance de subvenção para os próximos trabalhos de pesquisa, reconhecimento entre os pares, ampliação de sua rede social e, decerto, satisfação e motivação pessoal" (ibidem). O princípio da fidedignidade refere-se à revisão da publicação feita pelos pares com o intuito de conferir validade e qualidade ao conteúdo. Já o acesso refere-se à organização, permanência e acesso ao conteúdo da produção científica pela própria comunidade científica.

O acesso aberto, destaca Harnad (2007, p.3), pode resolver as desigualdades quanto ao acesso aos resultados de pesquisas científicas e acadêmicas e, consequentemente, algumas desigualdades sociais no mundo também poderiam ser corrigidas. A produtividade científica e acadêmica seria maior e mais rápida, características estas mensuráveis por métricas como publicações, downloads, contagem de citações, e que, indubitavelmente, são mais evidentes e palpáveis e favorecem o progresso da ciência.

$\mathrm{O}$ acesso aos resultados de pesquisa não estará mais limitado àqueles cuja instituição possui disponibilidade para assinar a revista na qual ela aparece. A compreensão e o uso dos resultados de pesquisa tornar-se-ão mais rápidos e amplos, e o público (a sociedade), que contribui com fundos de pesquisa e instituições de pesquisa, terá como benefício maior progresso e produtividade 
da pesquisa. O mundo em desenvolvimento, especialmente, será beneficiado, uma vez que esses países têm uma quantidade valiosa de talentos de pesquisa, mas não dispõem de recursos que possibilitem acesso à pesquisa corrente, de modo a estarem bem informados e capazes de utilizar e construir a sua parte. Estudantes de todo o mundo serão também beneficiados pelo acesso irrestrito a todas as pesquisas. A navegação, avaliação e análise do desenvolvimento da pesquisa e suas perspectivas serão também bastante enriquecidas pelo ALi $[\mathrm{AO}]$ assim como serão ampliadas a oferta a de ferramentas e de serviços de informação. (idem, p.4)

Contudo, a disseminação e o acesso amplo e irrestrito ao conhecimento científico, passíveis de serem alcançados no contexto do acesso aberto propiciado pelo uso das tecnologias de informação e comunicação, também encontram entraves. Um dos principais obstáculos está precisamente no hábito da cessão de direitos autorais. A titularidade do direito autoral é imprescindível para que o autor possa ter a liberdade de utilização flexível de sua própria produção intelectual e assim "atender aos interesses acadêmicos, reduzir os custos para as instituições, minimizar a assimetria do poder de barganha dos editores e promover o acesso aberto" (Souto \& Oppenheim, 2008, p.141).

A construção e o acesso ao conhecimento científico podem efetivamente acontecer no contexto da Web Colaborativa e nos termos propostos pelo Movimento de Acesso Aberto, porém se exigem outras abordagens quanto aos direitos autorais, visto que a Web em questão, ao favorecer e facilitar a atuação do pesquisador/autor tanto na geração quanto na divulgação do conhecimento científico, lhe permite

liberdade e maleabilidade para reutilização e divulgação dos resultados de suas pesquisas, passando, assim, a trabalhar em benefício dos próprios interesses, incluindo a possibilidade de contribuição para sua área de atuação, o reconhecimento dos pares e a progressão na carreira. (idem, p.145) 
Portanto, as novas abordagens quanto aos direitos autorais devem viabilizar perspectivas em que a disseminação da informação científica constitua um bem de valor eminentemente social, e para tanto o autor precisa estar mais envolvido com a temática relativa à legislação vigente e como ela age no contexto do novo propiciado pelas TIC.

As situações citadas neste capítulo, concentradas nos tópicos "Ilicitude digital" e "Acesso livre ao conhecimento científico", propõem ilustrar como a sociedade contemporânea é afetada pelo desequilíbrio existente entre o que a tecnologia possibilita na amplitude do conceito de "obra intelectual" no ambiente informacional Web Colaborativa e o que a legislação que regulamenta a proteção das obras literárias, artísticas e científicas determina. Ela funciona, como destacado por Lemos (2005), como um grande "NÃO!".

É comum encontrar, em obras autorais exploradas economicamente, a inscrição "Todos os Direitos Reservados" (ou "All Rights Reserved"). Isso quer dizer que, se alguém pretende utilizar aquela obra, tem de pedir autorização prévia a seu autor ou detentor de direitos. Grosso modo, se alguém faz rabiscos em um guardanapo, aqueles rabiscos já nascem protegidos pelo direito autoral, e qualquer pessoa que deseje utilizá-los precisa pedir permissão ao autor. E esse mesmo modelo aplica-se a qualquer outra obra autoral: como regra geral, presume-se que, para se utilizar uma música, um filme, uma foto, um texto ou quaisquer outras obras, é necessário pedir autorização prévia, porque "todos os direitos estão reservados".

Como consequência disso, os custos de transação envolvidos na obtenção dessa autorização prévia restringem de forma brutal a quantidade de cultura que uma determinada sociedade tem disponível para acesso em um determinado tempo. (idem, p.83)

Com o olhar em uma direção semelhante à apontada por Lemos, em 2006 Eliane Y. Abrão, na época presidente da Comissão Especial da Propriedade Imaterial da OAB/SP, proferiu a aula inaugural "Uma introdução à propriedade imaterial. Princípios 
constitucionais. Visão sistêmica do Direito Autoral. Conhecimentos tradicionais e novos tempos" no seminário "Propriedade intelectual e bens de personalidade", promovido pela Escola Paulista da Magistratura (EPM), destacando como a revolução digital veio para implodir o sistema de direito autoral: "[...] antes dela tudo era controlado e fiscalizado com base no número de cópias, o que é impossível de se fazer com a Internet" (Abrão, 2006). Abrão afirma que a necessidade de um sistema de regulamentação internacional é notória, pois a base do sistema processual é física, territorial e não virtual: "E, para controlar os direitos autorais, precisamos de regras procedimentais" (EPM, 2006, p.1).$^{29}$

No cenário da publicação científica, Crow (2002, p.21), consultor da Sparc, aliança internacional de bibliotecas acadêmicas e de pesquisa que trabalham para corrigir desequilíbrios no sistema de publicação científica, considera elemento-chave da publicação científica a retenção da titularidade do direito de autor e a concessão de licenças não exclusivas.

O Brasil é um dos países que têm demonstrado interesse em criar ambientes de discussão na procura de soluções e modificações no âmbito da legislação de direitos autorais. A disposição oficial do Governo Federal fica denotada, por exemplo, na disponibilização no site do Ministério da Cultura, no encarte de 44 páginas em formato PDF "Direito Autoral: conheça e participe desta discussão sobre a cultura no Brasil, do Fórum Nacional de Direito Autoral". ${ }^{30}$ Esse documento é fruto de uma série de seminários e oficinas destinados à discussão das políticas de Direito Autoral no Brasil promovida pelo próprio Ministério da Cultura por considerar tratar-se de um tema de interesse da sociedade como um todo, "[...] uma vez que o Direito Autoral permeia a criação, a produção, a distribuição, o consumo e a fruição dos bens culturais" (Brasil, Ministério da Cultura, 2009, p.3).

29 <http://www.epm.sp.gov.br/SiteEPM/Noticias/18.12.06.+Propriedade+i material.htm $>$.

30 <http://www.cultura.gov.br/site/wp-content/uploads/2009/01/livro-direito-autoral.pdf $>$. 
O documento aborda o assunto tratando-o sob os aspectos de gestão coletiva de direitos, mediação de conflitos e arbitragem, domínio público, registro de obras protegidas, estrutura organizacional, ambiente digital, relação entre o público e o privado, obras sob encomenda, relação entre investidores e criadores e obras audiovisuais. Desde 2007, no denominado Fórum Nacional do Direito Autoral, praticamente todas as categorias envolvidas na questão (autores, artistas, editoras, gravadoras, usuários, consumidores etc.) expuseram suas críticas e sugestões. Após o encerramento do fórum, em novembro de 2009, iniciou-se o processo de elaboração da proposta de revisão da Lei de Direitos Autorais. Em junho de 2010, o Ministério da Cultura passou a disponibilizar para a sociedade civil a consulta pública para revisão da atual Lei de Direitos Autorais ${ }^{31}$ contendo as mudanças sugeridas a partir dos debates promovidos. A população pode oferecer sugestões ao texto no site do próprio Ministério da Cultura ${ }^{32}$ até 28.6.2010. Posteriormente, o governo enviará à Câmara o projeto com as alterações propostas para a Lei de Direito Autoral 9.610/98.

Entre as mudanças propostas consideradas positivas, Ortellado (2010), professor do curso de Gestão de Políticas Públicas da USP, coordenador do Grupo de Pesquisa em Políticas Públicas para o Acesso à Informação e membro da Rede pela Reforma da Lei de Direito Autoral, destaca:

- a exigência de um controle por meio da numeração dos exemplares ou por controle eletrônico da quantidade de cópias feitas para permitir ao autor monitorar a quantidade de cópias produzidas;

- a autorização para a realização de uma cópia extra, de backup ou de proteção dos bens culturais adquiridos legitimamente;

- a mudança de formato de quem adquire uma obra para uso privado;

31 <http://www.cultura.gov.br/consultadireitoautoral/consulta/>.

$32<$ www.cultura.gov.br>. 
- a livre apresentação de peças, a exibição de filmes e a execução de músicas no ambiente escolar, no âmbito familiar, nos cineclubes e nas igrejas, desde que sejam gratuitas e sem fins comerciais;

- a possibilidade de as bibliotecas, os museus e as cinematecas poderem fazer cópias livremente para preservação do patrimônio cultural do país;

- a autorização da livre cópia, sem finalidade comercial, de obras esgotadas;

- a autorização para o livre uso de obras para fins educacionais, científicos e "criativos", desde que respeitem a chamada regra dos três passos (devem ser feitas "na medida justificada para o fim a se atingir, sem prejudicar a exploração normal da obra utilizada nem causar prejuízo injustificado aos legítimos interesses dos autores");

- a autorização da paródia, ampliando a liberdade de expressão para a crítica, inclusive humorística;

- a licença compulsória de direitos autorais que dá ao presidente da República a prerrogativa de autorizar, quando requisitado, o licenciamento voluntário de obras esgotadas, de obras cujos detentores dos direito criam obstáculos não razoáveis à exploração, de obras cujos detentores dos direitos são desconhecidos (as chamadas “obras órfãs”) e de obras cujos detentores dos direitos não autorizam a reprografia;

- a fiscalização de organizações de gestão coletiva (como o Ecad e as associações que o compõem) passa a ser feita pelo poder público;

- a proibição da prática do "jabá", pagamento a um veículo de radiodifusão para executar uma música.

Ortellado (idem) considera, contudo, pontos necessários de revisão no Anteprojeto de Lei:

- o artigo $8^{\circ}$, inciso VIII, que se refere ao abandono da proteção das normas técnicas, porém a observação "ressalvada a sua proteção em legislação específica" precisaria ser melhor explicitada; 
- o prazo de proteção do direito autoral permanece inalterado e, considerando que o direito internacional obriga a "apenas" cinquenta anos após a morte do autor, não há motivo para não reduzir esse prazo de proteção;

- a ausência de referência ao acesso às obras raras e não publicadas no país e que deveria estar previsto no artigo 46.

Apesar dos problemas apontados por Ortellado (idem) e, inclusive, de todos os outros a serem identificados após a finalização da consulta pública, o Brasil destaca-se por sua preocupação na busca de alternativas que contribuam para uma melhor adequação da legislação sobre direitos autorais no contexto da contemporaneidade.

Neste capítulo procurou-se evidenciar que, se a legislação vigente sobre os direitos autorais não atende às necessidades que a contemporaneidade passa a impor após o surgimento das TIC, em especial a Internet e o ambiente informacional Web, há na sociedade segmentos que vêm procurando alternativas que possam garantir o equilíbrio necessário para que a produção de conteúdo intelectual não seja prejudicada, principalmente sob o lema de violação da Lei de Direito Autoral.

No contexto abordado, as licenças flexíveis, em especial as licenças Creative Commons, constituem-se em alternativas que naturalmente não preenchem todas as necessidades que se manifestam no contexto social contemporâneo, mas indubitavelmente podem contribuir para minimizar a paradoxal situação vivenciada, inclusive, no âmbito da produção científica em benefício do fluxo da informação, do acesso ao conhecimento e do desenvolvimento de uma cultura mundialmente com menos desigualdades. 



\section{REFERÊNCIAS BIBLIOGRÁFICAS}

ABRÃO, E. Y. Direitos de autor e direitos conexos. São Paulo: Editora do Brasil, 2002.

ACESSO ABERTO BRASIL. Sobre o movimento Acesso Aberto. Disponível em: <http://www.acessoaberto.org/>. Acesso em: 16 mar. 2009.

AMADEU, S. Inclusão digital, software livre e globalização contra-hegemônica. Disponível em: <http://www.softwarelivre.gov.br/softwarelivre/artigos/artigo_02>. Acesso em: 3 ago. 2009.

AMARO, M. Entenda a nova licença da Wikipédia. Publicado em $1^{\circ}$ jun. 2009. Disponível em: <http://info.abril.com.br/noticias/internet/ entenda-a-nova-licenca-da-wikipedia-01062009-6.shl?2>. Acesso em: 7 jun. 2009.

AMORIM, R.; VICÁRIA, L. A enciclopédia pop como a Wikipédia - gratuita e escrita apenas por internautas - se transformou no maior fenômeno editorial e na maior obra de referência do planeta. Revista Época, n.401, $1^{\circ}$ jan. 2006. Disponível em: <http:// revistaepoca.globo.com/Revista/Epoca/0,,EDG72932-5990,00A+ENCICLOPEDIA+POP.html>. Acesso em: 2 fev. 2009

ANBARASAN, E. Tim Berners-Lee, el señor de la Red. In: El Correo de la UNESCO, set. de 2000. Disponível em: <http://www.unesco.org/ courier/2000_09/sp/dires.htm\#top>. Acesso em: 26 jan. 2009.

ANDERSON, P. What is Web 2.0? Ideas, technologies and implications for Education. JISC Technology and Standards Watch, feb. 2007. 
ANTONIO, I. Autoria e cultura na pós-modernidade. Ci. Inf., Brasília, v.27, n.2, p.189-92, maio/ago. 1998. Disponível em: <http://www. jisc.ac.uk/media/documents/techwatch/tsw0701b.pdf >. Acesso em: 10 jan. 2009

ARAYA, E. R. M.; VIDOTTI, S. A. B. G. Direito autoral e tecnologias de informação e comunicação no contexto da produção, uso e disseminação de informação: um olhar para as licenças Creative Commons. Informação e Sociedade, João Pessoa, v.19, n.3., p.39-51, set./dez. 2009. Disponível em: <http://www.ies.ufpb.br/ojs2/index.php/ies/ article/view/3900/3124>.

BARIFOUSE, R. YouTube ganha 20 horas de vídeos a cada minuto. $\mathrm{Pu}-$ blicado em 21 maio 2009. Disponível em: <http://colunas.epocanegocios.globo.com/tecneira/tag/youtube/>. Acesso em: 16 jul. 2009

BARRETO, A. A. Mudança estrutural no fluxo do conhecimento: a comunicação eletrônica, Ci. Inf., Brasília, v.27, n.2, p.122-7, maio/ ago. 1998. Disponível em: <http://revista.ibict.br/index.php/ciinf/ article/viewFile/340/301>. Acesso em: 26 fev. 2009.

A condição da informação. São Paulo Perspec.(on-line), 2002, v.16, n.3 (cited 2010-02-25), p.67-74. Disponível em: <http://www. scielo.br/scielo.php?script=sci_arttext\&pid=S0102->. Acesso em: 20 fev. 2010.

BBCBrasil.com. Wikipédia pode ser 'tão precisa quanto britânica'. Disponível em: <http://www.bbc.co.uk/portuguese/ciencia/story/ 2005/12/051215_wikipediacomparacaofn.shtml>. Acesso em: 28 jan. 2009.

BERLIN DECLARATION ON OPEN ACCESS TO KNOWLEDGE IN THE SCIENCES AND HUMANITIES, 2003. Disponível em: <http://oa.mpg.de/openaccess-berlin/berlindeclaration.html $>$. Acesso em: 3 ago. 2009.

BERNERS-LEE, T. The World Wide Web: past, present and future. Aug. 1996. Disponível em: <http://www.w3.org/People/BernersLee/1996/ppf.html>. Acesso em: 21 jan. 2009.

The World Wide Web: a very short personal history. 1998. Disponível em: <http://www.w3.org/People/Berners-Lee/ShortHistory. html >. Acesso em 16 fev. 2009.

Frequently asked questions by the Press: spelling of WWW. Disponível em: <http://www.w3.org/People/Berners-Lee/FAQ. html\#Spelling >. Acesso em: 16 fev. 2009. 
BETHESDA STATEMENT ON OPEN ACCESS PUBLISHING, 2003. Disponível em: <http://www.earlham.edu/ peters/fos/ bethesda.htm\#note1>. Acesso em: 29 jul. 2009.

BITTAR, C. A. Direito de autor. Rio de Janeiro: Forense Universitária, 2000.

BRASIL. MINISTÉRIO DA CULTURA. Direito autoral. Brasília: Ministério da Cultura, 2006. 436p. (Coleção cadernos de políticas culturais; v.1). Disponível em: <http://www.cultura.gov.br/site/ wp-content/uploads/2008/02/caderno-politicas-culturais-direitosautorais.pdf $>$. Acesso em: 26 jan. 2008.

Direito autoral: conheça e participe desta discussão sobre a cultura no Brasil, do Fórum Nacional de Direito Autoral. Disponível em: <http://www.cultura.gov.br/site/wp-content/uploads/2009/01/ livro-direito-autoral.pdf>. Acesso em: 15 dez. 2008.

BRIQUET DE LEMOS, A. A. Periódicos eletrônicos: problema ou solução? Nov. 2005. Disponível em: <http://www.briquetdelemos.com. br/briquet/briquet_lemos7.htm>. Acesso em: 12 fev. 2009.

CAMPUS PARTYTM. Uma porta para o conhecimento digital. Disponível em: <http://www.campus-party.com.br/index.php/oevento.html>. Acesso em: 3 mar. 2009.

CAPURRO, R.; HJORLAND, B. O conceito de informação. Perspectivas em Ciência da Informação, v.12, n.1, p.148-207, jan./abr. 2007. Disponível em: <http://www.eci.ufmg.br/pcionline/index.php/pci/ article/viewFile/54/47>. Acesso em: 5 jan. 2009.

CASTELLS, M. A galáxia da Internet: reflexões sobre a Internet, os negócios e a sociedade. Rio de Janeiro: Jorge Zahar, 2003.

CERN, EUROPEAN ORGANIZATION FOR NUCLEAR RESEARCH. Where the Web Was born, 2008. Disponível em: <http:// public.web.cern.ch/Public/en/About/Web-en.html>. Acesso em: 4 dez. 2008.

The website of the world's first-ever web server. Disponível em: $<$ http://info.cern.ch/. Acesso em: 4 dez. 2008.

CHACKSFIELD, M. YouTube begins silencing music videos: due to copyright infringement, uploads face silent treatment. Publicado em 14 jan. 2009. Disponível em: <http://www.techradar.com/news/internet/ broadband/youtube-begins-silencing-music-videos-501117>. Acesso em: 20 mar. 2009.

CLEGG H. Wiki pinpoints Brazilian crime. In. BBC News. 15 abr. 2008, 09h16 UK. Disponível em: <http://news.bbc.co.uk/2/hi/technology/7347101.stm>. Acesso em: 2 fev. 2009. 
CODINA, L. Las propiedades de la información digital. In: El profesional de la información, v.10, n.12, p.18-25, diciembre 2001. Disponível em: $<$ http://www.elprofesionaldelainformacion.com/contenidos/2001/ diciembre/5.pdf $>$. Acesso em: 19 maio 2009.

CREATIVE COMMONS. Conceitos legais: o commons. Publicado em 7 nov. 2005. Disponível em: <http://www.creativecommons.org.br/ index.php?option $=$ com_content\&task $=v i e w \& i d=39>$. Acesso em: 14 nov. 2008.

Revista Nature adota licença Creative Commons para artigos sobre o genoma. Publicado em 19 dez. 2007. Disponível em: <http://www. creativecommons.org.br/index.php?option $=$ com_content\&task=vie w\&id=95\&Itemid=59>. Acesso em: 30 jan. 2009.

Barack Obama adota licença Creative Commons. Publicado em 4 dez. 2008. Disponível em: <http://www.creativecommons.org.br/ index.php?option $=$ com_content\&task $=$ view $\&$ id $=110 \&$ Itemid $=1>$. Acesso em: 15 jan. 2009.

Google Imagens habilita Filtro de Licenças Creative Commons. Publicado em 15 jul. 2009. Disponível em: <http://www.creativecommons.org.br/index.php?option $=$ com_content\&task=view\&id $=1$ 25\&Itemid=1>. Acesso em: 17 jul. 2009.

Versão 3.0 das licenças Creative Commons: atualizações e aprimoramentos. Publicado em: 29 jan.2010. Disponível em: <http://www. creativecommons.org.br/index.php?option $=$ com_content\&task=vie w\&id=133\&Itemid=1>. Acesso em: maio 2010.

CROW, R. The case for institutional repositoreies: a SPARC Position Paper. The Sholarly Publishing \& Academic Resources Coalition, release 1.0, 2002. Disponível em: <http://www.arl.org/sparc/bm doc/ ir_final_release_102.pdf $>$. Acesso em: 7 set. 2009.

DOAJ. Directory of Open Access journals. Disponível em: <http:// www.doaj.org/>. Acesso em: 6 set. 2009.

ÉPOCA. Google terá que divulgar lista de vídeos vistos por usuários no YouTube. Publicado em 3 jul 2008. Disponível em: $<$ http://revistaepoca.globo.com/Revista/Epoca/0,,EMI7299-15275,00.html>. Acesso em: 30 mar. 2009.

ESCOLA PAULISTA DE MEDICINA. EPM promove o seminário "Propriedade Intelectual e Bens de Personalidade". Publicado em 18 dez. 2006. Disponível em: <http://www.epm.sp.gov.br/SiteEPM/Notici as/18.12.06.+Propriedade+imaterial.htm>. Acesso em: 2 mar. 2009.

FARIA, C. G.; GIRARDI, R. Uma análise da Web Semântica e suas implicações no acesso à informação. 2002. Disponível em: <http://maae. deinf.ufma.br/ensino/ia/artigos/>. Acesso em: maio 2010. 
FAUSTINO P. Cuidado com as imagens que usa! (explicação sobre os direitos de autor). Disponível em: <http://www.fique-rico.com/2008/07/18/ cuidado-com-as-imagens-que-usa-explicacao-sobre-os-direitos-deautor>. Acesso em: 12 fev. 2009.

FERREIRA, S. M. S. P. Repositórios versus revistas científicas: convergências e convivências. In:___ ; TARGINO, M. G. (Orgs.). Mais sobre revistas científicas: em foco a gestão. 1.ed. São Paulo: Senac; Cengage, 2008, v.1, p.111-37.

FREITAS, G. Problemas com direitos autorais de imagens nos blogs. GF Soluções. Publicado em 21 jul. 2008. Disponível em: <http://www. gfsolucoes.net/gustavo/web-20/problemas-com-direitos-autoraisde-imagens-nos-blogs/>. Acesso em: 12 fev. 2009.

GAMA, J. G. de O. Direito à Informação e Direitos Autorais: desafios e soluções para os serviços de informação em bibliotecas universitárias. Campinas: PUC-Campinas, 2008. Disponível em: <http://www. bibliotecadigital.puc-campinas.edu.br/tde_arquivos/2/TDE-200804-30T072102Z-1444/Publico/Janete\%20Goncalves\%20de\%20Oliveira\%20Gama.pdf>. Acesso em: 5 fev. 2009.

GANDELMAN, H. De Gutenberg à Internet: direitos autorais na era digital. 5.ed. revista e atualizada. Rio de Janeiro: Record, 2007.

GLOBO.COM. YouTube bate recorde e atinge 100 milhões de usuários em janeiro. Disponível em: <http://g1.globo.com/Noticias/ Mundo/0,,MUL1031052-5602,00-YOUTUBE+BATE+RECOR $\mathrm{DE}+\mathrm{E}+\mathrm{ATINGE}+\mathrm{MILHOES}+\mathrm{DE}+\mathrm{USUARIOS}+\mathrm{EM}+\mathrm{JANEI}$ RO.html>. Acesso em: 15 abr. 2009.

GNU OPERATING SYSTEMS. Licencias: Copyleft. Atualizada em 12 abr. 2008. Disponível em: <http://www.gnu.org/licenses/licenses. es.html\#GPL>. Acesso em: 15 fev. 2009.

HARNAD, S. et al. The access/impact problem and the green and gold roads to Open Access. 2004. Disponível em: <http://users.ecs.soton.ac.uk/ harnad/Temp/impact.html>. Acesso em: 4 set. 2009.

. Entrevista com Stevan Harnad. Enc. Bibli.: R. Eletr. Bibliotecon. Ci. Inf., Florianópolis, n.Esp., $1^{\circ}$ sem. 2007. ISSN 1518-2924 x.

HESS, C.; OSTROM, E. Ideas, artifacts, and facilities: information as a common-pool resourse. 2003. Disponível em: <http://www.law. duke.edu/journals/66LCPHess>.

JACCOUR M; MAYER R. A observação direta e a pesquisa qualitativa. In: A pesquisa qualitativa: enfoques epistemológicos e metodológicos. Petrópolis: Vozes, 2008, p.254-94. 
JBONLINE. Tecnologia impõe mudanças à lei. Entrevista deVivian Rangel: Ronaldo Lemos. Publicado em 22 ago. 2005. Disponível em: <http:// jbonline.terra.com.br/jb/papel/cadernos/internet/2005/08/21/jorinf20050821005a.html>. Acesso em: 20 nov. 2008.

JORENTE, M. J. V. et al. O papel da Ciência da Informação no desenho antropocêntrico das Tecnologias de Informação e Comunicação. Disponível em: <http:www.cibersociedad.net/congress2009/es>. Acesso em: maio 2010.

SANTOS, L. A. C. P; VIDOTTI, A. B. G. S. Quando as webs se encontram: Social e Semântica - promessa de uma visão realizada? Ci. Inf., Londrina, v.14, n.Esp, p.1-24, 2009. Disponível em: <http:// www.uel.br/revistas/uel/index.php/informacao/article/viewFile/2215/3209>. Acesso em: abr. 2010.

KJAER, V. K. Potencial uso dos "wikis" para a atualização continuada e aprimoramento do conhecimento médico. Arq. Bras. Oftalmol, São Paulo, v.70, n.5, set./out. 2007. Disponível em: <http://www.scielo. br/scielo.php?pid=S0004-27492007000500031\&script=sci_arttext $>$. Acesso em: 10 fev.2009.

KOSAK, A. Educacional search and discovered. Disponível em: <http:// creativecommons.org/weblog/entry/22500>. Acesso em: 25 jun. 2010.

LEINER, B. M. et al. A brief history of the Internet. Disponível em: $<$ http://www.isoc.org/internet/history/brief.shtml:. Acesso em: 4 dez. 2008.

LEMOS, A. CIBER-CULTURA-REMIX - Seminário "Sentidos e Processos" dentro da mostra "Cinético Digital”. São Paulo, Itaú Cultural, ago. 2005. Disponível em: <http://www.facom.ufba.br/ciberpesquisa/andrelemos/remix.pdf>. Acesso em: 4 jan. 2009.

LEMOS, R. Creative Commons, mídia e as transformações recentes do direito da propriedade intelectual. Revista DIREITOGV, v.1, n.1, p.181-7, maio 2005. Disponível em: <http://www.inovacao.unicamp. br/report/Ronaldo-Lemos.pdf>. Acesso em: 9 out. 2007.

Tecnologia como ferramenta de inclusão: teoria \& debate. In: Observatório do direito à comunicação. Maio 2007. Disponível em: <http://www.direitoacomunicacao.org.br/novo/content. php?option $=$ com_content\&task $=$ view\&id $=400>$. Acesso em: 11 set. 2008.

Direito, tecnologia e cultura. 2005. Disponível em: <http://www. overmundo.com.br/banco/livro-direito-tecnologia-e-cultura-ronaldo-lemos\#comentarios>. Acesso em: 27 dez. 2008. 
Jornal do Brasil. <http://jbonline.terra.com.br/jb/papel/cadernos/internet/2005/08/21/jorinf20050821005a.html>. Acesso em: 2005.

LESSIG, L. Free culture. 2004. Disponível em: <www.free-culture.org> e $<$ http://www.free-culture.cc/freeculture.pdf $>$. Acesso em: 20 set. 2007.

Free culture. Lawrence Lessig keynote from OSCON 2002. In: Policy DevCenter em 15 ago. 2002. Disponível em: <http://www. oreillynet.com/pub/a/policy/2002/08/15/lessig.html>. Acesso em: 20 dez. 2008

Internet em estado de sítio. Web não deve ser limitada ao poder de um dono. 2001. In: Revista Consultor Jurídico. Disponível em: $<$ http://conjur.estadao.com.br/static/text/35272,2\#null>. Acesso em: 15 out. 2007.

The people own ideas! Technology review.com. 2005. Disponível em: <http://k-12.pisd.edu/c@es/people_own_ideas.pdef>. Acesso em: 9 nov. 2007.

MacHAN, W. T. Middle english text production and modern textual criticism. In: MINNIS, A, J.; CHARLOTTE, Brewer (Eds.). Crux and Controversy in Middle English Textual Criticism. Cambridge: D. S. Brewer, 1992.

MARCIAL, V. M. Epigramas. Zaragoza: Institución Fernando el Católico, (CSIC), 2004. Disponível em: <http://ifc.dpz.es/recursos/publicaciones/23/14/ebook2388.pdf>. Acesso em: 20 dez. 2008.

MARTINS, F. P. Direitos autorais na Internet. Ci. Inf., Brasília, v.27, n.2, p.183-8, maio/ago. 1998. Disponível em: <http://www.scielo. br/scielo.php?script=sci_arttext\&pid=S0100-19651998000200011 > . Acesso em: 3 jan. 2009.

MATUCK, A. Linguagem computacional e criação textual híbrida homemmáquina: uma prospectiva da informação científica. 2005. Disponível em: <www.eca.usp.br/njr/curso/PI-Escritura.ppt>. Acesso em: 20 fev. 2009.

McLUHAN, M. A galáxia de Gutenberg: a formação do homem tipográfico. São Paulo, Editora Nacional, 1977.

MORVILLE, P. Ambiente findability. Cambridge: O'Reilly, 2005. 204p.

MURILO, J. Flickr: deleite virtual para os olhos. Publicado em 13 abr. 2008. Disponível em: <http://www.cultura.gov.br/site/2008/04/13/ flickr-deleite-virtual-para-os-olhos>. Acesso em: 10 fev. 2009.

NATURE. Nature's publishers are expanding the licence for reuse of genome papers. Editorial Nature 450, 762 (6 dez. 2007), doi:10.1038/ 
450762b. Disponível em: <http://www.nature.com/nature/journal/ v450/n7171/full/450762b.html>. Acesso em: 8 set. 2009.

NELSON, T. Xanadu: a scenario. Disponível em: <http://www.aus. xanadu.com/archive/scenario.html>. Acesso em: 26 jun. 2007.

NUNES, M. Novas tecnologias da comunicação e a função-autor na sociedade contemporânea. Rastros, Brasil, v.8, n.8, 2007. Disponível em: $<\mathrm{http}$ ///www.revistas.univerciencia.org/index.php/rastros/article/ view/5517>. Acesso em: 11 jul. 2009.

ONG DERECHOS DIGITALES. Falabella infringe los derechos de autor de joven diseñador. Publicado em 12 abr. 2007. Disponível em: < http:// www.derechosdigitales.org/2007/04/12/falabella-infringe-los-derechos-de-autor-de-joven-disenador/>. Acesso em: 12 nov. 2008.

O’REILLY, T. O que é Web 2.0: padrões de design e modelos de negócios para a nova geração de software. Publicado em 30 set. 2005. Disponível em: <http://pressdelete.files.wordpress.com/2006/12/o-que-eweb-20.pdf>. Acesso em: 10 dez. 2008.

ORTELLADO, P. Primeira leitura da proposta de reforma da lei de direitos autorais. Disponível em: <http://culturadigital.org.br/site/ lda/2010/03/13/direito-autoral-e-direito-a-educacao/>. Acesso em: 27 jun. 2010.

PORTAL TERRA. YouTube remove áudio de videoclipes para proteger copyright. Publicado em 15 jan. 2009. Disponível em: <http://tecnologia.terra.com.br/interna/0,,OI3450527-EI4802,00-YouTube+ remove+audio+de+videoclipes + para+ proteger+copyright.html $>$. Acesso em: 16 jun. 2009.

França aprova lei antipirataria e pode desconectar internautas. Publicado em maio 2009. Disponível em: <http://tecnologia.terra. com.br/interna/0,,OI3765365-EI4802,00-Franca+aprova+lei+antip irataria $+\mathrm{e}+$ pode+desconectar+internautas.html $>$. Acesso em: 7 jun. 2009.

PRETTI, L.; MARTINS, R. Então você é pirata! Caderno Link. O Estado de S.Paulo, n. 901, 2 fev. 2009.

PUENTES, A.; DIAS J. F. Historia de las leyes, prebiscitos y senadoconsultos mas notables, desde la fundación de Roma hasta Justiniano. Madrid, Imprenta de D.Vicente de Lalama, 1840.

SERPRO. Software livre é uma necessidade social. Disponível em: <http:// www.serpro.gov.br/noticiasSERPRO/2009/agosto/201csoftwarelivre-e-uma-necessidade-social201d-afirma-stallman>. Acesso em: 7 set. 2009. 
SHERMAN, C.; PRICE G. The invisible web: uncovering information sources search engines can't see. New Jersey: Information Today, Inc, 2001.

SILVA FILHO. 2006, Blog: um novo poder de comunicação. Revista Espaço Acadêmico, v.6, n.63, ago. 2006. Disponível em: <http://www. espacoacademico.com.br/063/63amsf.htm>. Acesso em: 20 mar. 2009.

SOARES, E. Exército tagger para o bem comum. Disponível em: <http:// blog.flickr.net/pt/2008/01/17/chamando-exercito-tagger-para-obem-comum/>. Acesso em: 11 mar. 2009.

SOUTO, P. C. N.; OPPENHEIM, C. Direitos autorais e o movimento do acesso aberto: um equilíbrio que demanda novas atitudes. In: FERREIRA, S. M. S. P.; TARGINO, M. G. (OrgS.). Mais sobre revistas científicas: em foco a gestão. 1.ed. São Paulo: Senac; Cengage, 2008, v.1, p.139-65.

SPYER, J. Conectado: o que a Internet fez com você e o que você pode fazer com ela. Rio de Janeiro: Jorge Zahar, 2007.

STALLMAN, R. Por qué el software no debe tener propietarios. 1994. Disponível em: <http://www.gnu.org/philosophy/why-free.es.html>. Acesso em: 2 fev. 2009.

TECHNORATI. State of the Blogosphere/2008. Disponível em: <http:// technorati.com/>. Acesso em: 15 jul. 2009.

TERRA. Número de blogueiros na China cresce para 50 milhões. Disponível em: <http://tecnologia.terra.com.br/interna/0,,OI3431566EI4802,00-Numero+de+blogueiros +na+China + cresce+para+milho es.html>. Acesso em: 16 jul. 2009.

VALZACCHI, J. R.Wikis: la creación colectiva y colaborativa de documentos. El magazine de horizonte informática educativa, Buenos Aires, v.7, n.76, abr. 2006. Disponível em: <http://www.horizonteweb. com/magazine/Numero76.htm>. Acesso em: 7 mar. 2009.

VIDOTTI, S. A. B. G. O ambiente hipermídia no processo ensino-aprendizagem. Marília, 2001, 201 f. Tese (Doutorado em Educação). Faculdade de Filosofia e Ciências, Universidade Estadual Paulista.

VITRÚVIO POLIÃO, M. Los diez libros de architectura de M. Vitruvio Polión. Traducidos del latín y comentados por Joseph Ortíz y Sanz. Madrid: Imprenta Real, 1787.

YOUTUBE. Comunicados à imprensa: The United States Congress is In Session on YouTube. 12 jan. 2009. Disponível em: <http://www. youtube.com/press_room_entry?entry $=$ FsRXSG0CCTg $>$. Acesso em: 15 fev. 2009 
YU, L. Introduction to Semantic Web and Semantic Web services. Florida: Taylor \& Francis, 2007

WALDROP, M.Darpaand the Internet revolution. Disponívelem:<http:// www.darpa.mil/Docs/Internet_Development_200807180909255. pdf $>$. Acesso em: 20 maio 2009.

WARD, T. W.; et al. The Cambridge history of English and American Literature. New York: G. P. Putnam's Sons, 1907-21. Disponível em: $<$ http://www.bartleby.com/221/1405.html>. Acesso em: 2 fev. 2009. ZINS, C. Redefining information science: from "information science" to "knowledge science". Journal of Documentation, v.62 n.3, 2006. Disponível em: <www.emeraldnsight.com/0022-0418.htm>. Acesso em: maio 2010. 


\author{
SOBRE O LIVRO \\ Formato: $14 \times 21 \mathrm{~cm}$ \\ Mancha: 23,7 x 42,5 paicas \\ Tipologia: Horley Old Style 10,5/14 \\ 1a edição: 2010 \\ EQUIPE DE REALIZAÇÃO \\ Coordenação Geral \\ Marcos Keith Takahashi
}

